University of Louisville

ThinkIR: The University of Louisville's Institutional Repository

Electronic Theses and Dissertations

$5-2017$

\title{
Hard to see through the smoke : remembering the 1912 Hillsville, Virginia courthouse shootout.
}

Travis A. Rountree

University of Louisville

Follow this and additional works at: https://ir.library.louisville.edu/etd

Part of the Appalachian Studies Commons, Other Rhetoric and Composition Commons, and the Rhetoric Commons

\section{Recommended Citation}

Rountree, Travis A., "Hard to see through the smoke : remembering the 1912 Hillsville, Virginia courthouse shootout." (2017). Electronic Theses and Dissertations. Paper 2620.

https://doi.org/10.18297/etd/2620

This Doctoral Dissertation is brought to you for free and open access by ThinkIR: The University of Louisville's Institutional Repository. It has been accepted for inclusion in Electronic Theses and Dissertations by an authorized administrator of ThinkIR: The University of Louisville's Institutional Repository. This title appears here courtesy of the author, who has retained all other copyrights. For more information, please contact thinkir@louisville.edu. 
HARD TO SEE THROUGH THE SMOKE:

REMEMBERING THE 1912 HILLSVILLE, VIRGINIA COURTHOUSE SHOOTOUT

By

Travis A. Rountree

B.A., James Madison University, 2004

M.A., Appalachian State University, 2007

A Dissertation

Submitted to the Faculty of the

College of Arts and Sciences of the University of Louisville

in Partial Fulfillment of the Requirements

for the Degree of

Doctor of Philosophy

in English/Rhetoric and Composition

Department of English

University of Louisville

Louisville, Kentucky

May 2017 
Copyright 2017 by Travis A. Rountree

All rights reserved. 

HARD TO SEE THROUGH THE SMOKE:

REMEMBERING THE 1912 HILLSVILLE, VIRGINIA COURTHOUSE SHOOTOUT

By

Travis A. Rountree

B.A., James Madison University, 2004

M.A., Appalachian State University, 2007

A Dissertation Approved on

April 19, 2017

by the following Dissertation Committee:

Dr. Stephen Schneider

Dr. Amy Clukey

Dr. Timothy Johnson

Dr. Sara Webb-Sunderhaus 


\section{DEDICATION}

This dissertation is dedicated to my family

and our love of remembering.

Dedicated to:

James Rountree

Gladys Rountree

Alan Rountree

Cheryl Rountree

Molly Trask

In Memory of:

B.K. Allen

Helen Allen 


\section{ACKNOWLEDGMENTS}

I would like to first acknowledge all of my contacts in Hillsville who were willing to be interviewed by me and generously share with me their knowledge of the shootout: Bill Webb, Gary Marshall, Kay Cox, Howard Sadler, Allison Craig, and Ronald W. Hall. I hope this project honors the story of the shootout for each of you.

I want to next thank each member of my committee: Sara Webb-Sunderhaus who first demonstrated to me that I could combine my love of composition and rhetoric and Appalachian Studies at the Conference on College Composition and Communication in

Indianapolis, Indiana. Her friendship and knowledge of Appalachian culture and literacy helped to make this dissertation into a meaningful project. Tim Johnson who meticulously read each chapter and gave me extensive notes. His careful eye and our meaningful conversations were integral in the development of this dissertation. Amy Clukey who reread each chapter with a close eye. Her mentorship and encouragement inspires me to want to continue to pursue the links between The New Southern Studies and Appalachian Studies. My highest thanks goes to Stephen Schneider who has provided me with so much support throughout the dissertation process. When I first met 
Stephen in his office he encouraged me that this was a project worth doing and exploring and has never stopped encouraging me. His support throughout the process and determination to help me finish on time was a valuable asset.

Saving the most significant for last, I want to thank my grandparents, James and Gladys Rountree for their constant encouragement during my education. I would not be here without their support. I also want to thank my parents, Alan and Cheryl Rountree and my sister and brother-in-law, Molly and Justin Trask for their unwavering support through not only this project, but my educational career as a whole. Their continued encouragement helped me to realize my full potential as an academic.

Finally, to Caleb Pendygraft, who has been with me through this entire writing process. I owe my deepest and heartfelt thanks. Words can hardly express how much this dissertation has grown because of you. It truly shows how much we can do together. 


\begin{abstract}
HARD TO SEE THROUGH THE SMOKE:

REMEMBERING THE 1912 HILLSVILLE, VIRGINIA COURTHOUSE SHOOTOUT

Travis A. Rountree

May 12, 2017
\end{abstract}

This dissertation examines rhetorical rememberings of the 1912 Hillsville, Virginia courthouse shootout. It begins with an overview of the historical event, then through four chapters focuses on different rememberings that take up the event. Using Burke's terministic screens, the study presents several lenses through which to view these rememberings.

Chapter One presents the national and local newspaper constructions of the shootout in three terministic screens: the violent mountaineer, the gangster, and the uncolonized other. These three screens predate what is now the hillbilly image of the mountaineer. Chapter Two analyzes performative actions of the shootout. The ballads about the event demonstrate the bifurcation of the town: "Sidna Allen" uses the dangerous mountaineer terministic screen whereas "Claude Allen" presents a more sympathetic, humanistic account of the shootout. Recent plays written by Hillsville local, Frank Levering, reveal the shootout participants and their families with sympathy and 
humanity, especially in scenes that acknowledge that these plays are performed in the historic courthouse where the shootout occurred. Chapter Three presents how the three local museums continue to engage with these terministic screens. The Carroll County Historical Society and Museum demonstrates a local vernacular remembering of the event as it concentrates on the local families involved whereas the Mt. Airy Museum of Regional History argues for a national view of the shootout that still engages with stereotypical terministic screens. The last museum located in the Harmon Western Wear Store contains purely vernacular remembering of the shootout. By relying on local and national newspapers and various other artifacts of the shootout, the exhibit encourages patrons to create their own version of the shootout. Chapter Four centers on new portrayals of the shootout through the mostly unheard voices of the women in Hillsville who were left over when their husbands and sons either died or were incarcerated by the state of Virginia. This chapter explores how these mountain women demonstrated resilience through refusing to talk about the event. In addition, it explores recovered women's through nonfiction and fictional rememberings of the shootout. These chapters demonstrate how the shootout contributed to the Appalachian identity that continues to develop in today's America. 
TABLE OF CONTENTS

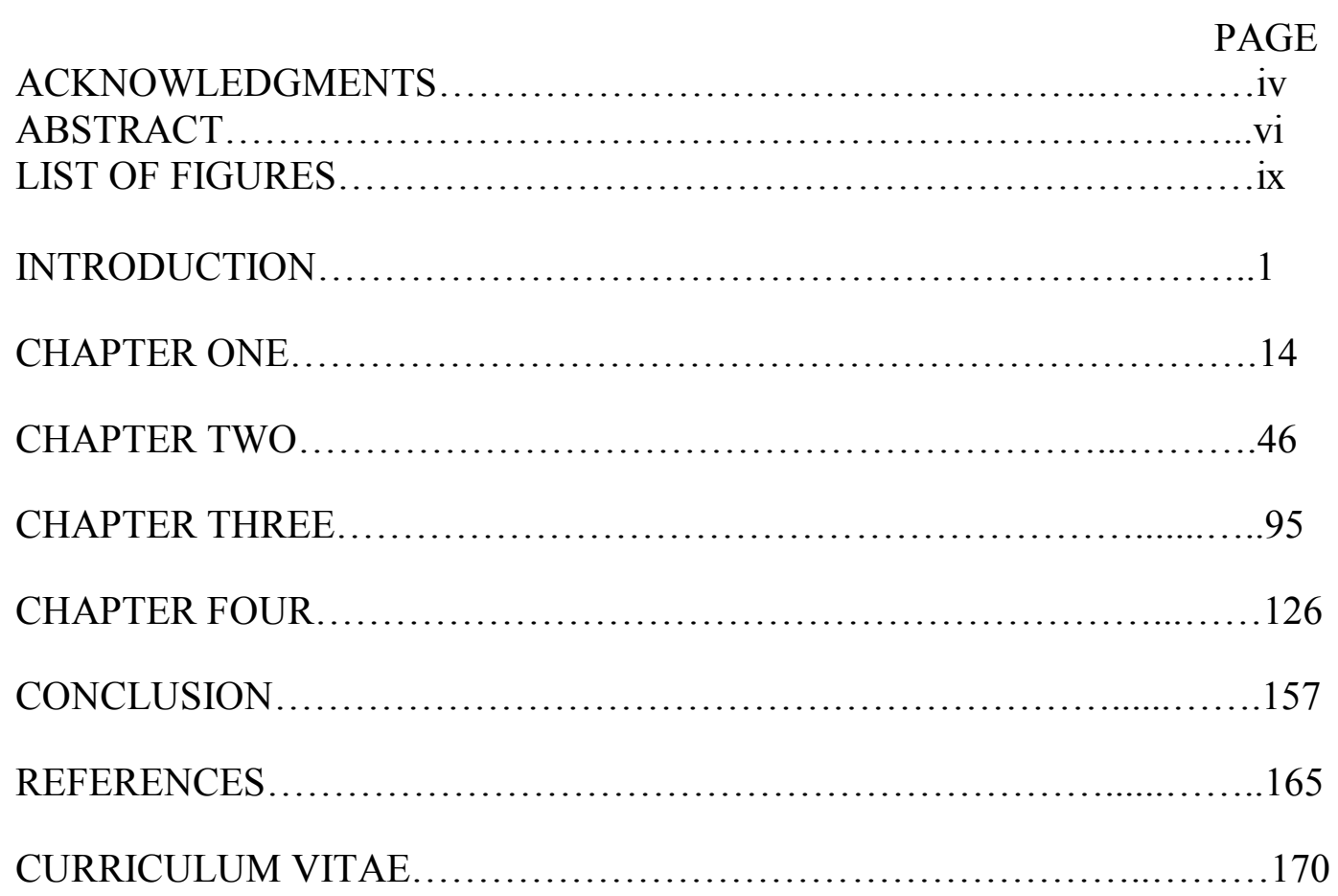




\section{LIST OF FIGURES}

FIGURE

PAGE

1. New York Times Political cartoon of the Shootout..........................28

2. Life Magazine Political cartoon of the Shootout............................31

3. "Sidna Allen" ballad..............................................55

4. "Claude Allen" ballad...........................................6 60

5. Claude's Medal.................................................61

6. Present day Hillsville Courtroom.................................72

7. Courtroom schemata............................................ 73

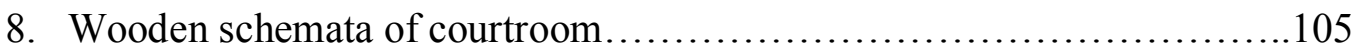

9. W.H. Mann letter to Jezebel Goad.................................107

10. Jezebel Goad's medal...........................................107

11. Mt. Airy Museum of Regional History Courthouse Shootout exhibit.......113

12. Harmon's museum.............................................. 121

13. Photos of Allen men............................................. 136

14. Photograph of Sidna and Betty Allen............................... 138

15. Photograph of Sidna and Betty Allen............................... 138 


\section{INTRODUCTION}

"Are you an Allen?"

He stood there hearing what the man said. The question brought thoughts in his mind. Was he an Allen?

The oldest of five, he remembered his own father. "Orphaned" is what the state had written on the birth certificate. His father a tall, powerful presence was known to come to violence quickly. A moonshiner in Powhatan county, Virginia. A scar on his face that told about a time when he jumped a fence to escape federal agents and got his face caught on the barbwired only for a second before sprinting away in the darkness bleeding. Violence begets violence, but was his own Daddy tied to this place? Could he have been an orphan from the shootout that happened here in the courthouse? Did that violence still run in his blood?

The shadow of the confederate statue lengthened on the sidewalk as the man spoke again, "You'd better leave town. We don't like your kind around here." Not looking for more trouble, he, his wife, and the couple they traveled with left the sleepy mountain town of Hillsville to travel on.

The narrator of this story was my own grandfather. This telling of the Hillsville story intrigued me not only because it involved my own family, but also the overt division of the town even to a stranger who merely looked like an Allen. Immediately after talking to my grandfather, I started doing research. I read Ron W. Hall's The Carroll 
County Courthouse Tragedy. I even made a trip to the town to see the courthouse and visit with Ron. After I wrote a graduate seminar paper on the shootout, aspects of the courthouse still stayed with me. Similar to most of Hillsville's citizens, I wanted to know more. Who were the Allens? Why is the town still divided? What further constructions of the shootout existed? To begin, I had to look to the facts of the story itself.

\section{The Story of the Century}

The story of the shootout starts with a fight over a young woman. The basis is that the brothers Wesley and Sidna Edwards got into a scrap during one of their uncle Garland Allen's church services. Wesley had drawn a red ear of corn at a corn shucking earlier in the week and had kissed a girl who already had a boyfriend. Specific details about the fight at the church differ, but the fact stands that a fight did break out between the boys at the church house. Wesley was charged with "assault, disturbing public worship with a second count of doing so while intoxicated, attempting to kill Wiliam Thomas by aiming and shooting a pistol at him and a fourth one for carrying a concealed pistol with a second count of carrying a concealed blackjack"; whereas, Sidna Edwards was charged with "disturbing worship, carrying a concealed weapon and felony assault" (W. Hall 45). Carroll County deputy Thomas F. "Pink" Samuels and recently deputized Peter Easter tied the two boys up and chose to drive them past their uncle Floyd's house on their way into Hillsville. Floyd was like a father figure to them as his sister, Alverta, was their mother and their father had passed. Locals note that the lawmen took the boys past the house to spite Floyd Allen as they worked for the local republican government and Floyd was a Democrat. Floyd comes out of the house and then accounts again vary as to what happened. He was rumored to have knocked Samuels in the head with his pistol and freed 
the boys. Despite the rumors, Floyd was charged with "three indictments...one for rescue of prisoners in custody, one for assault and one for maiming" (52).

On the morning of Monday, March 11, 1912, Floyd Allen was brought to trial and found guilty of the three charges. After Judge Massie announced the jury's verdict, Floyd stood in the courthouse and uttered the famous words, "Gentlemen, I ain't a-goin." Immediately, shots rang out in the courthouse that led to the death of five people: the Commonwealth Attorney, the judge, a jury member, the sheriff, and a female witness. It also led to the wounding of seven more. The Allen men immediately fled the scene, some traveling to the nearby mountains and others to the Midwest. However, by September 1912 detectives for the Baldwin Felts Agency apprehended the rest of the men, and the following spring both Floyd and his son, Claude, were put to death by electrocution in Richmond, Virginia while the rest of the Allen men were pardoned months later.

Prior to the shootout, however, tension had already been building between the Allens and the local government. The Allens' objection to the town's progressivism could have been one of the lead causes of the shootout and their trouble with the local government. Wake Forest professor, Randal L. Hall explains this point in his article, “Justifying Violence: Ninety Years of Remembering a 1912 Courtroom Massacre in Virginia’s Blue Ridge Mountains.” He states, In Carroll County, the Republicans had gained control of local government in the years just after the turn of the century, ending Democratic dominance there. At the state level, though, Virginia remained firmly in the hands of the Democratic party, and the state government had adopted some modernizing measures in the first decade of the twentieth 
century, some as part of a revision of the state constitution that passed in 1902. A significant aspect of the new constitution was the strengthening of state control over local courts. Beginning in 1904 the judge for Carroll County's criminal court came from outside the county and held in Hillsville periodically as part of a circuit. (3)

In Hall's essay he further argues that the Allen family represented an escape from progressive government. He states that Governor "Mann emphasized that the Allens had done much more than commit murder; they had challenged the allegiance to rationality and social order by which Progressives expected to guide Virginia to a bright and stable future" (268). Thus, the Allens not only stood as small town entrepreneurs, but as social radicals as well. Their way of living encroached on the town's progressive aspirations. Not only were they considered criminal outlaws in the sense that they often broke the law and ended up in jail, but they were political outlaws as well as they believed in a political system that existed outside of the system that operated in their small town of Hillsville.

\section{A Brief Literature Review}

Despite front-page coverage in The New York Times until the Titanic sank, there has been very little scholarly research done on the Hillsville Shootout of 1912. Soon after the shootout several religious pamphlets and novellas were published depicting the Allen men as evil. Both nonfictional and fictional accounts of the shootout continue to be published, but without the religious fervor of the initial publications. The play "A Tragedy in Hillsville: A Play in Three Acts," by Ronald J. Larson was published in Appalachian Journal in 1979. William Lord published many of the trial transcripts in 1999 in The Red Ear of Corn. Sidna Allen's granddaughter, Betsy W. Chandler, 
republished his 1929 memoir in 1999 with her own last chapter entitled "Leaving Behind the Hillsville Courthouse Happenings, Recalling Another Era (at your own risk of course!)," illustrating her own distance from the incident. There was even a rock opera written titled Sid Allen and the Devil's Den: An American Rock Opera by Tom Harvey that was performed at a reunion of the event in 1997 in Hillsville. Recently, two novels, No Villains, No Heroes by Thomas Moore (2012) and Mountain Justice by Jerry L. Haines (2012) were published fictionalizing the event. Local playwright, Frank Levering, continues to have his courthouse plays performed in the historic courthouse. He has produced four so far and he plans to have another performance in April of 2017. Because of the centennial of the event there seems to be a resurgence of fiction about it; however, very few of these texts critically examine the event.

Academic scholarship on the shootout is indeed sporadic. The Carroll County Historical Society published local historian, Ronald Hall's pivotal text The Carroll County Courthouse Tragedy, A True Account of the 1912 Gun Battle that Shocked the Nation; Its Causes and the Aftermath in 1997. However, Peter Aceves' article, "The Hillsville Tragedy in Court Record, Mass Media and Folk Balladry: A Problem in Historical Documentation" in the Keystone Folklore Quarterly (1971) analyzes different variations of the "Sidna Allen" and "Claude Allen" ballads. The most recent work has been done by historian Randal L. Hall (no relation to Ronald W. Hall) in 2004 in the articles, "Constructing Violence: Historical Memory and a 1912 Courtroom Massacre in Virginia’s Blue Ridge Mountains” and "A Courtroom Massacre: Politics and Public Sentiment in Progressive-Era Virginia."

Unlike most of the national and local examinations of the shootout, this study will 
look at particular acts of remembering occurring in the media depictions, ballads, plays, museums, and then the construction of gender in the retelling. Whether stereotyping as found in the newspapers, leaning towards the government side or the Allens in the ballads, or humanizing all the parties involved as in Levering's plays, each of these research sites reveal rhetorical decisions that are made in the remembering of the story. By examining each of these rememberings, rhetorical decisions emerge in depicting the Allen men and others involved in the shootout. In fact, the use of Burke's terministic screens are useful here to demonstrate the beginning of the stereotypes in the media portrayals to how the Allens are humanized and sympathized in more recent depictions. These past and contemporary rhetorical rememberings of the shootout produce new views of how Appalachia was constructed and continues to be constructed through public memories of the event.

These terministic screens adhere to public memory scholarship because they align with three intersections that Dickinson, Blair, and Ott discuss in Places of Public Memory. The first intersection is that "public memory is understood by most, if not all, contemporary scholars as activated by concerns, issues, or anxieties of the present" (Dickinson, Blair, and Ott 6). This definition works well with Hillsville because all of these depictions of the event present the tension and "anxieties" of the past and present in the creation of the identity of Appalachia. In noticing the recirculation of these materials recently on the anniversary of the event, local newspapers and local playwrights still present anxieties about the region. It's a region that is not like the norm; one where certain violence occurs that is not found elsewhere. A violence that happened 105 years ago, but one that the citizens of Hillsville still remember well. 
The second intersection is that "public memory is theorized in most scholarship as narrating a common identity, a construction that forward an at least momentarily definitive articulation of the group" (7). This "group" is the Allen men who participate in the shootout. They are "articulated" in many different screens; however, we see through the newspaper accounts that this "common identity" also represents connotations of Appalachia as represented by through the different stereotypical accounts of the Allen men whereas later screens present more realistic, tragic portrayals.

The third intersection is "public memory is typically understood as animated by affect...rather than representing a fully developed chronicle of the social group's past, public memory embraces event, people, objects and places that it deems worthy of preservation, based on some kind of emotional attachment" (ibid). This intersection is particularly useful with the shootout because this uptake of certain "event[s], people, objects, and places...worthy of preservation" is seen in what artifacts the screens can be placed upon. Artifacts and ideas like: Who does the newspaper frequently mention and why? Who and what actions do the ballads and plays linger on? How do the museums tell their story of the shootout and through what artifacts? How does gender play a role and why should we look towards that construction of the shootout? How do they depictions give us a larger understanding of the nations conception of Appalachia at the time?

\section{Creation of Appalachia as a Region}

This story, however, is couched within the nation's definition of the Appalachian region. Past scholarship done on Appalachia has defined it as a region, an ethnicity, or a shared set of cultural practices and representations. In order to understand how rhetorical work can navigate these definitions and what it reveals about Appalachia we have to first 
take a look at what these categories are and who engaged in these definitions. Appalachia as a region was first designated in the early 1920s (these assumptions sprouted from late $19^{\text {th }}$ Century travel writers about the region). Historians such as Caudill, Weller, Kephart, C. Williams, and Campbell wanted to define the region based on the culture that was occurring from within the geographical confines within the region. They separated the region from the rest of the country as exceptional (much like theories of the lowland South). Within their discipline, these scholars denoted the daily life of "the mountaineer" and his peculiar, pioneer way of living.

After this definition, Appalachia became an ethnicity. Scholars such as Batteau, Whisnant, and Moffett studied the region as a cultural one that stood distinct from the rest of the country. It was no longer defined geographically (but that still was a major component), but instead the culture of the region was looked at closely mostly using case studies (Whisnant and Moffett) and the development of the regional identity (Batteau). Newer conversations continue to emerge of Appalachia as a global regions; however, even contemporary Appalachian Studies scholars tend to create nostalgia for the region much like the earlier historians. Obermiller and Scott write about the tendency of some Appalachian studies scholars, artists, and activists to represent Appalachain communities in an ahistorical, idealized fashion that neglects political oppression and economic exploitation within the region's localities. Such a tendency results in a 'reactionary nostalgia' that, at best, does little to address economic inequity and, at worst, is complicit in the perpetuation of such inequity. (145) 
The nostalgic musings on the region by these contemporary scholars and the early historians is important because these identities also happen within the cultural productions of the shootout. Notions of a pioneer America and Appalachia as the "last frontier" emerge frequently in the media, ballads, and museum portrayals of the event. For example, in the museums coupled with the shootout there is often pioneer images of a fireplace and cookware. The media depictions represent the Allen men as part of a culture that is in the past. These rememberings can be categorized in a couple different ways.

\section{Remembering the Shootout}

The creation of Appalachia was (and still is) dependent on the vernacular and official public memory that is created about the region from those within and outside the region. John Bodnar explains that "public memory emerges from the intersection of official and vernacular cultural expressions" (13). Vernacular culture depends on the constantly changing personal views and values of a small group of people rather than a larger national community, i.e. the citizens of Hillsville. These views express "what social reality feels like rather than what it should be like" (Bodnar 14). In comparison, official culture "promotes a nationalistic, patriotic culture of the whole that mediates an assortment of vernacular interests" (ibid). In other words, the memory entails a documented history that the government or other sanctioned organizers or officials deem true and necessary to record. Vernacular and official histories help us to examine these memories in ways that rhetorical study scholars find useful. They allow us to examine the kairos and rhetorical situation of these memorial sites and to analyze how, when, and why

they are used. Engaging with Bodnar's definitions, vernacular histories ask us to participate. They depend on the oral narratives such as the curator of the Courthouse 
museum, Bill Webb, to tell us about the exhibit. These rememberings may ask us to consider which side we're on like the ballads or even to consider the consequences of the shootout itself, such as in Levering's plays. The official rememberings instruct us on how to remember it with limited or no participation. These can be located in the newspapers about the event that describe the initial reactions to the event by reporters. These articles do not ask for our participation, but are there to inform us of the situation. The official is also found in public memory sites, such as the Mount Airy museum where the exhibit is made with limited conversation or interaction. Unlike the other museums, it doesn't ask for us to construct the shootout, but rather performs for us, explaining all the details vividly and with little vernacular interruptions.

Both the vernacular and the official rememberings, however, contribute to the development of the terministic screens to view the shootout. These screens range from moving from stereotypical depictions of the Allen men to more realistic, tragic portrayals. For example, Floyd Allen is portrayed in the newspapers as unlawful and mean as Jesse James, but in the plays Frank Levering writes him as a mournful, sympathetic character who regrets causing the shootout. These terministic screens, then, give us a means to understand what DeVoss and Ridolfo describe as the rhetorical velocity of the shootout and its circulation at various moments in history. Each of these screens illustrates how the shootout is "the text" that is "recomposed" ("Velocity"). The artifacts are retrofitted to serve the purposes of those who use them, whether they are to provide news and entertainment in media depictions, to demonstrate a side of the story through the ballads, or to serve as a memorial to those who were killed in the instance of the museum-each illustrate how these materials are used to serve different public purposes. While noticing 
what is "taken up" Sara Ahmed's idea of culture of emotion pertaining to "what sticks" or what "becomes saturated with affect" is useful in analysis of the circulation of these artifacts (qtd in Dickinson, Blair, Ott 15). While the shootout is the event that is "taken up" the objects demonstrate what becomes "affective" in the remembering of the event.

\section{Chapter Overviews}

“'The Many Untruths': Newspaper Accounts of the Hillsville Shootout” focuses on rhetorical representations in media depictions of the event. Using Burke's terministic screens, the chapter establishes the three screens: violent mountaineer, gangster, and uncolonized other. These appear in front page articles, editorials, and even in political cartoons drawn about the shootout. These initial portrayals demonstrate how the media presented the shootout to the public and, in turn, how the public reacted to the shootout.

"Performing Hillsville: Rhetorical Discourse on the Allen Ballads and Levering's Shootout Plays" examines the performances of the ballads and the recent plays about the shootout. Fitting in the genre of the traditional mountain ballad, "Sidna Allen" and "Claude Allen" both depict the two different sides of the shootout. They demonstrate the schism that happened in the town and the emotional trauma is still felt in Hillsville today. "Sidna Allen," however presents a stereotypical portrayal of the Allen men whereas "Claude Allen" evokes a sympathetic and tragic screen. Levering plays display similar sympathetic characters of the shootout. Presented in the historic courthouse by ancestors of the shootout and citizens of Hillsville, these plays provide a public space where the story can be retold and conversation can occur that were taboo before the play's existence. 
“"Feelings Are Still Very Strong': Sites of Public Memory in Hillsville” will look at the vernacular and official histories of the shootout in three museums local to Hillsville. These histories demonstrate the values of the communities where they are located and provide epideictic history making moments as patrons are lead through three different constructions and experiences of the shootout. These constructions engage with the terministic screens from providing vernacular, humanistic views located in the courthouse museum to official, stereotypical portrayals in the Mt. Airy Regional History Museum. The courthouse museum gives a ground zero approach that depends on the guidance of the curator, Bill Webb, to guide patrons through. Whereas the Mount Airy Regional History Museum attempts to officially place Hillsville in the construction of the Appalachian region. Lastly, the most vernacular museum, the Gooch Harmon Museum, asks patrons to construct their own versions of the shootout through an assortment of artifacts ranging from local newspapers to more intimate objects like Floyd Allen's saddle bags. Each of these museums demonstrates that the story of the shootout continues to emerge in Hillsville's culture today.

"Feminine Silence and Action: The Gendering Courthouse Shootout Public Memory" focuses on giving voice to the women involved in the shootout. Using the feminist archival theories of Jessica Enoch and Cheryl Glenn, this chapter speaks back to the male-dominated version of the stories. Evoking a screen of resilient silence, the women directly involved with the shootout do not want to retell the story. While these archival voices are crucial in understanding the emergence of women's voices in the shootout, Levering's plays also provide a fruitful place for recovering women's voices. Whether they are archival or fictional, the women's voices demonstrate that there is a 
need to approach the shootout in a different way rather than the masculine-based violence that has served as the dominant narrative for so long.

These chapters work together to not just retell the story of the shootout, but to analyze the rememberings of cultural artifacts that serve as sites of rememberance. Within this retelling, these rememberings struggle with Appalachian stereotypes; however, they also show the possibility of expansion of scholarship on the shootout by including gender through the rhetorical agency and acts of the women in the shootout. Analyzing the shootout through the use of these terministic screens allows a return not only to the tragedy of that rainy day in March, but also new understandings of the production of memories and stories that evolved out of the event. 
CHAPTER ONE:

“THE MANY UNTRUTHS”:

\section{NEWSPAPER REPRESENTATIONS OF THE \\ HILLSVILLE, VA COURTHOUSE SHOOTOUT OF 1912}

In the Hillsville, Virginia courtroom on March 11, 1912 the trial of Floyd Allen finally happens after several continuences. After a few minor tasks in the courtroom and some pleading from Floyd's lawyer and friend, Judge Bolen, Judge Massie stated, "Judge, is there anything further you can do with your case today" to which Bolen replied “No sir, I don't reckon there is" (W. Hall 78-79). Massie then asked Sheriff Lewis Webb to take charge of Floyd Allen. As Webb ambled his way over, Floyd dropped his chair from sitting on two legs, stood up, supposedly put his hand in his jacket pocket and said “Gentlemen, I ain't a'goin.” What happened after Floyd uttered those words has been speculation for the past 105 years. Nevertheless, the gun fight that broke out continued from the courthouse out into the street where Floyd is wounded and taken to a hotel across the road. The rest of the Allen men fled to surrender or found later.

Within two days of the shootout, coverage started in local and national newspapers. Despite the coverage of the event, each depiction is sensationalized and presents readers with a stereotypical view of the Allen men on the front page issues of their papers: 
Dispatched from Richmond, Virginia in The Times Dispatch on March 15, 1912 under the title: "Expecting Death in Discharge of Their Duty, Court Officers Are Shot Down in Cold Blood by Carroll County Desperadoes" with subheadings of : "Acts of Outlaws Terrorize Town to Point of Paralysis, Citizens Take to Flight and Mothers Carry Children to Places of Safety---No Man Left to Organize Pursuit”:

A Troop of mountain outlaws rode down out of the Blue Ridge to-day [sic] to the Carroll county courthouse here and assassinated the judge upon the bench, the prosecutor before the bar and the sheriff at the door while sentence was being pronounced upon Floyd Allen, one of their number. When the crack of the rifles died away only one member of the human fabric of the court—Dexter Goad, the clerk — was alive, and he had been wounded. Jury and onloookers were struck in the fusillade, but none was wounded seriously.

Dispatched from Topeka, Kansasa in the Kansas Baptist Herald on March 16, 1912 under the title, "Mob Wipe Out Court":

In a flame of unprecedented outlawry the entire human fabric of the Carroll county circult court in session here today was wiped out by assassination. Judge Massie had sentenced Floyd Allen to one year in prison for aiding in the escape of a county prisoner. two [sic] of Allen's brother and several of their friends opened fire with revolvers. Judge Massie fell dead in his place on the bench on the first volley. Then the weapons were turned on Commonwealth Attorney Wm. Foster and he sank to the floor with several bullets in his brain, death being instantaneous. 
Dispatched from Roanoke, Virginia in The New York Times on March 18, 1912 under the title, "Outlaws Slay Judge In Court":

a troop of twenty mud-splashed mountaineers [who] galloped in with rifles from the surrounding hills early this morning, and in less time than it takes to tell it to the Judge upon the bench, the prosecutor before the bar, and the Sheriff at the door lay dead in the courtroom.

While this writing is entertaining, it is utterly false. The Allens most certainly did not "gallop in with rifles" nor were there "twenty" Allen men at the courthouse during the time of the shootout. These dispatchers, similar to other reporters at the time, create a narrative that relies upon Appalachian stereotypes that were starting to take shape in the nation. In fact, these reporters feed off of each others' articles with the repetition of words like "troop," "human fabric," and "mud splashed." While entertaining for readers, these absurd accounts push forward the Appalachian stereotypes that we often see today.

Through creating these stereotypes, journalists create a rhetorical Hillsville. These depictions do not represent the "true" Hillsville in the mountains of Virginia, but one that exists in the folklore and stereotype of the media uptake of the shootout. The creation of this fictional place emerged from visiting reporters who frequented the region. These reporters arrived several days after the shootout and relied on public witnesses of the shootout to construct their stories. They depended on collective eyewitness memories that they then constructed into newspaper articles. The passing down of this information conflated and fictionalized what was told. These articles brought existing stereotypes and cultural anxieties to bear on the situation in Hillsville, even if these depictions resulted in 
the perpetuation of those stereotypes rather than reflecting an actual account of the shootout.

In addition to the collective memories of the people of Hillsville, the reporters also drew on nineteenth century fictional depictions of Appalachia as an underdeveloped region of the United States that was once glamorized by fiction writers. These local color writers from the lowland South contributed to stereotypical fiction about the mysterious mountaineer. In 1912, the image of the mountaineer was just beginning to emerge from publications like Mary Noailles Murfree's Tennessee Mountains (1886), William Eleazar Barton's Life in the Hills of Kentucky (1890), and Lucy Furman's Mothering the Perilous (1913). These writers created overtly lurid or humorous Appalachian figures. They made Appalachia appear as an exotic land full of lazy mountain characters who "feuded," drank moonshine, and rocked on their ramshackle porches all day. ${ }^{1}$ Similar to novels about the old South based on the romanticized Sir Walter Scott fiction, the authors of these "local color" works exaggerated elements of the characters and the land. As historian Henry Shapiro notes, they were "local color writers [who] set stories of upper-class romance and lower-class passion" in the Southern Appalachian Mountains (44). These writers constructed their stories out of brief visits to the Appalachian region — while local color stories often included at least some factual information, they usually made Appalachia seem like a foreign, isolated land.

\footnotetext{
${ }^{1}$ These stereotypes still exist in the twenty first century, from the newspaper comic "Snuffy Smith" to the Dukes of Hazzard movies and the fearsome inbred West Virginian monsters in the gruesome horror film, Wrong Turn. Much like the earlier fiction mentioned, these films summon observers to take note and be amused by exaggerated, absurd mountain characters. The directors and writers know that these stereotypes will sell in popular culture, although they are, in fact, detrimental to understanding Appalachia. For further descriptions of the hillbilly figure see Anthony Harkins Hillbilly and J.W. Williamson's Hillbillyland
} 
These beautiful, albeit stereotypical constructions of Appalachia illustrate that the region had become a problem for American society at this time. 1912 was the last year of Taft's presidency, when the United States moved forward into the progressive era and shifted into the modern era. In A Fierce Discontent, The Rise and Fall of the Progressive Movement in America 1870-1920 Michael McGerr explains how the movement encouraged the middle class: "Progressivism, the creed of a crusading middle class, offered the promise of utopianism - and generated the inevitable letdown of unrealistic expectations" (xiv). McGerr continues: "Progressives wanted not only to use the state to regulate the economy; strikingly, they intended nothing less than to transform other Americans, to remark the nation's feuding, polyglot population in their own middle-class image" (ibid). The rememberings in the newspapers demonstrate the discomfort of nationalist approaches to Appalachia. It was a place that was foreign and did not fit within the progressive, middle-class norms that continued to develop during this time. Thus, the construction of the hillbilly image in the newspapers creates Appalachians as an "other" to "fix" and remold to be folded back into the developing national culture.

While these progressive, industrial ideas seemed fruitful they met their demise in the sinking of the Titanic in April of 1912; however, the danger of this progressive movement can be seen earlier in March with the shootout. While the Titanic signifies the dangers of industrialism globally, the shootout demonstrates the dangers and anxieties of modernism that emerged both nationally and locally. The incident represents a case study for not only a national progressivism that clashes with the newly developing idea of Appalachian identity, but how local politics played a role in the event. These struggles manifest in how the Allen men struggled against the Republican views of Hillsville (and 
the rest of the state of Virginia) at the time. In his article, "Constructing Violence: Historical Memory and a 1912 Courtroom Massacre in Virginia's Blue Ridge Mountains," Hall writes that the "Republican party maintained an active political opposition, a legacy of the mountain areas' divided feelings about the American Civil War decades earlier" (32). Except for a couple of minor votes, the Allens remained staunch democrats in the town. The political leaning of the family attributed to much of the turmoil that occurred between them and the local government of Hillsville. Even though they were successful citizens in the community, the stigma of their political opposition remained dominant in their lives until the shootout.

Despite these progressive politics, Hillsville was still stereotyped by the public media as a backward Appalachian town that needed to move into modernity. Batteau argues that during the turn of the century Appalachia's construction moved from fictional, nostalgic stereotypes to something more sinister and real. ${ }^{2} \mathrm{He}$ writes that "Appalachia is no longer an anodyne for the discontents of civilization; instead it is an embarrassment, a reminder of an imperfect past. Instead of a pristine wilderness affording escape, Appalachia became epitomized by..sloth and ignorance" (87). From these descriptions, Appalachia has no longer become a place of the nostalgic pioneer past, but

\footnotetext{
${ }^{2}$ Later in the twentieth century, historians further added academic stereotyping to the region that the fiction writers create. Works such as Horace Kephart's Our Southern Highlanders (1913), John C. Campbell's The Southern Highlander and His Homeland (1921), Jack Weller's Yesterday's People (1965), or Henry Shapiro's Appalachia On Our Mind (1978) contribute to exceptionalism ideas of Appalachia, much like the identification of the lowland South at the time. These writers describe mountaineers as "yesterday's people" designating the mountain culture as a thing of the past. ${ }^{2}$ Oftentimes, these writers recognized Appalachia as an ethnic other to be examined as through a microscope. Mountain society and customs interested these historians to the point that they declared it was a region worth studying because of its distinct features.
} 
rather a place of industry, growth, and inevitable violence. Batteau best describes Appalachia's emerging identity as he states “As Appalachia entered history, it lost its innocence" $(88)$. The innocence of the $19^{\text {th }}$ Century travel writers is gone and now is replaced by depictions of industry. Sprouting from these ideas of industry, Appalachians reacted to development with violence. They no longer were the ignorant hillbillies who signed over their mineral rights, but were now starting to understand that they could stand up for their rights leading up to the West Virginia coal mining wars in the 1920s. Congruent with these depictions mountain violence starts to erupt in the mountains more regularly.

Historian John Williams places Hillsville in the context of this mountain violence starting with Tom Dooley and Frankie Silver in NC and the Hatfield-McCoy feud in West Virginia, and ending with the mining wars that happened thereafter the shootout. Williams states, "Folklorists William Lynwood Montell argues that the violence of the Civil War years trained mountain people in the use of force to settle personal and political disputes, and that these effects lasted through at least two generations" (186). The sensationalism of mountain violence in the media most certainly could have contributed to its continuation. As seen in the journalists' reactions when they first arrived at Hillsville, these mountain people were dangerous, but they were also interesting to watch and observe.

Within these observations the reporters wrote of Appalachia as a violent region and then changed its depiction to reveal mountaineers as an ethnic other. To borrow from Kenneth Burke, these newspaper articles function as terministic screens through which to look at the Hillsville shootout. Terministic screens work as filters to view a certain event; 
in other words, the use of these stereotypes are lenses for the media to view the shootout. The media creates a distance from the actual Hillsville and engages with the rhetorical Hillsville of its own creation. In fact, Burke writes about this distancing:

We must use terministic screens, since we can't say anything without the use of terms; whatever terms we use, they necessarily constitute a corresponding kind of screen; and any such screen necessarily directs the attention to one field rather than another. (his emphasis, Burke 50)

The "screen" that we see the reporters using with the shootout is indeed one that is tied to the rhetorical Hillsville that they create, a Hillsville inhabited by mountaineer stereotypes.

However, these depictions change through the circulation of the shootout in national and local newspapers. These terministic screens move from dangerous mountaineers to representing Appalachians as an ethnic other. Despite their change in tone both of these depictions still contain stereotypical images of the Appalachian mountaineer. This shift follows the Burkian idea that screens can change:

Within that field there can be different screens, each with its ways of direction the attention and shaping the range of observations implicit in the given terminology. All terminologies must implicitly embody choices between the principle of continuity and the principle of discontinuity. (ibid)

In this chapter, I will explain how these representations of the Allen men are mediated through local and national news media, editorials, and political cartoons. From these mediations I use Burke's terministic screens in three specific ways to help theorize the 
depictions of the Allen men: the violent mountaineer outlaw; gangster; and an uncolonized other. These depictions were crucial to the development of the Appalachian identity during the late nineteenth century and lead to common stereotypes of the contemporary, marginalized hillbilly figure today.

\section{"Rude, Unlettered, and Traditionally Lawless": The Noble Mountaineer turned}

\section{Violent Hillbilly}

The national media neglects to depict the people of Hillsville in a realistic light, instead the writers continue to rely on stereotype. In "The Recall at Hillsville" the reporter writes "the people of the Hillsville neighborhood are rude, unlettered, and traditionally lawless." Not only does this reporter stereotype everyone in Hillsville as "rude" and ignorant, he also depicts them as taking up their own version of the law: "The mountaineers felt that the prosecution of Allen, for performing an act of friendship in helping a prisoner to escape, was unjustifiable. The court opposed their views and they have made the court feel the 'people's' power." This report gives us quite a negative vision of the town, meanwhile the Roanoke version explains that Hillsville "lies in the Beaver Dam Valley, four miles from the top of the Blue Ridge Mountains. Across the valley a strip of indigo along the sky on a clear day shows the Alleghenies." Even though these descriptions seem beautiful, the writer continues explaining that "The country is rough, the roads are bad, and at this time of year, with spring thaws, nearly impassable. Illicit stills are said to be many." While the weather and road conditions most certainly are true, the inclusion of the moonshine still shows that this writer is most certainly interested in invoking the hillbilly stereotype here as the stills are illicit. The fascination 
with Hillsville as a mysterious Appalachian place preserves its identity as other in comparison to the rest of the nation.

The arrival of the media to this mysterious locale and their role within Hillsville had an impact on these depictions of the shootout. Local historian Ronald W. Hall writes about the arrival of the media to after the shootout: "By Monday, it was estimated that that [sic] some thirty-odd reporters had descended upon Carroll County. Between the detectives and the reporters, hotel rooms were difficult to get and local citizens boarded some of the newsmen" (137). Much like the travel-writers of the nineteenth century in Appalachia noted earlier, these writers did not do their research and instead relied upon local lore of Hillsville and lore that they created themselves. Hall continues with "Instead, [the reporters] enjoyed the luxuries of the Texas House Hotel and wandered about town, interviewing 'knowledgeable' people and either taking or posing for photographs" (134). These descriptions show how the media conflates the coverage of the shootout with a tourist mindset as they take pictures and pose at the various sites where the shootout occurred. There is very little actual coverage done of the aftermath of the shootout, instead these reporters were lead out into the hills by locals where Claude, J. Sidna, Wesley Edwards, and other Allen men supposedly were hiding. These wild goose chases are brought up frequently in the papers and led to the publication of numerous blatantly fictitious articles. Two examples of inventive reporting were articles about a shootout at Sidna Allen's house where his wife, Betty, was killed, and Clerk of Court Dexter Goad's daughter helping him to reload his gun in the shootout. Because of the media hype behind Miss Goad's "heroic," but fictitious action, a medal was struck for her by the governor's wife and the governor wrote her a letter. While these two incidents 
seem harmless, the false media representations had a huge influence on the Allen men as they went to trial after the shootout.

\section{"Three Killed in Virginia Court": The Gangster and Outlaw Terministic Screen}

As news of the shootout intensified, media outlets refer to the Allens as not only mountaineers, but as a "gang" as organized crime was first starting to take its hold in urban areas like Chicago and New York. These depictions use another terministic screen with the shootout as the mountaineer/hillbilly image is merged with the more contemporary image of the urban gangster. In The New York Times index for 1912, gang is written 15 times to refer to the Allens in the shootout, mostly appearing during the month of the shootout itself. During the months surrounding the shootout the word was used to depict any sort of organized, premeditated crime. These appearances and the use of gang illustrate that the media conflates this Appalachian crime to urban crime of the time.

Correspondents from the Wall Street Journal write that "Three persons, including the judge, were killed by a gang in the court house at Hillsville, Virginia, Carroll County" (Three Killed in Virginia Court). The article continues with an "Outbreak occurred when Lloyd [sic] Allen, head of the Allen gang, had been found guilty of felony by the jury. Members of the gang...began shooting when the verdict was announced" (my emphasis, ibid). In fact, we see that these reporters even write about how the Allens are supposedly taking a stand against the law:

Reports have been coming down the mountain all day that the outlaws have recruited a big band to their defense. A lawless element, in which the Allen were ringleaders, has ruled the mountains fastnesses for years. There is a saying among 
revenue officers that every pine tree shelters a moonshine still. A battle between law and crime is sure to draw recruits here. ("Two More Dead")

These details clearly demonstrate that the Allen men participate in a moonshine ring that operates like an urban organized crime gang. According to these newspapers this entails recruitment from locals and the constant battle between lawmen and the moonshiners. There are even eyewitness accounts that attempt to corroborate with the reporter's gangster imagery:

Perkins says that he knows the Allen gang well. Their territory is about sixteen miles from Hillsville. Near by runs Shooting Creek, which got its name from the number of revenue men who met their death in the neighborhood. Perkins says the Allen gang is about the worst in Carroll County, where the 'moonshiners' are the most desperate. 'I know their attitude at a time like this,' said the revenue agent, 'for I have been within an inch of death at their hands. (my emphasis, "Dead Judge Was a Fine Shot")

While these descriptions have some semblance in truth as Sidna and Floyd were moonshiners, they are exaggerated. Perkins' association with the Allens serves more as a publicity stunt than factual. His observations continue the entertaining and lurid qualities of the shootout. There were no deaths of revenue men near Hillsville and his contribution is pure speculation. Perkins's depictions and the previous other accounts do not conceive of the mountaineers as European clans, as we see in later newspapers articles (and in later historical texts such as Shapiro and Campbell), but rather as gang members who reside in a changing progressive world. 
This gangster imagery is still used in newspapers that are not mainstream newspapers demonstrating that these stereotypes were not just occurring in white, dominant newspapers of the time, but across all media outlets. On March 16, 1912 the Kansas Baptist Herald, an African American newspaper based out of Topeka, Kansas opens with dramatics: "In a flame of unprecedented outlawry the entire human fabric of the Carroll county circuit court in session here today was wiped out by assassination" ("Mob Wipe Out Court"). The article makes the shootout seem methodic and not a melee of bullets flying like the New York Times article: "Judge Massie fell dead in his place...then the weapons were turned on Commonwealth Attorney Wm. Foster and he sank to the floor with several bullets in his brain" (ibid). In fact, the power of the courtroom remains in the hands of the Allen men as they "backed slowly out of the room holding all pursuers in check at the point of the revolvers" (ibid). These depictions change the view of the shootout as spontaneous to now an organized assassination of the government men. As outlaws, they methodically blow away everyone in their path without remorse. The raw intensity and drama from these news reports is much different than what is portrayed in mainstream accounts. This gangster terministic screen contains much more drama and bloodthirst from the Allen men.

The writer of the Kansas Baptist Herald further supports the organized crime image produced before, but invokes the race of the Allen men. The rest of the article reads, "The vicious white men of this country have let the negro alone long enough to form a mob and kill all of the officers of the court. This is merely the beginning of the mob rules being applied to white men" (ibid). This reaction demonstrates the mob rule that is forming in the South; instead of reacting to an African American, white, 
Appalachian men shoot up the courtroom. No other newspaper accounts of the shootout refer to the race of the Allen men except in later accounts, when editorials refer to the Scots-Irish clans that settled in the Appalachians. It's strange that this writer decided to take up race; however, it demonstrates the reaching effect of the shootout across the nation.

\section{No North- No South- All Wild and Woolly West}

In addition to the textual representations of the shootout, media outlets created political cartoons invoking the gangster outlaw terministic screen. These political cartoons contribute to the rhetorical construction of the shootout because they present images of how the media and the American public as a whole visually constructs the Allen men. These visuals move beyond the textual descriptions using stereotypical accents and portrayals of the citizens of Hillsville to realistic and cartoonish images of the Allen men, in particular Floyd Allen. The depictions in The New York Times the month of the shootout and Life Magazine are the most productive for this study because they invoke the terministic screens of gangster and violence that the articles address. These are important because these visuals guide the American public as to how to conceptualize the Allen men.

The first political cartoon occurs in The New York Times on March 24, 1912. Before this date, Claude surrendered, the Baldwin Felts detectives found the last of Allen men, and the lawless symbols of the Allen men solidified in national culture. The visual rhetoric of the illustration itself demonstrates how the nation views the shootout: 


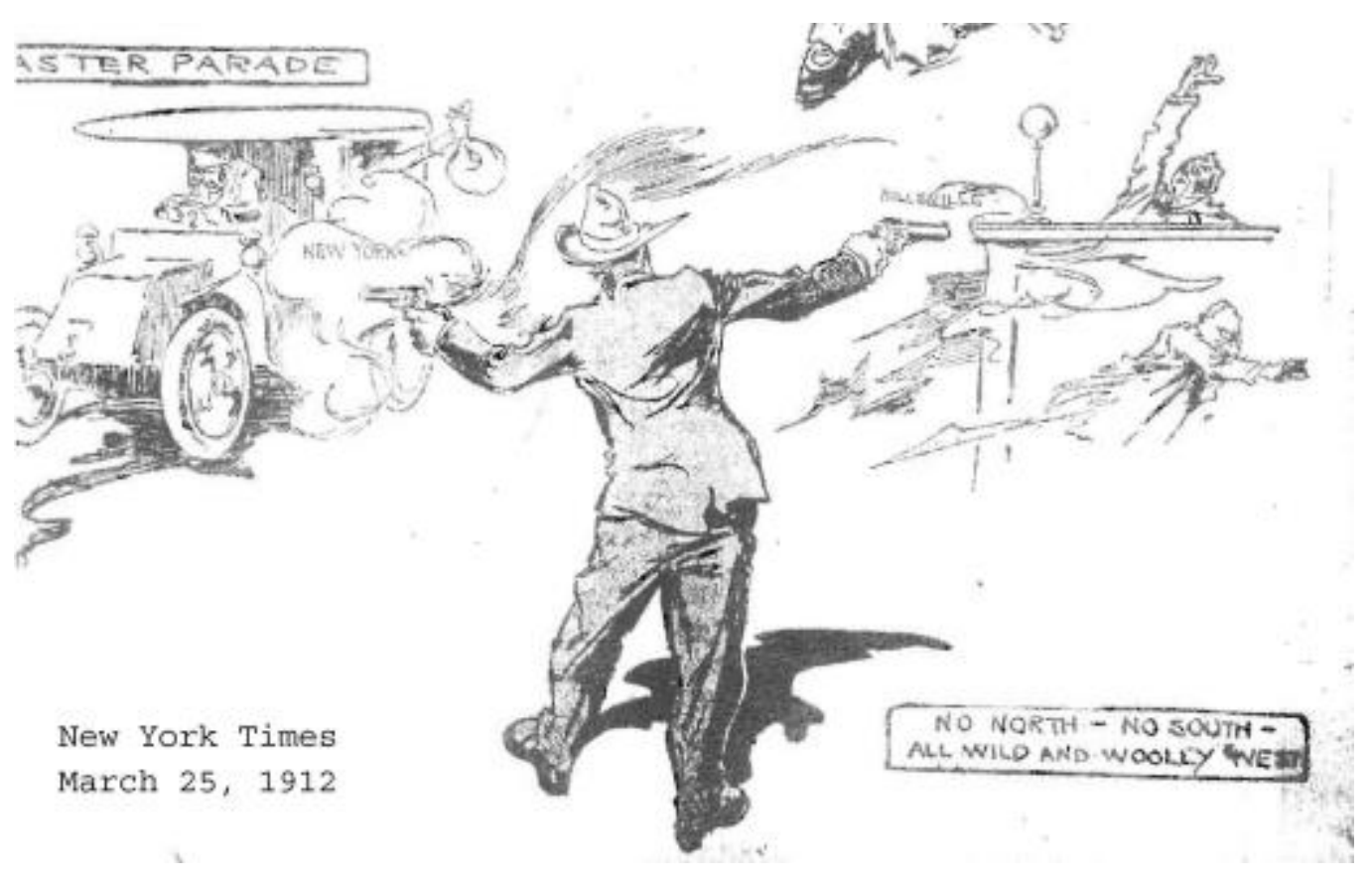

Figure $1^{3}$

In the cartoon the unknown (but more than likely Floyd) Allen man is drawn in a suit with two guns blaring. The sketch does not present the traditional hillbilly figure in overalls, straw hat, or with a pipe in his mouth. The man appears to be well-dressed and wearing nice shoes. In Hillbilly, A Cultural History of an American Icon Anthony Harkins writes about how the traditional hillbilly stereotype is not yet apparent in films from 1904-1920:

No figures appear with excessively long beards, oversized and tattered hats, granny dresses, bare feet, or any of the other markers of the cartoonish hillbilly that would subsequently be established. Instead, most characters are dressed in ordinary turn-of-the-century clothing with a

\footnotetext{
${ }^{3}$ This cartoon is part of a much bigger cartoon that is located under "Impressions of the Passing Show." The New York Times (March 24, 1912): ProQuest Historical Newspapers: The New York Times pg. SM16.
} 
slightly rural look. Male leads, even ones portraying moonshiners or feudists, often are dressed in suit coats, boots, and even ties. (61) Harkins' comments collaborate with the idea that the identity of the Appalachian hillbilly was still in development in American culture. The artist draws the figure as a violent gangster rather than a comic or dangerous buffoon. He wields two pistols blazing as he ambles through Chicago. The judge raises his hand as if shot and the other man, possibly the sheriff or the Commonwealth attorney, flees for his life.

The depiction of the Allen man also entertains the public. Conflating the shootout with the rising gangster activity in Chicago reveals that this editorial is a moment of not only entertainment, but also a revocation of the law. An editorial that occurs the next day in The New York Times explains that

In the so-called novels of adventures, men very much like these and equally ready to use knife and pistol according to the dictates of private judgment, cut figures by no means repulsive or absurd and the gentle reader thrills with very much more of sympathy than of horror when men are killed and property stolen without due—or any - process of law. 'They used to do such things' seems to be a sufficient excuse for the heroes of fiction, and of history, too, for that matter, but the Allens have made the grave mistake of living several centuries too late. ("Explanations That Are Excuses")

Similar to the earlier stereotypes in the written texts, this writer sets apart the lawlessness with a work of fiction. Much like the exploitative and entertaining aspect of the cartoon above, this shooting provides a "thrilling" moment for the audience similar to adventure 
novels. Both pieces depict that the Allens still occupy a time that refuses to keep up with progress; they can no longer be a part of modern society.

The society that the Allen men now belong to is part of the "Wild Woolly West." The two regions are combined through the violence that occurs in both of them represented by the outlaw in the middle. East and West are united by ideas of stereotypes that occur with the cowboy/outlaw figure and the hillbilly figure. In fact, in another editorial dispatched from Charlotte, NC, Floyd is compared to Jesse James by H.C. Thomas, an employ of the Secret Service Department of the Government: "Jesse James was a harmless as a Sunday School teacher in comparison with Floyd Allen" ("Outlaws Slay in Court"). While Floyd was well known locally as a quick tempered man, these stereotypes, again, are used mainly for entertainment. Thomas's statement demonstrates that Floyd is even more dangerous than the western outlaw; a description that makes readers more invested in reading more about his adventures and dangerous character. As we see in the figure in the drawing, he is shooting not only the courthouse, but also the bank robbers in the car holding a bag of money. This drawing reinforces the idea that the west is becoming settled, but Appalachia still remains a lawless region.

In addition to this rather realistic portrayal of the shootout in The New York Times, another more comic depiction emerges in Life Magazine on April 4, 1912. This depiction invokes more of a cartoonish depiction of the shootout. From the rough sketch, the drawing could easily be included in modern day newspaper comics. Below the sketch 
focuses on one aspect of the shootout, the killing of the judge:

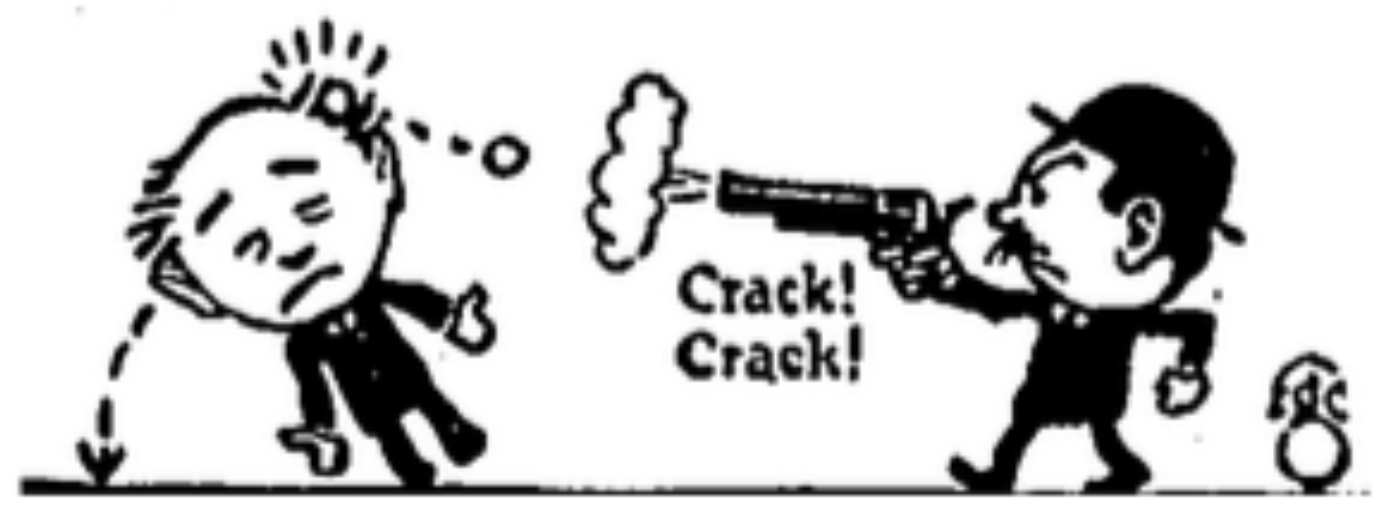

Figure 2

Similar to the action in the previous cartoon, this sketch continues to participate in the hillbilly ganster terministic screen. Because of his famous mustache, the figure on the right is likely Floyd Allen. These cartoons transform Floyd into the original shooter, a violent hillbilly to blame for the violence. He has a look of disappointment and rage drawn by his arched eyebrows and his mustached adorned scowl. He stands, again, welding a powerful revolver, arm akimbo to show his anger. The bullet from his gun connects to the head of whom we would assume to be Judge Massie because of his haircut. The judge has his eyes closed and is in the process of falling over. The artist draws an arrow going down from his head to the ground. There is a "crack, crack" from the gun that is reminiscent of contemporary comic books. The artist chose to focus on this scene because of the vast amount of coverage of Judge Massie's death that recognizes him as one of the most powerful figures in the shootout. He is depicted as being gunned down by Floyd when in actuality the judge declared that it was Sid Allen who killed him.

In this cartoon, Floyd blatently kills Judge Massie at point blank range. This illustration opposes the earlier, more complicated cartoon by focusing on the violent act 
itself, instead of placing the Allens in relation to the rest of the nation. Despite their differences, both of these cartoons make use of the gangster terministic screen. These cartoons stand as examples of how the depictions of the Allen men transcend to the new genre of the political cartoon. These cartoons reflect the public's interest in American society, thus the inclusion of the courthouse shootout demonstrates the relevance of the event by the American public.

\section{"He had thirteen bullet holes in his body": Creating Rhetorical Floyd Allen as Hillbilly Gangster Stereotype}

This construction of Floyd does not stop with these political cartoons, but continues with stereotypical, outlaw depictions. His role is pivotal in the retelling of the shootout because it gives the American public a definitive figure to examine and villainize. Descriptions range from local color dialogue, physical features, and Floyd's own boisterous, violent demeanor.

On March $16^{\text {th }}$ in a NYT article titled "Two More Dead In Allen Feud" the reporter clearly creates a local color voice to use for Floyd that participates in the outlaw terministic screen:

Ole Floyd Allen ain't never been sent to no prison yet... and there ain't no Jedge [sic] or Sheriff what's a-goin' to send him thar [sic] now. The boys fit like hell yesterday and I hope they all will git away. One of them hounds got me, but I'll never go to no prison. The Allens is all fighters. I reckon as how I've been purty free with my gun, and when I gets away I'll be free with it again. The boys'll be acomin' back for me. But if they don't come I'll never go to no prison alive. 
Stereotyping is clearly seen here in the use of words such as "fit like hell," "purty," and through the use of double negatives and the a-prefix. This was clearly not Floyd's voice, but instead a gross stereotyping of how this reporter thought mountain people spoke. Much like the Nineteenth Century travel writers' treatment of the mountaineer, this reporter has turned Floyd into a caricature complete with stereotypical hillbilly vernacular.

Fictional Floyd also speaks of himself in the third person, which further cements him as being a legend in Hillsville and beyond; he now stands as an icon in the memory of this event and an active member in the rhetorical Hillsville that the media created. His refusal to go to jail reinforces the idea that the Allens refused to participate in law enforcement. His tendency towards violence against the law also demonstrates his "outlaw" nature. He would rather choose death than jail.

Just a few days later on March 18, a Roanoke dispatcher for the NYT writes Floyd as "tall and gaunt, much the familiar type of mountaineer...in his youth he was a fine figure of strength, and even at 50 now, when his reddish brown whiskers are turning to gray, he is no weakling" ("Outlaws Slay in Court”). This article shows Floyd as a strong mountaineer even in his 50s. The description continues as Floyd's "familiar boast was that he had thirteen bullet holes in his body, and that five of them had been put there by his brothers" (ibid). This description shows the skirmishes among the Allen men; it depicts them in the media as violent not only to those outside their family, but to themselves as well.

Floyd is described next as not a "friendly mountaineer," but the type of mountaineer who would appear in the novels of Fox Jr. and Murfree. He (and the rest of 
the Allens) are threatening and violent. In "Outlaws Slay in Court," the dispatcher includes a testimonial from a law enforcement agent:

They have planned to kill me more than once, and but for a friendly mountaineer, Floyd Allen would have succeeded when I last went into the mountains after him...I arrested the Allens, and when the trial came up they threatened to slay all the officers of the court at Greensboro as well as myself, but their scheme was nipped.

The depiction of the agent presents Floyd as a menacing figure who is out to defend his family even in the face of the law and judicial proceedings. It shows the media's use of the violent mountaineer terministic screen and how these depictions not only construct a rhetorical Hillsville, but also a rhetorical, stereotypical Floyd that inhabits the fictional place.

\section{“Of Course They Are Not Monsters": The Uncolonized Other Terministic Screen}

While these descriptions and cartoons of the Allens use the violent hillbilly terministic screen, the media also uses a new terministic screen to convey pity for the Allen men as an uncolonized other. They are dangerous, but their actions are due to the culture in which they belong. Dr. George W. Summers, who was an educator in Southwest Virginia at the time of the shootout, elaborates on his view of the mountaineer: "Open, frank, and willing to be friendly is the way I have found [the mountaineers], but once wronged they would go any length to wreak revenge upon the one who harmed them" ("Outlaw Once an Officer"). Summers continues "I have never known an instance where an innocent man suffered at the hands of a Virginia mountaineer. The Hillsville tragedy is beyond conception" (ibid). These descriptions frame mountaineers as innocent 
and honest. They live in their own culture and are not violence unless provoked.

Summers' comments do not take into consideration the complicated political climate that created the shootout; instead, it relies on the "innocence" of the mountaineer's culture.

Whereas Summers response to the shootout was that of shock, in "Shoot the Judge" in the Wall Street Journal the next day after "Outlaws Slay in Court" was printed, a separate writer codes the violence as a cultural reaction to the judge's verdict. The correspondence from Boston notes that "when the sudden personal issue confronted him, he swiftly and passionately expressed in the crack of his mountaineer's rifle, his belief in the recall of judges" ("Shoot the Judge"). The act is labeled "a piece of cowardly terrorism" with their victims having "no defense." The use of the "mountaineer's rifle" still invokes the violent mountaineer stereotype; however, the writer also includes Floyd's "belief" that he was wronged. The violence is not random, but a reaction. Unlike Summers it was a predicable reaction from a culture that is deemed personal rather than political.

The pinnacle of how the public views the Allens and Appalachia as an uncolonized other occurs in an editorial in the Baltimore Sun, which states that "There are but two remedies for such a situation as this, and they are education and extermination. With many of the individuals, the latter is the only remedy" (Hawkins 35). While this paper advocates death to ignorant and violent mountaineers, the piece takes a more blatant turn towards race: "Men and races alike, when they defy civilization, must die. The mountaineers of Virginia and Kentucky and North Carolina like the red Indians and the South African Boers, must learn this lesson" (36). This piece demonstrates that there is absolutely no room in progressive society for the violent mountaineer. The writer 
groups the Appalachian region into other regions and cultures that needed to be colonized. The way of life in Appalachia does not match up with "civilized" society. There is an option of education, but this writer is clear that that option is not the best. The editorial reveals a reactionary violence to the violence of the shootout.

While the Baltimore Sun editorial is indeed violent, "Of Course They Are Not Monsters" in The New York Times demonstrates how the media has been "harsh" in their treatment of the mountaineer: "several people have apparently resented the unmitigated harshness which has marked most of the comment upon [the Allens'] crime and have protested that the class to which they belong has its virtues as well as its vices and should be understood as well as condemned." While they are uncolonized, this writer further notes that there needs to be a more public understanding of the mountaineer and his culture. Through that understanding the possibility of rationale for the shootout could be deciphered. Within this understanding the public will see "the savage individualism which is the characteristic of every race with an environment as theirs" rendering the Allens as victims of their violent culture (ibid).

In addition to the cultural traits, the writer then turns to a paternalistic view of the Allen men:

Like everybody else, the mountain people are combinations of good and bad. Probably they are, on the whole, more ignorant than vicious. They are the victims of heredity and alcohol, and now that their isolated region has been invaded they must change or perish. (ibid)

This passage pushes the uncolonized other to include moonshine, but also the inference of inbreeding through the use of "heredity." These men can't help themselves because of 
their raising. While it isn't clearly stated here, these stereotypes give way to more modern cultural stereotypes of Appalachia.

The subset of breeding under the uncolonized other is seen in another editorial which determines that the Allens were a result of their genetic past. In "Should be a Hunt Not a War" the writer explains that an "explanation of the Allens and like families troubles lie in heredity" (10). Agreeing with the previous article, this writer elaborates on the rationale behind the Allens' "heredity": "Often spoken of as 'of purest English strain,' they are, in fact, the descendants of criminals and defectives sent over to Virginia while England still got rid of minor offenders by transporting them to her colonies" (ibid). This passage makes the Allens seem redeemable as members of European ancestry; however, it is the worst ancestry that made them. They are a result of criminals who came to America. This writer wants to distinguish that these citizens are an unfortunate part of America's history. Giving a historical background, the writer continues with "They were driven back into the mountains when a better class or settlers came over in Cromwell's day" (ibid). The argument that Appalachians were "driven" into the mountains does not give credit to western migration or the migratory patterns of different cultures into the mountains. This genetic addition to the uncolonized other terministic screen demonstrates that the mountaineer is prone to violence because of his historical past. Violence is in his blood because of his uncivilized past. The cartoonish and tongue in cheek presentations of the political cartoons are no longer here, instead the writer presents the mountaineer as an ethnic other that needs to be "educated" or "exterminated." 
One of the final editorials for this terministic screen that demonstrates the need for education occurs in June of 1912 in The Chautauquan. In an attempt to offer solutions for the problem of the uncolonized mountaineer the writer argues:

The trouble is that the mountaineers and the nation have grown apart. The former need more schools, more sympathetic interest in them, more tact in the administration of law and justice, more sweet reasonableness in the enforcement of regulation that the mountaineer cannot understand or finds detrimental. The mountaineers will not tolerate bureaucratic arrogance, a brutal tone, and more than they will tolerate patronage and condescension, but they will respond to spontaneous good will and helpfulness. In the case of the 'Allen gang' the law must, of course, take it rigorous course. Crime must be punished...but the larger problem of prevention, of reconciliation, of rescue, is the problem, which should appeal to the serious and enlightened citizenship of the country generally. ("Highways and Byways")

This article is most certainly concerned with the anxiety of the mountaineer on the present as it notes that they "need more schools" and "more reasonableness in the enforcement of regulation." The mountaineer (and the Allens more specifically) are created into a group who must grasp these concepts in order to operate in a progressive America. Their assimilation is not necessary; instead, patience and cultural awareness from the nation is required to approach this distinct region. As seen in the last sentence, education of this group of people will act as a "prevention" method so an occurrence like Hillsville won't happen again. 
“Judicially Murdered By the State of Virginia over the Protests of More than 40,000

\section{Of Its Citizens": A Rhetorical Turn to Pitying the Allens}

While the violent mountaineer, gangster, and uncolonized other terministic

screens work for analyzing the initial responses to the shootout, hunt, and capture of the Allen men, another screen emerges as Floyd and Claude face the death penalty in the state of Virginia. This screen demonstrates tragic figures who face death as the justice for the crimes that they acted upon against the state. These men stood trial and were found guilty despite the alleged 40,000 names that were signed to public petitions. These petitions still reside in the Governor Mann's papers in the Library of Virginia archives. In fact, Floyd acknowledges their existence to Claude during a written statement in prison:

I thank the Journal for the fight that they have made to save our lives. I also want to thank the papers in the State who have helped us and who have tried to give the true facts to the people of this and other States. It has been a great comfort to us to see how many people believe in our innocence and have helped us as they have (Floyd's manuscript 32).

The existence of these "papers," i.e. petitions for pardon, illustrate the importance of these public memory documents. Despite the pushback from petitions from throughout Virginia, the governor did not pardon Floyd or Claude.

Along with these petitions, the news media presents us with a tragic and pathetic image of Floyd and Claude working against the stereotypical and cultural terministic screens used earlier. Floyd is "ready to go"" meet his maker "in a half whisper" ("Allens Executed"). Floyd's voice here is much different than the stereotypical voice that we heard from "Ole Floyd" on March 16. Even though the writer presents him as "a stalwart 
and powerful figure, with beeting [sic] brows and bushy, reddish whiskers," Floyd's voice is rendered as pitiful (ibid). His depiction has changed from the hardened gunslinger to a convicted criminal headed to his death. While Floyd's voice is heard, Claude's is mostly silent in the media making it easier for the public to create him as the other scapegoat victim. We see in these media depictions of Floyd and Claude how the public's anxiety has turned from aggression to sympathy. They realize that another two lives will be taken in addition to those killed in the shootout.

In response to the frequent sympathetic media portrayals of Floyd and Claude and after their deaths, petitions were passed around for Sidna Edwards and also J. Sidna Allen. There is a distinct change in the media as petitions are circulated around the state for their pardon. Sidna Allen depicts the change in the media in his memoir as he cites two articles occurring in The Danville Register as well as The Richmond Evening Dispatch. Both of these articles explain that since Governor Boyd pardoned Friel Allen and Sidna Edwards, J. Sidna and Wesley Edwards should be pardoned as well.

On April 23, 1926, the daily papers carried a news story to the effect that on the following Thursday, April 29, our friends, led by Attorneys English and Moss, would present our petitions to the Governor. Bankers, business men, clergymen and others accompanied these volunteer legal representatives when they went before the Governor

To their surprise the Governor informed them that the pardons would be granted immediately — that there would be no delay whatever in giving us our release 
Sidna's statements as well as some of the media of the time demonstrates that the public finds fault in killing two more men related to the shootout. Because of the changed public opinion seen in the many petitions sent to the governor he pardons Sidna and Wesley.

\section{"Such is the Power of the Press": Sidna Allen's Commentary on the Media}

\section{Coverage of the Shootout}

F.H. Lamb published Memoirs of J. Sidna Allen, A True Narrative of What Really Happened at Hillsville, Virginia in 1929. In the small chapbook, Allen details the shootout, his escape, arrest, incarceration, and eventually his pardon; however, he also clearly writes about how journalists construct his family in the popular media at the time. His response to the media's portrayals of his family gives us a glimpse into how these terministic screens actively affected the Allen family. His comments on the press demonstrate how powerful these depictions were not only to readers of these articles, but to the Allen men who were affected by the interpretations of these violence images. Sidna writes:

Overnight the boss of a courthouse ring of selfish politicians became a brave champion of the law, while those hitherto opposing this courthouse ring sank into the role of villains - such is the power of the press. (66)

Sidna's comments show that the press's "power" relied in their creation of making the Allen men into "villians." This stereotyping of the men also gives way to a rhetorical Hillsville manned with violent hillbillies. The media had complete control over how the Allen men were portrayed to the public eye. 
Sidna elaborates on the power of the press as he writes about how they had a hold over how he and his relatives were perceived in the media and how this contributed to the deaths of Floyd and Claude. He writes:

And at the day of judgment, I feel confident, those editors and reporters who so inflamed the public against us will be held responsible for the deaths of Floyd and Claude Allen and for the heavy sentences imposed upon the rest of us. More than anything else, the many untruths circulated by the press were responsible for the execution of my brother and nephew. (ibid)

The description illustrates the "many untruths" that the reporters created about the shootout. This piece of text presents a clear distrust of outside media that was brought to the mountains. While some reporters did come from smaller cities like Roanoke, most came from bigger cities like New York and Richmond, VA. These reporters stayed in hotels during the shootout and were often looked upon as outsiders by locals such as the Allens. While the trial itself was not significant, the shootout and man hunt afterwards brought dozens of reporters to the area. This distrust is founded by Appalachia's distrust of industry in the region - a region where coal and timber barons bamboozled its residents to sell their lands for cheap for industry. These concerns were most certainly justified with the twisted portrayals of the Allens and Hillsville in the media.

Not only does Sidna find these reporters responsible for the deaths of his brother and nephew, but he also writes about them as displaying the Allen men as "cold-blooded" killers:

The news of the shooting spread rapidly, and the blame for it, of course, was laid upon the Allens. We were pictured to the world as having 
deliberately and cold-blood-edly shot up the court, while those who had actually brought on the fight were held up as heroes. (ibid)

In other words, the journalists used the terministic screen of the violent mountaineer to rationalize the killings. They were dependent on this depiction because these reporters were not present for the shootout itself; they could only rely on the accounts of those who were present to provide an account of the events. Sidna disagrees with this news coverage of his kin and instead empathizes with the Allen men throughout his memoir. In this account, he attempts to displace the popular, official remembering that the vengeance of the Allen men are the only thing that led to the shootout when it was much more complicated. Sidna's humanizes the Allen men and demonstrates how much power the press truly had at this point in history. Their depictions of the men as ruthless outlaws vilifies them, when in fact, the identities of the men were much more complicated spanning from their own personal interests in the shootout to the political factions at work as well; however, as we see in the media coverage these complicated and humanistic descriptions were boiled down to violent hillbilly stereotypes.

Despite these representations, the people of Hillsville were cognizant of how the media represented the town and its residents. Antony Harkins explores the uptake of the shootout with the people of Hillsville in Hillbilly, A Cultural History of an American Icon. Harkins writes about Harper's magazine's William Aspenwall Bradley and Bradley's relationship with the shootout and the people of Hillsville: "[Bradley] reports that the townspeople remain indignant about the 'flights of fancy in which they [news reporters] indulged in order to create the requisite local color so sadly lacking in reality"” 
(66). Despite these representations the citizens of Hillsville wanted to create their own version for the national media.

Harkins continues, "Bradley thus acknowledges the national media's deliberate distortions of mountain society and the industrial transformation of the region, while perpetuating standard tropes about mountain violence, lawbreaking and backwardness" (ibid). He acknowledges the town's perceptions that these depictions are indeed false; however, they are still invested: “The townspeople's surprising willingness to discuss the case, akin to the willingness of the Hatfield clan to brandish weapons for newspaper photographers, might also reveal their secret pride in playing a central role in a national media event" (ibid). The media is falsely representing the town, yet still, residents of Hillsville are proud to have this court case. ${ }^{4}$ They know that it's bringing money into the town and providing them with income. While those closely involved stay silent, as seen with the women I mention in Chapter Four, the rest of the town is happy to guide the press and the detectives on wild goose chases around the mountains.

However, coverage of the shootout is brought to a halt as soon as the titanic sinks. An editorial in The New York Times notes "The Allens? Hillsville? It requires a small effort to recall who they are, what they did and where, and when recalled, it is hard to realize how recently we were all intensely interested in and excited by what then seemed a wholesale slaughter" (“Obsessions Should Be Shunned”). These statements show that the interest of the national media has most certainly shifted. Hillsville was no longer a concern. It also noted that this "thrilling" event was in actuality a "slaughter." The writer continues with "All that seems a small matter of more intrinsic importance. To nothing

\footnotetext{
${ }^{4}$ This duality is also reminiscent of how citizens embrace the shootout currently. They're proud that it draws tourists in, but feelings are also still raw about the event.
} 
except a really great war, perhaps has here been given in modern times so nearly the exclusive attention of so nearly everybody as the loss of the Titantic" (ibid). Despite the concluding remarks that this writer implies, the circulation of the shootout most definitely did not end. In fact, the media's narrative of the shootout demonstrates the profound influence that they had on contributing to the retelling of the story of the shootout. These retellings give way to the public memory of the event because they were the only way that the public knew about it. They were told the story through the interpretation of the reporters. The public's reading of the newspapers and then retelling of the story to each other contributed to the collective memory of the event. However, the retelling goes beyond just the oral as numerous citizens kept the articles to document the event. The three museums that I mention in Chapter Three demonstrate the importance that these articles have in retelling the event in the public sites of memory in Hillsville. While housed in Hillsville, the irony is that nearly all of these articles were written by outsiders of the region despite the participation of the citizens of Hillsville in welcoming the reporters. The museums as well as other rememberings use the terministic screens that the national and local media first establish to retell the story of the shootout.

More recent retellings of the event portrayed by the citizens of Hillsville attempt to humanize the participants and reject the news articles. In fact, in one of the local plays by Frank Levering, the article about the fictional killing of Sidna's wife produces laughter as she states, "Well, I guess they got me." The false reporting and stereotypical imagery in these articles provoked locals to react and tell their own renditions of the shootout. Ones that still carried many untruths, but that give a more humanistic than stereotypical telling of the event. 


\section{CHAPTER TWO:}

\section{PERFORMING HILLSVILLE:}

\section{RHETORICAL DISCOURSE ON THE ALLEN BALLADS AND}

\section{LEVERING'S SHOOTOUT PLAYS}

Rather, oral histories are constituted anew, recorded and "saved" through technology in the name of identically and materiality. Though this "new" archiving is supposedly against loss, doesn't it institute more profoundly than anything the loss of a different approach to saving that is not invested in identicality? Doesn't it further undo an understanding of performance as remaining? Do not such practices buttress the phallocentric insistence of the ocularcentric assumption that if it is not visible, or given to documentation or sonic recording, or otherwise "houseable" within an archive, it is lost, disappeared? (her emphasis, Schneider 101).

Live theatre is a powerful thing and like now it's all over. You have to do it and then let it go. Just let go of it. (Frank Levering)

The Hillsville tragedy may be viewed as having elicited the oral responses of a society whose values were in a state of transition from the individualism and cooperative spirit of the frontier to the social ethic of twentieth century bureaucratic middle class America (Aceves18).

The media circulation of the shootout focused mainly on how outsiders developed portrayals of the event using images of the dangerous mountaineer, gangster, and uncolonized other. Shortly after the shootout, however, locals produced their own artistic rememberings of the shootout in ballads and plays that build upon the media portrayals. While the "Sidna Allen" ballad continues to portray Sidna Allen using the dangerous mountaineer image, "Claude Allen" presents a more tragic portrayal of Claude as his mother and girlfriend weep over his grave. This shift demonstrates how these ballads move from the stereotypical terministic screen that the media depicted to one that evokes 
pity for the Allen family. Whereas, 105 years later, the plays of Frank Levering continue to contribute to humanize those involved in the shootout. These humanizing moments occur when the characters recognize themselves as characters in the event and that the play occurs in the historic courtroom. These moments emphasize the suffering and endurance that results in a more conciliatory emphasis on healing.

\section{“A Story About A Brave Mountaineer": The Hillsville Ballads}

The ballads about the shootout serve as powerful reminders of the terministic screens because they present episodic details that include the characters of the outlaw and the tragic hero. The ballad genre places an emphasis on characterization that draws on these terministic screens. The emotional effect of the ballads helps drive these terministic screens as their singing is one of the most emotional transmissions of music as they are generally sung without accompaniment and in a mournful tone. These ballads retell the history of the shootout in ways that demonstrate clear distinctions for the town or for the Allen side of the story while participating in the ballad genre. Each ballad tells its own version of the shootout. Sidna's focuses on the shootout and his escape while Claude's dramatizes his death by electrocution. "Sidna Allen" invokes the outlaw terministic screen portraying Sidna as a dangerous mountaineer whereas Claude's ballad renders him as a tragic hero as his girlfriend and mother weep over his grave. Much like the European ballads that were passed down in the Appalachian Mountains, these stories are told in third person. More than just words that were put to a melody, the two songs convey a vernacular history of the event that entails the historical conflict of the Allen family and the town. "Sidney Allen" and "Claude Allen" expose the political complications of Hillsville when the shootout occurred. In the processes of composing, singing, and 
passing down of these ballads, community members have invested in either the town's role or the Allen family's role in the shootout.

Ballads served as a way for Appalachians to pass down fictional and historical stories through a specific European song tradition. Because of their formulaic nature and the cultural role that ballads played (and continue to play), these ballads serve as "a point of connection between intention and effect, an aspect of social action" (Miller 153). The social action here is the investment in retelling the story of the shootout that involves "intention" because in the choosing of which ballad to tell. Within each ballad there were variations, though the plot stayed the same.

Folklorist Roger deV. Renwick defines the complicated features of a ballad as "a song composed in stanzas sung to a repeating tune that recounts a short, usually singleepisodic, tale of complication, climax, and resolution" (57). His description here denotes the telling of a tale: a beginning, middle, and end. The ballads explain the shootout happen, the escape, then the incarceration of Sidna and the death of Claude, but they also convey these two men in certain ways through the telling. Sidna is rendered into masculine violence whereas Claude is rendered pitiful.

While these two rememberings of the shootout convey a slight sense of emotion, it does not dwell too far into the sentimental like folksongs. The ballads focus "on the leading character, features two interacting protagonists to a scene" (Renwick 57). Each ballad "develops an episode in which action takes place and is concluded, whereas the other folksongs focus on the articulation of feelings, ideas, fantasies and attitudes without utilizing a narrative thread to achieve their ends" (Toelken 152). These observations determine that the objective of a ballad is storytelling, in opposition to the often first 
person, emotionally charged folksong. I.G. Greer, ballad collector and singer, elaborates on the ballad genre:

The ballad singer doesn't have a trained voice; you'll soon find that out. The trained voice doesn't interpret the ballads. And this is truly an interpretation. The ballad is a story that you sing. It isn't a ballad unless you sing it. It isn't a ballad unless it tells a story. (Greer, "Talk at the G.F. Women's Club Asheville, NC") 5 Agreeing with Renwick, Greer argues that the ballad must be sung and tell a story. He also asserts that the ballad must contain third person narrative and not be in the first person as seen in the Allen ballads. Greer's comments also state that ballad singers and collectors interpret ballads. The use of the terministic screens on these ballads is most certainly an interpretation of how to understand their use in popular culture and the history of the shootout. The two screens present two ways of viewing the sides of the shootout.

While interpretations exist, it is also important to understand where these ballads fall in relation to the classifications of the ballad genre. Renwick splits the ballads into subtypes consisting of broadside, parlor, blues, and the medieval/Child ballad. The broadside ballad was written down and sold for money on the streets. G. Malcolm Law Jr. categorized the broadside ballad into "two logical divisions for the purpose: ballads

\footnotetext{
${ }^{5}$ This description is taken from a recording that I received from I.G. Greer from the I.G. Greer Folksong Collection at Appalachian State University's Belk Library and Information Commons. The recording was on a wax cylinder and was converted to CD for me by one of the archivists there. I never had the privilege of knowing Professor Greer as he passed in 1967; however, I did have his great grandson in my Appalachian Studies course at Caldwell Community College where I played this clip for him. It was the first time he had heard his great grandfather's voice. I use this anecdote to illustrate just how powerful the study of ballads and ballad collecting still remains in the twentyfirst century.
} 
that originated in the British Isles (Laws 1957), and ballads that were made on this

continent" that had to do with "North American experiences" (60). They are generally in first person and concern "regional and occupational groups" such as "logging, ranching, coalmining, seafaring" (58). Parlor and blues ballads are generally in first person (despite Greer's definition) and are generally played on the piano and the guitar or banjo respectively. These ballads contained moral tales that often paralleled the temperance movement. These details and specifications of the ballad are important to keep in mind as the "Sidna Allen" ballad fits into the "broadside ballad" format whereas "Claude Allen" is most certainly a parlor ballad because of its moralistic nature. These qualifications are not designated as folk songs, which are songs that rely on feelings whereas ballads rely on the story itself. The ballads tell a story that is distinctly Appalachian at the time. These singers invest their story in a narrative that includes hillbillies, mountains, and a sensationalized plotline that is reminiscent of those found in the earlier media depictions.

\section{Remembering the Ballads: Collective and Public Memories of the Shootout}

These variations could stand as pieces of collective memory as they come from vernacular, oral rememberings of the ballads. Edward Casey's definition of collective memory in Framing Public Memory helps to define how the ballad variants exist as such:

...the circumstances in which different persons, not necessarily known to each other at all, nevertheless recall the same event—again, each in her own way. This is a case of remembering neither individually in isolation from others nor in the company of others with whom one is acquainted but severally....All that matters is commonality of content...Not the experience but the focus-amounting to a monothetic obsession — is what is shared in collective memory. (23) 
From this definition we can see how these recollections of the event can serve as examples of a specific kind of collective memory. Collective memory first must occur before an artifact of public memory can be established. This definition fits well with the development of the ballads, as there are numerous variations of these ballads; however, they all maintain the same basic plot, characterization, and resolution. Each balladeer recollects the ballad "in her own way" as she recites the event. The ballad remains vernacular, rather than official, as it is not materialized or written down; rather, it exists orally. It exists merely from word of mouth to the audience's ear. It is not memorialized on paper to be studied. ${ }^{6}$

However, as the ballads are collected and written down something happens to their circulation. The genre changes as words are transcribed; for example, the change of Sidna to Sidney in mountain vernacular. In addition to the name change, various local vernacular words could be changed in the gathering of the ballads. Rhetorical decisions are made in how to construct the ballad from oral to written. Meanings are lost, but also built in the new construction of the artifact. These objects are made official as they are written down to be studied by folklorists and curators. In Places of Public Memory Blair, Dickinson and Ott explain how documents operate as they move from collective to public memory:

We have chosen to use the designator 'public' memory here, because of rhetoric's emphasis upon concepts of publicity...we believe, because 'public' situates shared memory where... in constituted audiences, positioned in some kind of

\footnotetext{
${ }^{6}$ Old ballad singers were often known, however, to have "ballat boxes" where they wrote down lyrics to their favorite tunes to keep them.
} 
relationship of mutuality that implicates their common interests, investments, or destinies, with profound political implications. (6)

Memory here is shared by its constituents and is made concrete in some sort of artifact that is made public, i.e., the publication of the ballads. These ballads can now be circulated more widely than just to those who listen to the ballad singer. The transcribing of the verses has "profound political implications," not only because it shows the political slants of each ballad, but also because the ballads no longer belong only to those who recite them. The ballads also belong to those who can read them from the page (6). They no longer are passed down from family member to family member, but circulate outside the region, ready to be taken up by anyone who can read and study them. The ownership of the ballads goes from personal to public. The crux of this is that the rhetorical constructions of these ballads are now available to be analyzed in full.

While circulation shows how the ballads culturally operate, the materiality of these ballads is key in distinguishing them as a piece of public memory. Blair, Dickinson, and Ott note that public memory "relies on material and/or symbolic supports" (ibid). The public memory here depends on the materialistic nature of the ballads being written down; they are no longer oral, but a tangible artifact. Because they tell the story of the shootout and rhetorically construct the two different sides, they are able to operate symbolically as well.

The material construction of the ballads also gave way to the monetary production of them from music agencies including Henry Whitter on Okeh records in 1924, Hobart Smith, Clarence Ashley, among other old time musicians (blue ridge institute.org online exhibit). Interestingly, Ernest "Pop" Stoneman, a popular singer at the 
same time as Whitter claims to have written the ballads. In his book on the singing Stoneman family, Ivan Tribe explains Stoneman's inspiration, "Ernest...later told his children about seeing a posse search for the Allens while he [Ernest] hid in a tree" (69). Despite these recordings and local stories, the circulation of the ballads now exists outside of a person-to-person network. The ballads are no longer passed down from person to person, but instead are studied by folklorists and musicologist.

Peter Aceves's (aka Peter Narváez) article “The Hillsville Tragedy in Court Record, Mass Media and Folk Balladry: A Problem in Historical Documentation” demonstrates what happens when a folklorist and musicologist studies the Hillsville ballads. He writes about the "archetypes" in the ballads that he describes as "a grouping of the most common traits of a particular oral tradition, i.e., a lumping of the most stable elements of a ballad over a given period of time" (10). By grouping the variants together and boiling down the essential plot points, Aceves creates a larger memorial landscape because he takes the public memory artifacts and then sees how they all fit together. These "stable elements" are basically the main plot lines of each ballad. These archetypical groupings allow readers "to analyze general social attitudes and ideas toward an event, the historian must stress common denominators regardless of what kind of documentation he utilizes" (10). They show how the "social attitudes" surface in grouping these actions together. Providing that the summative nature of these groupings will leave out some minor details in particular ballads, these "archetypes" provide an easier way to analyze closely the structure and narrative of the ballads.

Each of these groupings that Aceves has put together exists from the variants of the ballads. Even though they contain thematic features, there are still small distinctions 
among the two ballad variants. For example, in Variant No.9 of "Claude Allen," the reference to his grave is "Way up on that old, high mountain" (Aceve 25). In Variant No. 10 the singer notes that it is "Away up there on that cold mountain" (25). Even though these changes are small, they are crucial to the telling of the story and the integrity of the singer. The difference here is that the "high mountain" does not present the loneliness and despair that we see of the "cold mountain." The singer makes a rhetorical decision to recite the ballad in a certain way to depict a certain emotion.

The way that the ballad is constructed denotes the place where it is from, as Aceve notes, "all available song texts have been traced to the southern Appalachian region" (11). While each of these variants is fascinating to study, it is not the scope of this project to go into close analysis of each one; instead, this study will look at particular points in the ballads where the bifurcation of the town and the Allens occur. These places in the ballads demonstrate the schism that still remains in the town. A fissure that the Levering plays attempt to heal. While citing from a few variations for textual support, this analysis will demonstrate how the development of the plot of the ballad contributed to the political connotations. Before each analysis a short biography will introduce Claude and Sidna to demonstrate their roles in the shootout. These biographies are meant to disrupt the political leanings of the two ballads. They present what the history gives us about these two men; they are meant to offer assemblages of truth in the fictional nature and sensationalism of the ballads themselves. 


\section{"The Story About A Cruel Mountaineer": Sidna Allen's Ballad}

The Pardon of Sydna Allen
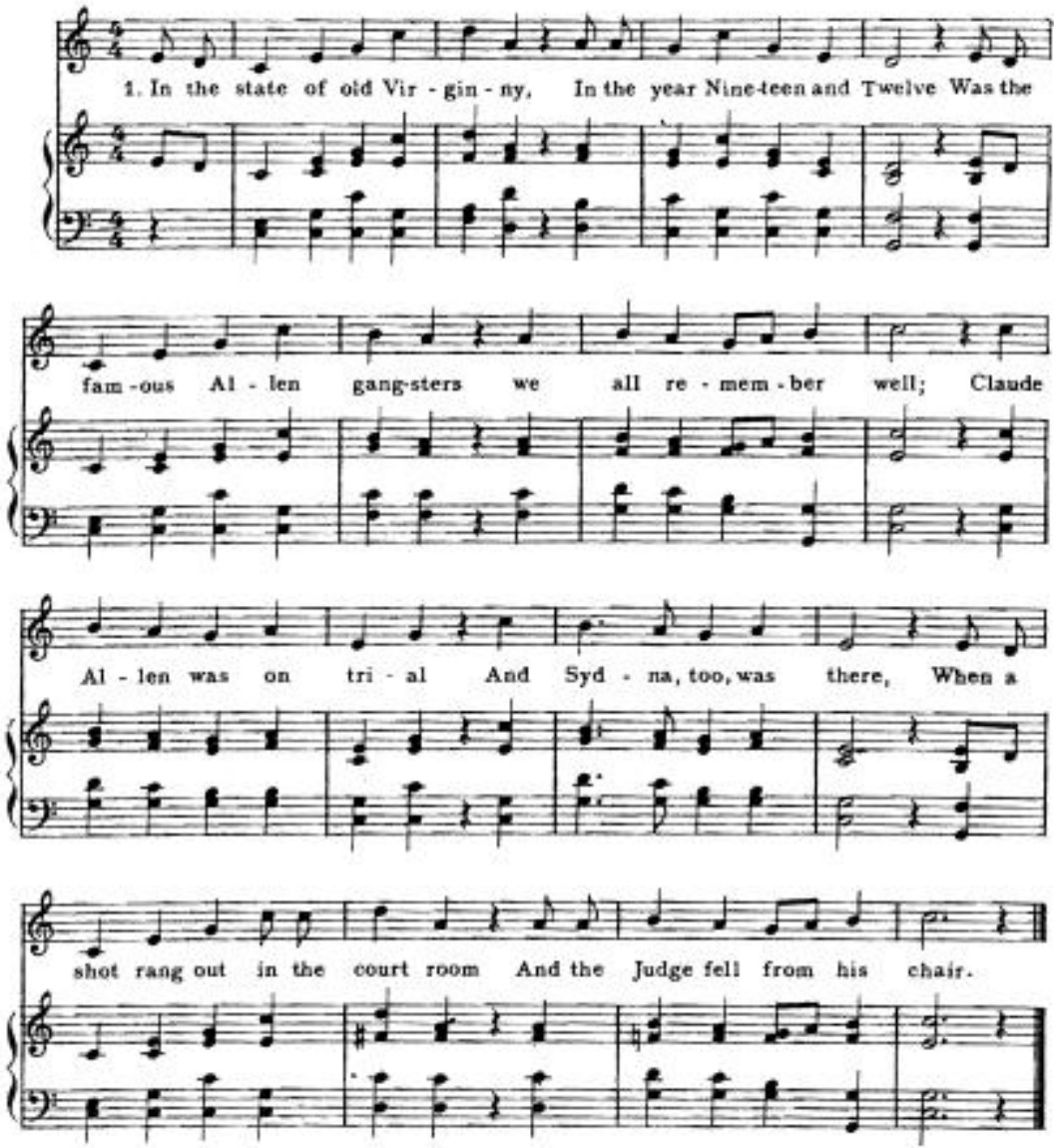

2. The Sheriff, too, was murdered, an attorney of the state,

The blame was laid on Sydna and no one kuew his fate

Till the jury found him gailty and the Jutge his sentence read

And the court propounced his sentence: 'twas twenty years they said!

3. Now fourteen years this Sydna was forced to leave his friend, To go into a prison a lonely life to spend; To go into a prison a lonely life to spend; The Governor signed his pardon and gave him liberty!

4. Now, this, friends, is the story, of Sydna Allen's case, We all may seek vain glory but find, instead, disgrace! But if we eould remember, before it is too late. $3+$ Wed never have to suffer for Sydna Allen's fate

Figure 3: "The Pardon of Sydna Allen” from American Mountain Songs Compiled by Ethel Park Richardson, Edited and Arranged by Sigmund Spaeth in 1927, 1955 
Jeremiah Sidna Allen was Floyd's second brother (brothers Jack and Garland came after) born on July 19, 1866. After having financial success in the Yukon after the gold strike, he returned to Hillsville to run a store (W. Hall 26). His reputation in Hillsville was that of a business entrepreneur; however, he, like Floyd, was called upon often to maintain peace in the mountains. In "Outlaw Once An Officer," in The New York Times on March $17^{\text {th }}$ we see a violent side of Sidna: "when the Carolina, Clinchfield, \& Ohio Railroad was build several years ago the contractors had continual trouble with the men on the work. As regular as payday came all of the men would get drunk and then would follow gambling and shooting for days." Sidna was hired because he "knew the habits of the mountaineers" and was a "greater bully than they." We see a hardness in how Sidna is revealed. He means business (pun intended), but is also not afraid to commit violence to keep the men in line. Before the shootout, Sidna build an elaborate Victorian home off of Highway 52 on the way to Hillsville. He and his family only lived there for 11 months before the shootout happened and the house was "attached" to the trial and lost. Sidna was captured in Iowa on September 14, 1912 and was pardoned from his prison sentence on April 20, 1926 after serving 14 years (W. Hall 214, 255). These descriptions of Sidna are important, as the ballad continues to participate in the outlaw terministic screen that the newspapers evoked.

"Sidney Allen"7 starts with an invocation of audience: "Come all you people if you want to hear,/ The story about a cruel mountaineer./ Sidney Allen was the villain's name,/ At Hillsville courthouse he won his fame" (Variant No. 15 qtd. in Aceve 28). Three variations call him a "brave, famous or truehearted mountaineer" whereas six call

\footnotetext{
7 "Sidney" is the mountain vernacular term for "Sidna." Ballad variations appear under both names.
} 
him a "cruel mountaineer and a villain, bilious man, prisoner, rounder" (18). These attributes already portray Sidna as mountaineer, but we can see that the majority of them address him in a negative way following the media portrayals of the Allens. From there we see why this character of Sidna is important with the inclusion of the Hillsville courthouse.

Sidna's rash actions in the ballad contribute to his depiction as the violent "mountaineer" and follow those in the outlaw terministic screen. In the ballad itself, however, inconsistencies in the variations demonstrate that the mountaineer could be Floyd OR Sidna approaching the bench. While it was Floyd's trial that instigated the shootout, Sidna was on the docket that day for a counterfeit charge (he was later acquitted after his pardon). Despite why he was there several variants still state that either man "mounted to the bar with his pistol in his hand/ And sent Judge Massie to the Promised Land" (Variant 15). The words "mounted" attributes to not only mounting a horse, but also gathering up to the judge's bench. When Judge Massie is shot, we don't get a violent image, but merely that Sidna or Floyd "sent him" to the "Promised Land."

After Sidna kills Sheriff Webb in the ballads, the variants from Galax and Eries, Virginia include stanzas about Clerk of Court Dexter Goad. The inclusion of Goad further demonstrates the violent mountaineer terministic screen because Goad was known to have drama with the Allen family and reinforces the idea of a feud between the Allens and the Goads. Goad's presence is important here because it continues the entertainment value of the feud as Floyd considered him his "mortal enemy" which was well known not only throughout Hillsville, but in the surrounding area of Galax, Mt. Airy, and Cana. His 
presence further demonstrates the political division of the town. Collected from Galax, VA, Variant 18 states

Then Deck Goad says 'it's a pretty hot place, When a brave mountaineer stared right in the face He mounted through the window and these words that he said 'In a moment later and we'll all be dead' Generally, these lines are given to Sheriff Webb who is killed shortly after. It is important that these words are given to Goad, because this act demonstrates that he not only lives after the shootout, but is also included in the narrative. His voice is preserved in the oral narrative of the story much like the Allen men. The next stanza continues:

Dextry Goad, he mounted through the window Dextry Goad, he landed in the mud,

Dextry Goad he mounted through the window Cause the fatal feeble man all had covered in blood While repetition is obviously evident here, it's also important to see him fleeing the courthouse. In addition, Goad is a "fatal feeble man all...covered in blood." The ballads use of these words preserve the fact that Goad was ill, humanizing him unlike the stereotypical description of Sidna. Despite his condition, the local government side did corroborate with Goad and his inclusion here demonstrates their investment in his fight against the Allen men; while Sidna is referred to as "brave" he is still violent. It's also worth mentioning that Goad lived through the shootout to become a successful lawyer in Hillsville. His inclusion here demonstrates that the Allen men were not the only men to 
be memorialized in the ballads. The terministic screen here includes not only the violent mountaineers, but also those who suffered during the tragedy.

Next, the ballad presents Sidna as working with the local community to help him hide out before his journey west. "Sidney mounted to his poney and away he did ride;/ His friends and nephews were riding by his side;/ They all shook hands and swore they would hang/ Before they'd give up to the ball and chain" (Variant 15). This depiction demonstrates Sidna as fleeing from the courthouse, but also alludes to his family and neighborly connections. Their "shaking of hands" reveals a sense of honor and loyalty to one another. They refuse to give Sidna up to the law, but remain together as a band of outlaws similar to the description of the Allen gang in the media coverage.

Lastly, the ballads do leave us with a semblance of pity for Sidna as his prison sentence is invoked as his children and wife look on and ask, “Oh Lord, don't take papa away" (Variant 15). These descriptions still participate in the outlaw image, but Sidna is humanized as a father and husband. However, justice is still warranted for the violent mountaineer as "The people gathered from far and near/ To See Sidney sentenced to the electric chair;/ But to their great surprise the judge he said:/ 'He's going to the penitentiary instead"' (ibid). Historically, Sidna's trial was watched by many in the community. To see that he was convicted to a prison sentence was a surprise to most as Floyd and Claude had already been put to death. All but three of the ballads that Aceves collected stop at Sidna going to prison. One from Galax, VA and Eries, VA include that Sidna rode back from the courthouse to Galax or back to the courthouse. The ballad from an undisclosed location actually includes Sidna's pardon, but with an invocation at the end like Claude's: “Now, this, friends, is the story, of Sydna Allen's case,/ We all may 
seek vain glory but find, instead, disgrace!/ But if we could remember before it is too late,/ We'd never have to suffer for Sydna Allen's fate" (Variant 24). While these outliers are important to recognize, the majority of the ballads stop at his incarceration. The deed is done and Sidna pays for his crimes. From the town's perspective Sidna has paid his due for his crimes (although some locals still think that he should have carried out his full term) and his "disgrace." The murder of the victims has been justified by his prison sentence.

\section{"Poor Claude Was Young and Very Handsome": Claude Allen's Ballad}

Variant No. 5

1. Claud Allen and his dear old father Have met their fatal doom at last. Their friends are glad their trouble's over And hope their souls are now at rest.

2. Poor Claud was young and very handsome And had a hope until the end That he might in some way or other Escape his death in the Richmond pen.

3. But the governor being so hard-hearted, Not caring what his friends would say, Kindly took his sweet life from him, And in the cold grave his body lay.

4. His mother's tears are gently flowing, For the one is gone she loved so well. No one can tell her of her troubles: It seemed no one could tell but her.

6. Claud Allen had a pretty sweetheart Who mourned the loss of the one she loved. She hopes to meet him beyond the river With a fair young face in heaven above.

6. His bealth is like the rose in summer, But now he sleeps beneath the ground.

7. "Tis sad Indeed to think of killing A man Just in his youthful years And leave his dear old mother gxieving And all his friends in bitter tears.

Figure 4: "Claude Allen, Variant No. 5" from Aceves pg. 23

Claude was the youngest son of Floyd Allen and Cornelia Frances Edwards Allen. 
Claude was educated in Hillsville, but then

went to the Draughon's Business College in Raleigh, North Carolina where he studied typing and shorthand. After graduation, rather than pursuing a career, he came home to help his father farm the land and help care for his mother who was by then in poor health and nearly an invalid. (W. Hall 22)

Claude's education is significant as the media most certainly did not comment on any of it; instead, reporters depict him as an outlaw figure. Claude was twenty-two when the shootout took place. He and his father were put to death on March 28, 1913 in Richmond, Virginia. Many of the people in the town of Hillsville saw Claude's death as tragic. Sidna Allen explained that there was even a medal that the ladies of Southwest Virginia made for him stating "For Bravery in Defending his Father" (Allen 108). See figure 5 for a picture of the medal cast for Claude.

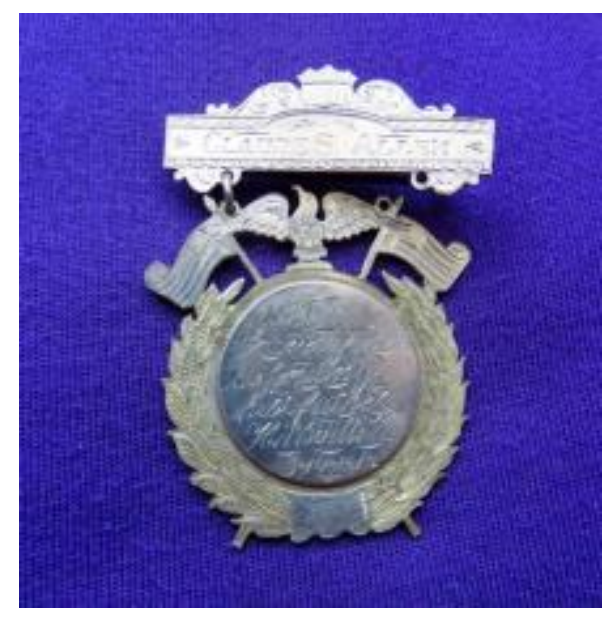

Figure 5: "Claude S. Allen For Bravery In Defending His Father Hillsville, VA 3-141912” Photograph by Allen Wertz

Sidna Allen continued to declare Claude's bravery as he stated, "the brave boy has long 
been dead but his memory is still fresh in the hearts of many of his friends. An unfortunate victim of circumstances, his life was demanded of him for defending his father" (109). After the bodies were lowered into the ground, a marker was placed upon the graves that stated "Sacred to the Memory of Claude S. Allen and his Father Who was judicially murdered in the Va. Penitentiary March 28, 1913 by order of the Governor of the State over the protest of 100000 Citizens of the State of Va. Placed here by a friend and citizen of Va." (W. Hall 238). Interestingly, this marker was immediately removed after Governor Mann threatened whoever cast it and placed it there with "criminal libel." According to an Allen family member, the marker is still with the family and "being used" to honor the dead today.

This brief biography of Claude is important to consider because of the way that the ballad casts him in a compassionate light providing the new terministic screen of tragic hero. Claude's ballad presents a humanistic view of the Allens unlike the stereotypical ones depicted in the newspapers. His ballad is most certainly a parlor ballad that conveys moral reasoning with a mournful tone, evoking feelings of sympathy for Claude for defending his father. The beginning of the ballad depicts the Allen side as it introduces the audience to Claude's death with "Claude Allen and his dear old Father/Have met their fatal doom at last" (Variant No. 1 qtd in Aceves 19). ${ }^{8}$ These lines demonstrate a familiarity between Floyd and Claude. The use of "doom" showcases the severity of the men's deaths. Most variants end the first stanza with "Their friends are glad, their trouble is over, And hope their souls are now at rest" (ibid). These lines demonstrate an ending to the shootout, but also some peace that is found for these

\footnotetext{
${ }^{8}$ All Variants cited here are included in Aceve's article unless otherwise noted.
} 
characters. Even though peace is found, however, the ballad continues to give us descriptions of Claude as "young," "very handsome," and "tall" (Variants 1 and 8.2). Next, the ballad contains "hope" for Claude because of the various petitions that were sent to Governor Mann from across the state. Currently housed in his papers in the Library of Virginia, these petitions beg the governor to pardon Claude. The inclusion of them in this ballad is crucial because it designates that Claude was a victim of circumstance and was not at fault (most certainly not the opinion of those on the local government side of the shootout). Interestingly, the ballads vacillate between the pardon applying to just Claude to both him and his father.

Nonetheless, Governor Mann does not pardon either man, ending in both Floyd and Claude's deaths by the State of Virginia. In this ballad we see their deaths as mournful, but if it were conveyed on the local politics side then these deaths would have been conveyed as justice for those murdered in the courtroom during the shootout. The ballad reads "But the Governor being so hard hearted,/ And caring not what their friends might say,/ He gently took his sweet life from him,/ And now in the cold grave his body lay" (Variant 1). In almost all the variants, this stanza is repeated almost word for word (lay sometimes is replaced with "in clay"). The stanza conveys a sense of retaliatory justice for those in favor of the court. Governor Mann is not conveyed as sympathetic to Claude in any way possible and, in fact, ignores the petitions that went to his office. From his comments in the archives in the Library of Virginia, he is adamant about finding Claude and Floyd guilty for the crime. The stanza, again, reproduces sympathy for Claude against the local and state government.

After Claude has been convicted (and presumably killed) in the ballad, we get 
displays of mournfulness from his girlfriend, Nellie, and his mother, Francis. These depictions humanize Claude and also evoke a sense of pathos in the ballads that is not found in the Sidna Allen Ballad. In these sections, the women in Claude's life are showcased as he "had a pretty sweetheart,/ who mourns for the loss of the one she loved,/ She hopes to meet beyond life's river,/ That fair young face in Heaven above" (Variant 1). This stanza demonstrates a Christian's view of Nellie meeting Claude in the afterlife. In fact, in Variant 2 collected in Rusk, North Carolina in 1917 Nellie returns at the end of the ballad: "His sweetheart must have been sad-hearted/ When she saw poor Claud lying still and cold./ Down on her knees she wept beside him,/ And prayed to God to save his soul." Again, we see a Christian plea for Claude's soul to be admitted to the afterlife. There was talk about engagement, but their love was only to be remembered in ballads like this one.

The other lament is for Claude's mother, Francis, who is depicted in the ballad: "Claude's mother's tears were gently flowing/ All for the one she loved so dear/ it seemed no one could tell her troubles/ It seemed no one could tell but her" (Variant 8.1). She is also mentioned in the next stanza in variant 8.2: "How sad, how sad, to think of killing/ A man all in his useful years/ A-leaving his old mother weeping/ And all his friends in bitter tears." Both of these depict Francis as the grief stricken mother. It most certainly evokes feelings of sympathy for Claude and his family; similar depictions of Francis appear in the Levering plays and media portrayals of her. These depictions further humanize the tragic nature of the shootout and enforce the tragic hero terministic screen.

What is not there is that Claude was tried and convicted for the murders during 
the shootout. He carried a gun to the courthouse whereas his father did not. What the ballad presents is most definitely a one-sided view of Claude and his family, a view that depicts him sympathetically for the Allen side of the shootout. These missing details evoke a sense of pity for Claude. While he is not depicted as fulfilling a sense of duty like the government officials, his justification was to defend his father. The affect of the shootout is not found on him, but in his loss of life. Variant 8 varifies that "Claud Allen was honored with a gold medal/ For taking his dear father's part./ He told them all when he was gone/ To give it to his dear sweetheart." The medal here plays a role in him defending his father's honor (which is actually stated on the medal) and bringing in Nellie again for more sympathy. In addition, in the people's lament, we see the presentation of Claude's grave: "High upon lonely mountain/ Poor Claud sleeps beneath the clay./ No one can hear his words of mercy/ Nor see his face till the Judgement Day" (Variant 6). This lament argues for a graphic portrayal of Claude in his grave on the mountainside (which, geographically, is true). Again, Christianity is evoked and Claude pleads for redemption from the grave.

The ending of this ballad is indeed moral as it serves as a warning to young men to avoid danger. It not only serves as a warning, but also deflects all conviction and control of Claude over the situation. The phrasing is appropriate for the moralistic parlor ballad in that it retains the moral at the end, but it also represents the sympathy that the Allen side of the shootout has for Claude. While standing as a memorial to Claude, this ballad also pushes for a sense of non-violence for Appalachians unless they want an "awful debt to pay." The moral being that even if Appalachians are defending their families, they too, could end up like Claude. 


\section{Shootout or Massacre?: Political Exigence in the ballads}

These ballads demonstrate the divisive attitudes that still resonate within the town. "Sidna Allen" represents the violent mountaineer unlike "Claude Allen" which depicts sympathy and tragedy. These terministic screens used to view the shootout demonstrate the fissure that is still felt in the town and are demonstrated in which ballad the singer chooses to perform. Aceves (aka Peter Narváez) addresses the politics surrounding the ballads:

The ballads of "Claude Allen" and "Sidney Allen" reveal this political conflict regarding the incident because of all twenty-one variants considered no one informant was reported as having offered both ballads to a collector. That is, since both songs have been in oral circulation simultaneously, it would seem that carriers of oral tradition possessing strong pro or con feelings toward the defendants and their political affiliations have chosen to sing one song or another and not both. (Aceves emphasis18)

These statements show that there is a deliberate choosing of which ballad to perform by the singer. If the singer memorizes and performs "Claude Allen" then she is in favor of the Allen side of the shootout; if "Sidney Allen" then she is in favor of the town-side of the shootout. What's Aceves doesn't mention here is audience. Clearly though, the singer would not perform "Claude Allen" to an audience of those who sympathize with the town.

In my research I have asked several community members and local historians if these ballads continue to be recited. The answers have been predominately no; however, 
this answer is a bit more complicated. Being an older genre of music, ballad recitations only occur in small local groups or at academic conferences, such as at gatherings of the American Folklore Society or the Appalachian Studies Association. In these academic circles, ballad collectors and scholars gather to swap ballads and tell stories about who and where the ballads come from. From my experience, I have seldom seen the Courthouse Shootout of 1912 brought up. In fact, when questioned about the ballads several members of the Hillsville community do not even know of the ballads, but instead brought up recent songs that local songwriters wrote about the shootout. ${ }^{9}$

Despite the absence of the ballads in the community, Hillsville continues to feel the disruption of the shootout. Rex Bowman, in a recent article for the The Richmond Times Dispatch, wrote that talk of the shootout, and the resulting executions, can still touch a raw nerve [in Hillsville]. Which is why Hillsville residents are now wrestling with a consultant's recommendation that they find a way to exploit the historical shootout to bring in tourists.

Shifting from the depictions of the stereotypical, violent "Sidna Allen" ballad some residents of Hillsville want to embrace the humanistic, tragic screen of the "Claude Allen" ballad.

\section{"It Helped With the Healing": Frank Levering's Shootout Plays}

\footnotetext{
${ }^{9}$ There is a long line of contemporary musical genres based on or around the shootout ranging from a rock opera titled "Sid Allen and the Devil's Den" by Tom Harvey, acoustic songs written by local musicians, such as John Carpenter's song from the perspectives of family members and Philip W. Jones' "Floyd's Lament," but the local ballads serve as ground zero for the rest of these musical renditions to develop.
} 
Whereas the ballads offer little reconciliation, Frank Levering's plays performed from 2012 to 2016 elaborate on the tragic aspect of the shootout. The 105 years that passed from the shootout to the present provided some time for the town to come together and remember the event through Levering's plays in the historic courthouse where the shootout took place. In remembering this event, emotions were high, but the plays represented an attempt to come together. It was an opportunity for the community to heal by observing a more humanistic, tragic portrayal of the shootout; a terministic screen that was reminiscent of the one presented in "Claude Allen." This new screen, however, resides in the realism of the characters involved and is centered on an attempt to heal the fissure of the town caused by the shootout.

Healing in Hillsville is different than in other aspects of the South and Appalachia. In John Smith's section on "Trauma" in Keywords for Southern Studies he focuses on how the lowland South's definition of trauma focuses on the South's loss in the Civil War, ideas of race, and ethnicity. In Appalachia, much of the historical healing ties into the history of the region, in particular the exploitation of extractive industry. In "The Ethics of Memory: Commemorating Disasters in an Age of Risk" Tom Bowers analyzes the rhetoric of the trauma and healing that came out of the Buffalo Creek Disaster where a coal dam broke and flooded the town killing 125 residents, injuring 1,100, and leaving 4,000 homeless (119). However, we see that the trauma with Hillsville falls in between these two definitions; it is tied in with a political schism in the town, but also with the trauma of the deaths involved in the shootout. Levering's plays rely on this sense of reconciliation and healing. In researching the shootout, members of the community are still unable to talk about it as the grief and trauma from their ancestors is 
passed down to them even centuries later. Levering's plays offer these ancestors and other members of the town the opportunity to gather in the historic courthouse where the shootout happened and listen to the story together. There are certain moments in the plays where the actors address the audience members directly to consider the trauma that happened in the courtroom during the shootout. Wendy S. Hesford's idea of spectacular rhetorics helps to explain these moments that make a spectacle of the players and the place. The communal gathering and then participation in the play act as moments of healing rhetoric because just by being there with those who were on the other side of the shootout, these community members open up the possibility of sympathy for the other side. Several community members have told me that "it helped with the healing" of the town.

Levering's ability to write the play as a community member also helped to make the play more realistic. The characters are not flat and are truthful to historical depictions instead of stereotyped portrayals from outside the region. Even though he returned from living in Los Angeles, Levering easily plugs back into the locale of Hillsville. He wrote Thunder in the Hills (two variations exist of this play), The Capture of the Allen Men, and most recently Sidna Allen's Dream and Thunder in the Hills which was lengthened to a production that lasted $1 \frac{1}{2}$ hours to a $3 \frac{1}{2}$ hours production that took place during the centennial of the shootout. Perhaps one of the most interesting parts of these plays is that they are not only written and (mostly) directed by Levering, but that all Hillsville natives perform in the plays, which took place in the courthouse. ${ }^{10}$

\footnotetext{
${ }^{10}$ After being told about the plays, I wanted to see them or read the script. One of my informants was able to give me a DVD of the plays that he recorded during one of the productions. He specifically told me not to make copies and that I was only to use it for
} 
When addressing this particular performance of the play, Levering notes that he was "Trying to tell a community story, a story that belongs to this whole area" (DVD interview). Interestingly, as he introduces the play he invokes the antebellum South noting that the play is "sort of like Gone with the Wind in Carroll County, maybe it's too long, by the time you get to the end it's kind of a tragic saga that happened here in Carroll County" (ibid). While the invocation of the antebellum South is interesting (Confederate flags are found frequently throughout Hillsville), perhaps Levering mentions Gone With the Wind here because of the epic nature of the newest rendition of the play. As noted earlier, the play is $3 \frac{1}{2}$ hours long and is most certainly episodic much like Mitchell's masterpiece.

The plot of the play starts with the episode around the ear of corn at Garland Allen's church and ends after the shootout when Sidna Allen is pardoned and welcomed home by his wife, Betty Allen. The action of the play includes the fight by the Allen boys in the church, the shootout itself, the jailing of Floyd and Claude, the electrocution of both men, and the pardon of Sidna. Understanding the space of the courthouse is crucial when rhetorically analyzing the play because it represents the Allen men as outlaws whereas the play attempts to humanize them. The play is performed in the very space where seven people were killed, a site of historical trauma. Levering deliberately uses the exact space to invoke realism, but also a sense of history. The space is currently not used for legislature, but for memorializing the dead and performing the history that took place there. While each side is presented in the play and each action in the play is depicted in a

this project. While I would like to gain access to all of the plays at a certain point, this production seems most relevant to analyze because of its use at the centennial, its expanded length, and mostly because this play recognizes that it is a cultural artifact representing the shootout. 
realistic manner that grants respect to both sides, the locale of the historical courthouse depicts the Allens using the outlaw terministic screen as it focuses on the deaths there.

The courthouse has changed little from when the shootout happened. It was built by Ira Coutrane in 1873 (Webb interview). The town stopped using the courthouse in 1997. Currently, the Treasurer's office houses the office and the museum. The Clerk of Court's old office is immediately above the museum and is currently used for storage. When entering the courthouse, you come up the cement steps from Main Street with a confederate statue immediately to your right. This statue was centered in the middle of Main Street, directly in front of the courthouse, during the time of the shootout. In fact, numerous accounts state that Floyd hid behind the statue as he fired back at Goad on the steps of the courthouse. When climbing the steps from Main Street you also notice two green stairways. The ones on the right go up to where Clerk of Court Dexter Goad's office was located at the time of the shootout. There are still bullet holes located within the steps from the shootout. Climbing the steps brings you into a hall that leads to the courtroom.

The space of the courthouse does not look as it did when the shootout occurred. The law library that exists across from the actual courtroom was not installed until much later. The judge's bench and the bailiff's bench are all pushed forward. See the figure 1 below for a current picture of the courthouse. 


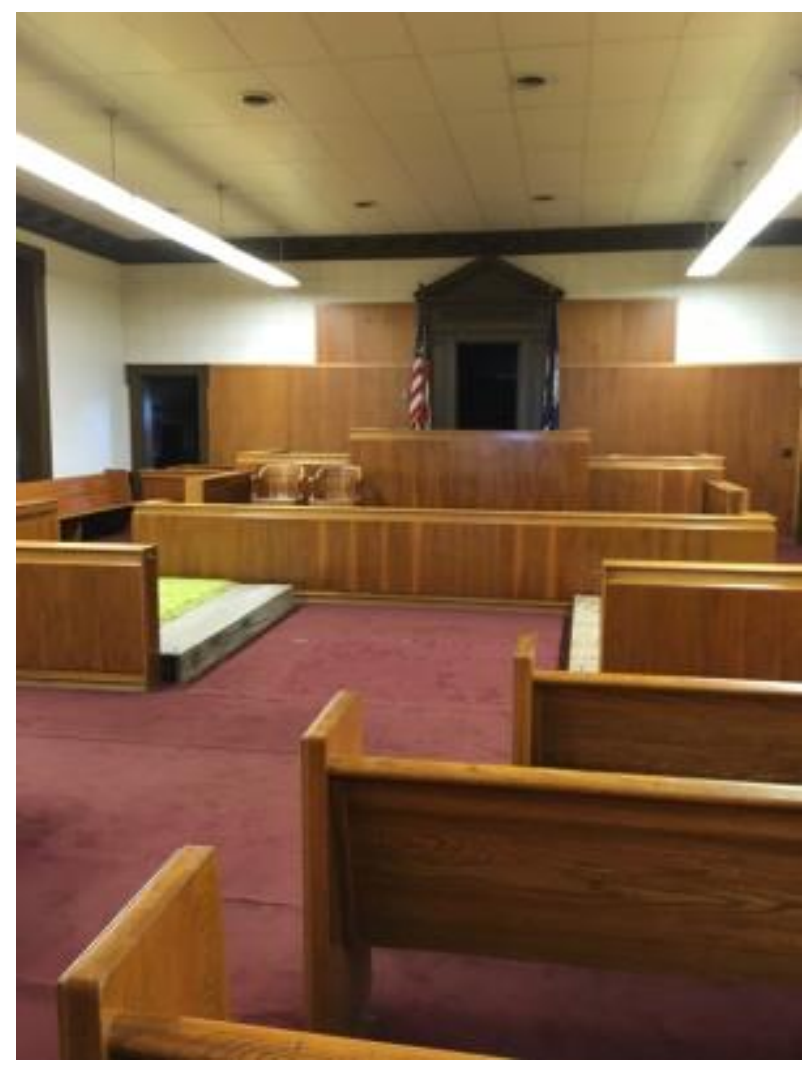

Figure 6: Photo taken by author

As a comparison, notice the courthouse layout in Figure 5 used to determine where everyone was standing during the time of the shootout. 

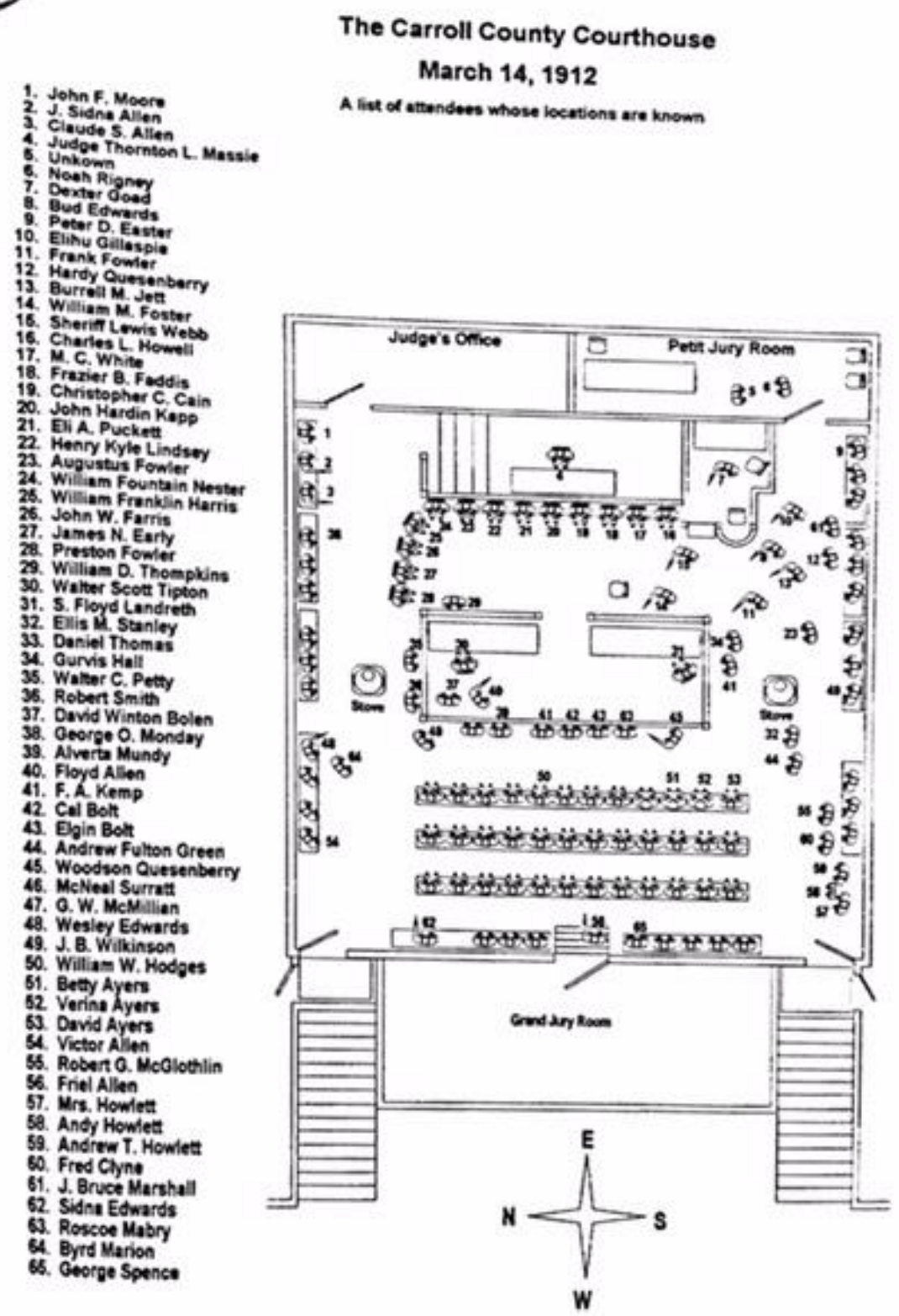

205

Figure 7: Schema adopted from Ronald W. Hall's book, The Carroll County Courthouse

\section{Tragedy}

Despite the changes in the layout of the courtroom, there are two important memorials that continue to exist there that evoke the outlaw terministic screen. On the north wall, a plaque stands honoring Judge Massie. Ronald W. Hall writes that "a fund 
raising had been initiated the previous May by the State Bar Association under the leadership of Judge R. Carter Scott” (238). The plaque reads

Erected by the state bar association of Virginia as a memorial to the legal accomplishments, the fidelity to duty and the courage unto death of Thornton Lemmon Massie Judge of the Twenty First VA Circuit who was assassinated while holding court in the courthouse of Carroll County Virginia on the Fourteenth of March 1912. To die in the discharge of duty is to live forever in hearts which honor courage and patriotism

The usage of "assassinated" is important because it demonstrates that this memorial most certainly deems it as the fault of the Allens and perpetuates the outlaw screen. In its closing statements the plaque leads us to believe in Massie's position as serving his country while on the bench. Both of these statements hold Massie highly and demonstrate that he was a perfect example of who a judge and civil servant should be only to be gunned by the Allens.

Above the text there is a Greco-Roman statue of woman with a large feather in her hand. She has recently placed a wreath on a large door with a lion's head as a door handle. It can be speculated that the figure is the Greco-Roman goddess Athena, since she is holding what could be understood as an owl feather. The owl is often seen with the goddess, which associates her with wisdom and the law. In the memorials of Judge Massie we often see him referred to as wise or having wisdom. The symbol of the door handle is also important because lions are often symbols of bravery (which we see in the earlier written text in the memorial in addition to the media accounts of Judge Massie). 
In addition to Judge Massie's memorial, there is another to the victims who were killed in the courtroom reaffirming the outlaw terministic screen. W. Hall notes that this plaque was one of two that was "dedicated in Wythville," but that an "identical plaque" is placed on the south wall of the courthouse in Hillsville. The plaque reads:

ERECTED BY THE STATE BAR ASSOCIATION OF

VIRGINIA IN MEMORY OF

WILLIAM M. FOSTER- COMMONWATHER'S ATT'Y

LEWIS F. WEBB- SHERIFF

AUGUSTUS C. FOWLER- MEMBER OF THE JURY

BETTIE AYERS- A WITNESS IN THE CASE THEN UNDER TRIAL WHO WERE ASSASSINATED IN THIS COURTHOUSE

WHILE IN DISCHARGE OF THEIR DUTY TO THE

COMMONWEALTH ON THE $14^{\mathrm{TH}}$ OF MARCH 1912

First, naming each victim gives power and significance to each individual. The plaque continues to use "assassinated" here as these victims were killed in cold blood in the courthouse (some dying outside). Similar to Judge Massie's plaque, this plaque wants to demonstrate that they were legislatively bound to this space and were doing their civic duty by being present there.

In addition to the text, another shrouded Greco-Roman woman places a wreath on top of a tomb that has "In Memoriam" on it. Unlike Judge Massie's plaque, we have no identifying features with this woman, just that she is placing another wreath on the grave. What is different in this plaque, however, is that it is signed in the bottom right corner. It 
is a circle with a line through it. While this could be a symbol of the freemasons (whose signage still pervades many structures in Hillsville) this signature is not identifiable.

This thick description is necessary to understanding the juxtaposition of the play to the memorials of the courthouse. Similar to the two ballads, two sides of the shootout are presented to the audience members of the play. The plaques on the wall and the layout of the courthouse both demonstrate that the courthouse still stands as a place of memory evoking the Allens as outlaw figures. It still operates in remembering the tragic event that happened there and reinstating the outlaw terministic screen by not acknowledging the deaths of the Allen men who died later because of the shootout.

Levering realizes the power of the use of the remembrance of the courthouse. He knows how placing the play in the historic courthouse itself will have an impact on the actors, the audience, and the play itself despite how these memorials convey the Allens. He comments on the intertwining of the local actors and the courthouse:

the actors being so good and the fact that oral tradition of this area, the story that everybody has very strong feelings about made this a unique experience I don't think you could have done this in any other play. And to have it here in this courtroom space where the shootout actually took place and then make a theatrical space of this courtroom kind of a space where everybody thinks of a public space, a community space I think was a very important element. (Levering interview)

Many of these actors have ancestors who were involved in the shootout. Some of the actors even played on the opposite side of their ancestors in the play. Victor Allen, direct descendent of Garland Allen, played Lewis Webb in the play. He admitted, "I got no 
qualms with playing Lew. The play has really helped heal the town.” His testimonial demonstrates that the play's sympathetic view to both sides of the shootout offers a sense of coming together and healing of the town.

Witnessing the play in the historical space places the performance in juxtaposition to the outlaw terministic screen suggested by the memorials on the walls. As Allen stated above it helps to "heal the town" because the play sympathizes with both sides of the shootout rejecting the stereotypical outlaw image. Without seeing it performed in the courthouse, there is a sense of loss in the tension between the outlaw image of the courthouse and the sympathetic, traumatic lens of the play. Levering elaborates on the play's temporary nature, noting that the actors and the location in the courthouse Made it an extraordinary experience and hard to repeat. You do it and it's gone. Thanks to you [Bill Webb] it won't be gone because it's recorded. Live theatre is a powerful thing and like now it's all over. You have to do it and then let it go. Just let go of it. (Levering interview)

Watching the play live in the courthouse adds to the interchange between the outlaw screen and the tragic narrative screen that the play portrays. As Taylor asserts "performance...insists on physical presence: one can participate only be being there" (her emphasis, 188). There is something that goes missing when I watched the play in my living room on my television instead of in the courtroom. While the technology makes it available, there is most certainly an absence or an abstention of place. Schneider describes how the "mode of access" to the play changed for me: "In the archive, the performance of access is a ritual act that, by occlusion and inclusion, scripts the depreciation of (and registers as disappeared) other modes of access" (104). As I watched 
the play, I was stripped of the "ethereal" experience of being in that space and experiencing the tension of those two screens. I was on a comfortable couch and could pause the $31 / 2$ hour play when I needed to, whereas those in the hard wooden courthouse benches could not get up until the intermission.

Despite this loss in experience, the transmission of the screens is lost to me as I sit on my couch to watch the play. The memorialization of the courthouse is not focused on on the DVD instead the focus is on the play. I lose the outlaw image, but focus only on the tragic in what Schneider deems the "repeated act of securing memory" (104). She asserts that my loss in not being there is

to rethink the site of history in ritual representation. This is not to say that we have reached the 'end of history,' neither is it to say that past events didn't happen, nor that to access the past is impossible. It is rather to resituate the site of any knowing of history as body-to-body transmission. Whether that ritual representation is the attendance to documents in the library..., or the oral tales of family lineage..., or the myriad traumatic reenactments engaged in both consciously and unconsciously, we refigure 'history' onto bodies, the affective transmissions of showing and telling. (my emphasis 104)

She notes that the transmission itself is embodied, which acts as a way to keep the play alive. Even though it's ephemeral, the shootout still exists because it has been acted and put into the world through the body of the actors. Because performance theory tells us that the ephemeral has value in preserving, affecting, and moving archives, then the ephemeral must have rhetorical value in public memory studies. No matter how it's 
watched, the experience of watching will affect the viewer through affect. For instance, the ephemeral is made public memory by my watching the play on a DVD miles away from Hillsville, years away from when the play was performed -it is still an enactment, still a performance of that memory that is made materialistic to be studied despite a certain amount of affect being lost to the viewer.

\section{"You're Greedy for Guns and Blood": Spectacular Moments in the Play}

In addition to the presence of the audience in the historic courtroom, there are four particular places in the play that break down the fourth wall or that dictate and speak to the presence of the play in the here and now. These moments in the play not only selfidentify it as a play, but also demonstrate the awareness of its presence in a historical site-a site that once represented a place of trauma and fissure, but now represents coming together, mourning, and healing. In these four places in the play, the characters are cognizant of themselves as characters in a play in the courthouse. They not only engage with the audience, but also speak to the moment in time and physicality of where they exist. The opening introduction with Francis Allen, the actual shootout in the courthouse, Floyd and Claude's death by electrocution, and the final words by Francis and Floyd Allen demonstrate how these performances produce what Taylor calls ghosts who "tap into public fantasies and leave a trace, reproducing and at time altering culture repertoires" (143). The performance itself

provokes emotions it claims only to represent, evokes memories and grief that belong to some other body. It conjures up and makes visible not just the living but the powerful army of the always already living. The power of seeing through performance is the recognition that we've seen it all 
before - the fantasies that shape our sense of self, of community, that organize our scenarios of interaction, conflict, and resolution. (Taylor 143)

These moments serve as powerful ways in which this traumatic history is recreated and performed. They most definitely evoke "memories and grief" and make those feelings tangible.

To give name to these performative moments I borrow from Wendy Hesford's term of "spectacular rhetoric." She defines the term as "to highlight the visual rhetoric of human rights, of which the spectacle is only a part, and to accommodate audiovisual and mixed-media forms and rhetorical techniques... that are used in speech and writing to convey experiences of vision." (8). Breaking apart from the "human rights" aspect of her definition, these moments in the play do function as spectacle as they reveal the actors as not only an object of the audience's gaze in the play, but also as functioning as emblems in healing the town. They indeed "acquire social value and symbolic overtones from larger frames of reference," as they give value to the shootout and demonstrates its role in Hillsville (Hesford 17). They make a spectacle of the shootout, but in a way that blurs the line between past and present, good and bad, and the Allen side of the shootout and the local government side. These spectacular moments create moments of catharsis in the play where sympathy for both sides is felt by the audience and the sympathetic, tragic terministic screen occurs.

Francis Allen's opening testimony immediately breaks down the fourth wall of past and present by addressing the morbid curiosity of the audience in wanting to see the event recreated; she is creating a spectacular moment in all senses of the word. Referred to as the "woman in woe" in many news accounts, she states, "What do you want from 
me now? Once ain't enough for you. You're greedy for guns and blood. You want to see folks shot, dead. That's what you're here for, trouble" (Levering). Through her character, Levering acknowledges the curiosity of those in the town and how it is disturbing that they are interested in an event where seven people died. ${ }^{11}$ Francis is working against the outlaw screen portrayed earlier in the newspapers. Her voice of reason conveys tragedy and pity for her family. We not only see a morbid curiosity of those who attended the play, but also a breaking down of the wall between past and present. Schneider elaborates on this breaking when she writes

The past can disrupt the present..., but so too can the present disrupt the past...; neither are entirely 'over' nor discrete, but partially and porously persist. Something is different here than simply remembering, or simple negotiation with 'a time gone by' (Schneider 15)

Francis Allen's beginning testimony does indeed "disrupt the present" as she makes the audience consider the cruel nature of revisiting the shootout. Her voice echoes many residents who blatantly do not want to talk about the shootout both right after it happened and now. In fact, some local community members refer to it as "the incident," "the tragedy," or just "the shootout." The event brings up too many bad memories and was simply not something to be talked about. However, this silence is juxtaposed by her statement that “once ain't enough for you." Through this statement she argues that, despite the silence around it, the shootout is always there; that there is no undoing of the tragedy.

\footnotetext{
${ }^{11}$ Many locals in Hillsville still continue to collect artifacts from the shootout from newspaper clippings to the badge that was given to Claude Allen after his death. Chapter Three will explain more about how these archival sites are important in the circulation of the history of the event.
} 
Francis Allen's testimony ends with a transition on how the shootout started in Garland Allen's church and how that small event led to the deaths of those in the courthouse. She states, “If you's ever at a corn shuckin'...you turn your head away and make a beeline for that door...7 people died before their time and the rest of them died still feeling the chilly prickles of what they seen here" (Levering). This invocation of the courtroom deems the space as a place of death, destruction, and trauma to those who witnessed it. Ending her beginning testimony and seguing into Floyd's initial speech, Francis states how we, as the audience members, have the right to decide who's side we are going to be on "Cause YOU are the jury" (ibid). This invocation for the audience to decide could be found similar to those of the jury at the actual trial to morally act for or against the Allens. Again, here we see a convergence of past and present merging in the performance of Francis Allen's call for action with the audience asked to consider the case anew, that is to engage with it rather than ignore it.

The second spectacular moment in the play is before the actual shootout. Levering draws attention to the fact that Floyd and Claude were not with Francis the night before the shootout. The night was stormy and the play depicts Francis as frantic. She talks in third person about the storm, herself, and the impending death: "wind and rain like Noah's flood arising. What could Francis Allen do? Old before her time because it's gone back so fast. Death coming quick" (ibid). In including this scene Levering sets up Francis Allen as a figure who truly suffered before and after the shootout. Her character is built in these moments of emotional turmoil. She is developed as a character, whereas in most of the male-dominated newspaper accounts she's largely absent. Her character is figuratively and literally haunted by the shootout as two murder victims appear to her. 
The trauma she suffered is real and contributes to the sympathetic, traumatic terministic screen in this depiction.

Bettie Ayers, a witness who was shot in the courtroom but died outside the courthouse, appears to Francis asking, "What was you going to do with the rest of your life?" to which Francis replies "I have lost myself and there is no place for me deep down" (ibid). Through this exchange, Francis's grief and loss of self is truly expressed. The deaths of Floyd, and Claude in particular, have left her a motherless widow. Even further, we see the embodiment of Bettie's ghost representing not only a character, but a ghost who "continues to act politically even as it exceeds the live" (Taylor 143). She is one of two "ghosts" who haunt not only Francis in the play, but also the audience in their remembrance of the shootout and the death suffered in that very space. Like the plaques that adorn the walls of the courthouse, her appearance is a physical representation of those who died there.

Next, Augustus Fowler visits Francis. Like Bettie, who claims she died outside, Augustus points to the very spot where he died in the courtroom. This performance again represents a clash of the past being brought immediately to the present. Merely feet from where they sit, watching this performance, the audience becomes aware of when and where his death took place. Instead of the pity that Bettie brings up for Francis, Augustus states, "I got nothing against Floyd that we can't settle our accounts down yonder" to which Francis replies, "I ain't got no family... you leave this earth. You go farm in hell" (ibid). This is rather a brash exchange, but most certainly brings up the feelings in the town versus the Allen family. This exchange most certainly brings up the lingering resentment of the town towards the Allen family. Francis does, however, standing up for 
herself and does not cower from Augustus's ghost. After this exchange Francis then yells, "Where are the rest of you? Why won't you speak to me?" (ibid). Her demands for response are eerie enough to read, but to hear in the actual courthouse makes them even more unnerving.

Her calling to the ghosts of the murdered represents a penance of her character to those who were killed for her husband's trial. In addition, this calling represents something much bigger. It represents the silence that has overshadowed the town after the shootout. Not only were Bettie Allen (Sidna's wife) and Francis Allen outcasts in the town, but the shootout itself was not talked about. The trauma was too much for those who were involved. Francis's invocation of the spirits represents a calling for conversation among the past residents of Hillsville, as well as the present. It is through this conversation and scenes like this one in the play that the strife and trauma that each person went through during the shootout are demonstrated. It creates a sympathetic terministic screen for those involved in the shootout, demonstrating that these were real interactions and not the exploited actions created by the media. By bringing the shootout out in the open and having local actors (and ancestors of the those involved) act in the plays and having the play in the actual courtroom, conversation has to happen about the shootout; the outlaw and uncolonized other terministic screens are no longer useful. From these conversations come the sense of healing that several residents said happened after the plays were performed. These performances bridged the gap between past and present - they unearthed the trauma and bitterness and brought it out in the open to be discussed. There is no skipping out on Levering's depiction of the three remaining most 
powerful spectacular moments: the shootout itself, electrocution of Floyd and Claude, and the final cry of Francis and Floyd.

Levering's portrayal of the shootout is realistic and tasteful. The traumatic event is complete with gun shots, which is shocking, but memorializes the tragedy in a way that provokes emotion from both sides. Before and after the shootout, Levering includes spectacular moments where the actors address not only the audience, but also the fact that they are standing in the historic landmark where the shootout happened. First, Sidna Allen comes out and talks about how he'll never forget what happened in the courtroom. He also talks about the circulation in and around the shootout:

All them years in the State pen in Richmond. Not a day went by that I didn't think about what happened here. What did happen here, there have been so many tales and outright lies told. It has been hard to see through the smoke to see the truth. Now memory, memory is like a loaded pistol it can turn agin' who's holdin' it. Now, somedays I can remember clear as creek water... (ibid)

Sidna's remarks demonstrate his pensive time spent in the penitentiary in Richmond, but also the circulation of the shootout. As mentioned in Chapter One, he knew about the "tales and outright lies" that the media printed about the shootout. These comments demonstrate the penance of his character, but perhaps what is most interesting here is Levering's use of memory. He, not surprisingly, connects memory with "truth" that is surrounded by "smoke" from a "loaded pistol." While this metaphor could be regarded as trite and a little too simplistic, it's necessary because it demonstrates how memory is not finite and that there are, as Sidna remarked in his memoir, "many truths." It resonates 
with the audience who understands the connection with memory and the gun violence that happened in the courthouse. The concept that the gun can 'turn agin' who's holdin' it" represents how memory is not stable. It changes over time, even if the person who was present at the event is the teller of the tale. The changing memories affected not only the oral recreation of the event, but had legal stature in the pardoning trails of Sidna, Wesley Edwards, Sidna Edwards, and many other Allen men.

After Sidna's comments we hear from Alverta Edwards, the mother of Wesley and Sidna (the boys who got in a fight in Garland Allen's church). She states, "This room was standing room only. You know if you were anywhere else you wouldn't be anywhere else. There were babies in here. God help them for what was coming their way" (ibid). These comments validate how popular Floyd Allen's trial was at the time. Most citizens of Hillsville (and the counties surrounding) would be at this trial as it was entertaining for them to come and see. These statements not only point to the popularity of the trial but also to the innocents who were in the courtroom that day. Her mentioning of babies to signify innocence is basic; however, when thinking about the death of young Bettie Ayers, who was merely a witness, it's accurate.

After Alverta's plea for the innocent we, again, hear from Sidna Allen, but we also hear from Dexter Goad, the County Clerk, who Levering portrays as having political and personal strife against the Allens. Sidna remarks that "Deck Goad has his eye on me. No doubt in my mind that he would kill me if he could get away with it...kill me and Floyd both. To which Goad replies: "Twenty minutes go by. Whatever happens I am here to enforce the law. I have no reason to kill anyone. A man has to keep his chin up. His courage up. To show no sign of weakness" (ibid). This exchange demonstrates the 
tension that was between the Allens and Goad. Levering at this point in the play has portrayed Goad as being on the defensive by wanting Judge Massie to carry a gun to the court and practicing shooting the morning of the shootout. Massie states that he will not be bullied by the Allens to carry a gun into his own courtroom. The exchange between Sidna and Deck Goad also builds the feeling of tension in the play and the room as a whole.

The next spectacular moment during the shootout happens immediately after Judge Massie dies and says that Sid Allen was the man who shot him. All the victims are lying on the floor, and the Allen men have left the scene. Francis Allen, again, becomes the mediator between the past and the present, the dead and the living, the Allens and the victims. She states: "There weren't no sun that day. Four days after Lewis Webb died, Nancy died." (ibid). She notes that Augustus Fowler comes to see her. Lew Foster hasn't come to see her yet, and that they "Took Massie back to Pulaski on the train." (ibid). When she mentions each character's name, he or she leave the scene of the crime. It's a surreal moment in the play because each of them gets up literally where each victim was shot and moves off stage. The memory of each of these characters is embodied through each actors and re-membered separately as they exit the performing area. Unlike the names that merely adorn the memorials on the wall, the exiting of each character acknowledges the tragic loss of each of their lives.

Francis Allen concludes the scene with another acknowledgement of the audience and their morbid curiosity. Her voice grows louder as she states, "And I wish you had not thought to come here and acted like it was something you needed to see. Claude, Floyd, all the rest of them didn't have [indiscernible] All of you right here are watching" (ibid). 
These comments, again, acknowledge the space and the trauma that occurred there. In this instance, she shames the audience in their morbid curiosity. Her mentioning of Claude and Floyd also illustrates that they didn't have a chance. She, like the audience that observes the play, could not take any sort of action in what went on in the shootout.

Besides the actual shootout, the electrocutions of Floyd and Claude are the second most powerful scenes in the play that include spectacular moments where the past and present collide, the space of the courtroom is acknowledged, and the tragic terministic screen is engaged. The scene builds up with Floyd's emotional breakdown in his jail cell, which is constructed from metal pipes. He asks forgiveness of his wife and also God by stating "The Lord says blessed is those who mourn, I am not blessed" (ibid). This depiction of Floyd follows the changing of his character from violent hillbilly to convicted prisoner in the media as well. Like his wife, Francis, Floyd has his own visions in the jail cell of Dexter Goad visiting him. Floyd states, "Deck Goad with your pistol drawn" (ibid). Goad replies, "No one ever forgets us in this courtroom. We are two sworn enemies who draw our guns in the theatre of another man's mind. Hell bent, Hell bent on destroying the lives, fortunes, of Dexter Goads or Floyd Allens. Floyd, I trust you made peace with God" (ibid). The actual historical documentation of this visit is insignificant to this part in the play. This visit demonstrates not only the memory of the shootout, but also the political factions that are involved.

The "drawing of guns in the theatre of another man's mind" works in two ways. The first is what Sidna referred to earlier in his remembering of the incident. The impartiality of memory of the incident, that is, collective memory and the retelling of the event brings about many different variations of the telling of the memory. The second is 
the literal play that is happening in the minds of the audience who watch it. They're not only creating their own beliefs about the characters in the play, but also the actual people who lived that Levering bases the play upon. Despite either interpretation of the line, both of them "destroy the lives" and "fortunes" of Goad and Floyd Allen. This statement is a bit of an embellishment, as Dexter Goad remained in Hillsville and lived a successful life working in the courthouse, whereas Floyd's family was splintered and utterly traumatized after the shootout. Only recently are family members willing to speak out about "the incident." The lines do indicate the destruction of the shootout and attempt to make resolution between Floyd and Goad regardless of whether it actually happened.

The final cry of Francis and final words of Floyd in the last scene establish the final spectacular moment depicting the tragic terministic screen. In the scene, Francis again acknowledges the courtroom as "This place here where I never come and never will again" (ibid). It is a symbolic and literal gesture that she will no longer go back to the courtroom because of the trauma that she suffered there. She then moves her commentary to the funeral of Floyd and Claude where the "coffin was open" and where there was "The awfullest crowd you ever laid eyes on" (ibid). Her explanation of the funeral demonstrates her hatred for Floyd for causing the trouble: "[I] walked past Floyd and I never did, would not look at my husband. When I came to Claude, I cradled my boy. I cradled him in my arms. I cradled my cold baby. He was so cold for the longest time" (ibid). Clearly here, we see her disgust for Floyd; the scene matches eyewitness accounts of her being at the funeral and not looking at her husband and holding her son. Her actions depict how traumatic this event was for her. The emotion in the scene is palpable. 
After the funeral, she turns back to address the audience one last time to conflate present and past. She says, "Hear that March wind a-blowin'? Well you all had to come see this again, a-lookin' at us this way. All the things we've done tried to do and tried not to do. So now you all go home tonight, crawl into your beds and have yourself a sweet dream. I hope you all are well satisfied" (ibid). The initial weather reference puts us back at the time of the shootout, but more importantly she addresses the audience for the final time. She references not only the play, but also the audience's perception of the shootout through the play as she notes "all things we've done tried to do and tried not to do." This comment also references the many depictions of the shootout that demonize the Allen side or the local government side of the shootout. The final words reach beyond the scope of the play as she follows the audience home to their own beds. Levering attempts to convey the temporality of the play, but also pushes on how it should stay with the audience. Not only in the fact that the audience is "well satisfied," but that they desired to see more of the violence and trauma of the incident. They want to witness the spectal of the shootout. These final comments by Francis breakdown not only to a personal space outside of the walls of the courthouse and into the audience's own homes, but to their own perceptions of the play and their own desires to see the violence and trauma enacted. Francis's dialogue here demonstrates the movement from the trauma to spectacle in the eyes of the viewers.

While this final reflective moment seems like a good ending to the play, Levering then has Floyd come out at the very end and yell, "Gentlemen, gentlemen I ain't a-goin." In the performance in 2012, the audience laughs at these lines as they seem rather comedic after the seriousness of Francis's lines beforehand. I would argue that these lines 
undo all the emotional reflection that Francis set up earlier; the lines draw the audience back to the violent mountaineer terministic screen instead of the tragic, sympathetic one that the scene sets up. The audience then must reckon with their desire to see the violence of the play then Floyd comes out and bellows his famous lines. Levering wants to include Floyd here to demonstrate the key moment of the trial, but it falls flat to a moment of comedy. Despite its comedic take up, the lines still resonate and echo in the memory of the courthouse and to those who came to watch the play. They demonstrate that Floyd is bound to remain in that memory, but that the repetition of the memory after Francis's lines undoes the retelling of the story. It is after those lines that 7 people died and the lives of everyone in the courthouse and the town of Hillsville were changed.

The close readings of these scenes where Levering collides both past and present in the courthouse affirm Rebecca Schneider's view that the play has staying power beyond the courthouse. While Levering, and many other performance scholars, state that the performance is temporary, its embodiment in the local give it staying power. Even Francis Allen in the last scene notes that the audience will think about the play as they "crawl into their beds and have a safe dream." Embodiment does not only stay on the stage though; as mentioned earlier, I would argue that it is the coming together of the ancestors of the shootout in this space that brings power and healing to the space. The traumatic, spectacular incident deemed unspeakable by those who witnessed it is now enacted and embraced by those buying tickets to see it. These moments enable the tragic terministic screen to not only exist, but to juxtapose the outlaw screen created by the memorials on the courthouse walls. Both the actors and the audience members "refigure 'history' onto [their] bodies, the affective transmissions of showing and telling” 
(Schneider 104). The commodification of the event renders it a spectacle, but because of the emotions behind the play it serves as a site of healing. By the end of the play both actors and audience members are indeed "well satisfied" as acknowledged what happened in the past and how that past plays in the present conditions of their own lives as they continue to heal from the tragedy.

\section{The Disruptive Past: How the Ballads and Plays Perform in the present}

This chapter explores how the plays demonstrate the intertwining of memory and performance theory to produce a new terministic screen that portrays trauma, pity, and sympathy for those involved in the shootout. The plays work as what performance theorists call archives - they retain a historical memory of the shootout. That memory is reconstructed in the way in which the performance takes place in the genre. Whereas, the ballads demonstrate a fissure in Hillsville with images of a violent Sidna Allen and a sympathetic, pitiful Claude Allen. These ballads mirror the uptake of two of the terministic screens mentioned in Chapter One as one creates the violent hillbilly gangster image the other sympathy and tragedy. Decades later, Levering's plays continue the tragic lens that "Claude Allen" uses, but relies on the place of the courthouse to act as a place of healing from the trauma of the shootout. The plays take out the stereotypes that the ballads reinforce and replaces them with actual fact (albeit, the plays could be deemed historical fiction).

Despite how these performances fissure or heal the feelings in the town, both acts of performance produce emotions and memories about the historical event. Returning to the ideas of Diana Taylor, we notice that these performances are powerful. Either type "evokes memories and grief that belong to some other body. It conjures up and makes 
visible not just the living but the powerful army of the always already living" (Taylor 143). These "memories and grief" belong to the bodies that are represented by the singers or actors, but also to the still traumatized citizens of the town in which they are performed. The act of seeing the performance changes those who see it: "the fantasies that shape our sense of self, of community, that organize our scenarios of interaction, conflict, and resolution. (ibid). The ideas of "conflict and resolution" are relevant here as historically the recent plays demonstrate that the community of Hillsville is ready to heal from the event whereas the "Sidna Allen" ballad split the town. They reject the terministic screen of the media stereotypes and embrace a screen of reality, trauma, and pity of the shootout.

These portrayals of the shootout demonstrate how it continues to be memorialized as seen in the performances of the plays during the shootout's Centennial Symposium (not celebration). Those who attended the plays were welcome to visit the grave sites of the victims of the shootout, including Floyd and Claude Allen. Like the courthouse during the play, the invocation and visitation of these sites demonstrates a change in the town's feelings towards the shootout. Both the Allen side and the local government side were sympathetic to each other. This interchange demonstrates that the "past can disrupt the present...but so too can the present disrupt the past...something is different here than just simply remembering, or simple negotiation" (15). The memories themselves are not being recreated, but rather the stances felt by the ancestors and people of Hillsville have changed. The days of holding the shootout as a grudge are passing. Their movement from the fissure of the "Sidna Allen" to the emotional healing of the plays demonstrates the 
power of these performances and how they continue to affect the perception of the shootout today. 


\section{CHAPTER THREE:}

\section{'FEELINGS ARE STILL VERY STRONG': SITES OF PUBLIC MEMORY IN}

\section{HILLSVILLE, VA}

I arrive at the Historic Sidna Allen House as rain starts to fall from the sky much like the day of the trial; however, it's a warm day in July instead of a frosty morning in March. The weather is appropriate to set the mood about the house whose first residents only lived there for six months. As I walk up, people are running to their cars to avoid the rain. There has just been a media event there about how much money the plays raised for reconstruction of the dilapidated house. ${ }^{12}$ The first step will be to jack up the house to do renovations on the foundation. Women gather up easels as I walk up the porch, the porch where decades earlier Floyd and Sidna might have stood to weigh their options for Floyd's trial the next day. The porch itself seems stable as boards are not warped like the upstairs inside the house; however, the white paint is peeling all over the outside of the house. Despite its conditions, while in the dining room in the house I meet Stu Shenk who plays Sidna Allen in Levering's plays. He begins to tell me and another visiting

\footnotetext{
${ }^{12}$ In addition to the money from the plays going toward the house there have been several other methods to raise funds for the house and to circulate the perceptions of this place of public memory. One is the work of Rita Edlein who took nostalgic pictures of the house with her subjects posing provocatively around the house. These pictures were made into cards and sold at the courthouse museum. Volunteers in the museum told me that the art wasn't their style, but that some visitors liked the contemporary take on the old building. In addition to the cards, the museum sells Christmas ornaments that go towards the renovation. There is also a "Friends of J. Sidna Allen House" Facebook group to keep those online aware of the fundraising and renovations of the house.
} 
couple the story of the shootout. I realize that he, too, performs the story just as the players in the play. He, as a spokesperson for the shootout, performs his own masculine rendition of it.

Shenk's oral story making is not the only way the shootout is conveyed, but also through the personal archives of local Hillsville residents that keep artifacts from and about the shootout in their own homes. Gary Marshall, local native of Hillsville, has over 15 file boxes of memorabilia associated with the shootout. These boxes contain newspaper clippings, copies of the Rock Opera, items from the Centennial Gathering, among other things associated with the shootout. Another informant researched enough to find the original verdict that was handed to Judge Massie right before the shots were fired in the shootout. He calls it the "Holy Grail" of the shootout. And yet another informant emailed me various pictures of the medal that was cast by a local women's group for Claude Allen after his death. These examples clearly demonstrate that residents in Hillsville want to re-create their own vernacular histories of the event. John Bodnar in Remaking America, Public Memory, Commemoration, and Patriotism in the Twentieth Century notes that these vernacular histories "convey what social reality feels like rather than what it should be like. Its very existence threatens the sacred and timeless nature of official expressions" (14). The citizens of Hillsville invested in not only collecting these for personal nostalgia, but in using them to retell the story in their own way. These small personal collections do not stand as government sanctioned or official histories of the event, rather they show how the residents want to reclaim the narrative and create their own story to tell about the shootout; one that is wound up in artifact and almost always rooted in the story passed down from their ancestors in Hillsville. 
The three museums in and around Hillsville demonstrate the local interest in the event. Much like the media, ballads, and plays mentioned in the earlier chapters, these museums still participate in the outlaw and tragic terministic screens invoking masculine violence. These screens develop from the stories created by each museum and rely on epideictic rhetoric to tell these stories. These vernacular and official retellings of the shootout participate in epideictic rhetoric as Cynthia Miecznkowski Sheard writes, Contemporary epideictic rhetoric is ultimately about conduct and values within communities addressed or invoked. It occurs in assemblies large and small, formal and informal, public and private. Its efficacy depends today as much as it did in antiquity on Kairos or 'exigency' in the broadest sense (not just the 'occasion' of discourse, but what makes the occasion what it is - the critical convergence of time, place, and circumstance, including audience needs, desires, expectations, attitudes, resources, and so on). (her emphasis, 771)

These museums do, indeed, tell about the conduct and values of the town. Each retelling demonstrates what the curator or collector of the museum deems valuable in the retelling of the shootout. The Carroll County Historical Society and Museum presents visitors with a view of the shootout that includes the rehabilitated J. Sidna Allen, but also includes vernacular histories contained on a peg board in the museum. This mostly vernacular exhibit presents the humanized terministic screen by demonstrating that the Allens were responsible citizens in Hillsville. The Mount Airy Museum of Regional History, a government sanctioned museum, offers an overview of the shootout to include the capture and final trial of the Allen men. The details of the shootout are tacked to a piece 
of carpet spanning only one short wall of the three-floor museum. This screen humanizes both sides of the shootout, but also sensationalizes the event by following newspaper depictions of it. Lastly, the Harmon museum located in the back of a western wear and boots store, gives us a purely vernacular take on the shootout that includes a one-sided view of the Baldwin Felts Agency. The story it conveys is historical, but also personal as each newspaper clipping is accompanied by an artifact spanning from pictures taken of the shootout to Floyd Allen's saddle bags. Using the terministic screens from Chapter One, each of these sites of public memory create a new way of re-telling the story of the shootout.

\section{Epideictic History Making through Vernacular and Official Stories}

These sites of public memory, using differing terministic screens, entail many variations of the shootout that negotiate the vernacular history of the region, but also attempt to make the history official by placing it in an exhibit, whether that be under glass or merely thumb tacked to a poster board. These vernacular retellings give rise to epideictic history making of the shootout. Each of these museums encourages a shared history of the courthouse shootout. They are all within an hour drive of each other. The Harmon and Courthouse Museum are only minutes apart where the Mt. Airy museum is only 30 minutes away. However, they do not share exhibits. The stories are kept separate

at each museum and materials are not exchanged. They each invoke their own terministic screen in the retelling of the shootout.

They offer different ways to approach the exhibits about Hillsville. Dickinson, Blair, and Ott state, “...the primary action the rhetoric of the memory place invites is the performance of traveling to and traversing it. That effort to participate in a memory 
place's rhetoric almost certainly predisposes its visitors to respond in certain ways" (26). Directions are not given as to how to read the exhibits; visitors are able to create their own ways. Each of these museums continue to participate in epideictic rhetoric as these materials combine to tell a story about the shootout. These stories demonstrate Sheard's argument that

Epideictic discourse today operates in contexts civic, professional or occupational, pedagogical, and so on that invite individuals to evaluate the communities or institutions to which they belong, their own roles within them, and the roles and responsibilities of their fellow constituents, including their leaders. (771)

While the knowledge of region is relevant, artifacts also help guide patrons to construct or "evaluate" the community of Hillsville. Sometimes the traversing of the museum goes opposite as in The Carroll County Historical Society and Museum that starts with the furniture that Sidna Allen made during his incarceration in Richmond. After this large exhibit, visitors see a carving of those involved in the shootout, a medal given to Jezebel Goad, and then a peg board that explains the shootout. This is different from the Mt. Airy Museum of Regional History that explicitly takes readers chronologically through each step of the shootout and includes a brief regional commentary on Hillsville itself at the beginning. These rhetorical choices provide visitors with a way of approaching the shootout and rhetorically building its history. By beginning with Sidna's furniture, the Carroll County Historical Society and Museum presents a rehabilitated model for the Allen men. By introducing the town and then going into the shootout, the Mt. Airy Museum wants to guide visitors in a linear path that tells a 
story about the event (in fact, they include "story" in much of their materials with the exhibit and within their own development as a museum).

In addition to traveling through the museums, visitors will negotiate their own knowledge of the region with the knowledge that the exhibit suggests. These negotiations can be seen in the Mt. Airy Museum of Regional History that presents an image of the Allens as part of Hillsville, but also bootleggers in the area. Patrons who read this can easily attach the drunken hillbilly image to these images or more educated visitors can understand that moonshining was a part of the socioeconomic class during the time in Hillsville. Dickinson, Blair, and Ott note that "each memory place proffers a view of who 'belongs and on what terms,' but the geography of these places also nominates for public audiences very particular views of which people and events of the past are most worthy of memory" (28). Each museum depicts Hillsville and its residents in a certain way as patrons navigate through the exhibits. As mentioned above in the Courthouse Museum patrons start with the wood carvings of J. Sidna and end with a description of the courthouse. Similar to the Mt. Airy Regional Museum, Harmon's museum offers a chronological path for patrons to follow as newspaper clippings are organizing in a chronological pattern for visitors to follow. In addition, framed pictures often accompany what occurs in the papers. These artifacts "prescribe particular paths of entry, traversal, and exit. Maps, arrows, walls, boundaries, openings, doors, build of memorial places often function as 'strategy' in Michel de Certeau's sense of the word" (Dickinson, Blair, Ott 29). While the Harmon museum may not have a government hired curator similar to the Mt. Airy museum and the Courthouse museum, the ways that these artifacts are placed still rhetorically tell the story that is sanctioned by the museum. 
Traversing the museums through artifacts also brings up differing ideas of how multi-faceted memory can be in these places. Dickinson, Blair, and Ott remind us that the creation of the past here is more complicated than just the re-creation of the memory that the exhibit has, but, in fact, that the varied histories of the museums deserve recognition themselves. These museums "do not just represent the past. They accrete their own pasts" (30). Dickinson, Blair, and Ott use the theories of memory scholar, James Loewen, to speak to how the first memory is what the memory place depicts, the second the development of the memory place itself, and the third the historical significance of the visitor of that place. While recognizing all three of these ways of creating memory, I would like to focus this study on the first of these ways of creating public memory. An analysis of each of these officially vernacular spaces will demonstrate how they each ask the viewers to participate in the creation of the history of the shootout.

\section{The Museums}

\section{"All in a Moment": The Carroll County Historical Society and Museum}

Before ascending the green stairs that have bullet holes in them, patrons to the Carroll County Historical Society and Museum are encouraged to visit what was once the Clerk of Court's office. It now serves as the main museum entrance. When first entering patrons go through a gift shop and welcome center. There is a welcome table there as well as book shelves that are lined with local lore about the shootout and about Hillsville in general. Some of these materials are about the shootout while others are genealogies located in the area. In the next room patrons see the exhibit on the shootout. The museum offers patrons a vernacular story through the shootout through the guidance of curator, Bill Webb; the wooden artistry of Sidna Allen, the brief mentioning of Jezebel Goad's 
fictional intervention in the shootout, and the story depicted on the peg board for others to trace.

What makes this museum distinct is the guidance of Bill Webb, the curator of the museum. When entering the museum Webb tells the story of the shootout as patrons walk through the exhibit. His knowledge of the shootout and the exhibit add to the experience making it vernacular. His vernacular story telling about different pieces demonstrate the epideictic retelling of the shootout as he invokes the community and its role in the shootout. He praises these pieces that were constructed in the past, but demonstrates how they play a role in the present of the museum. His story telling through the museum presents a humanizing of the men and women that were involved in the shootout. Similar to the audience in the plays, patrons see a sympathetic view of all those involved rather than the outlaw terministic screen.

Two pieces that are particularly important in this retelling besides the actual peg board recounting the shootout are Sidna Allen's woodworkings and the wooden replica of the shootout. Both of these pieces recount a masculine retelling of the story, one that is housed in violence, but also rehabilitation. Because of his good behavior in jail and his excellent relationship with the guards, Sidna was able to establish himself as a wellknown carpenter and artist. Upon his release, Sidna traveled the South displaying and selling his pieces. They are extremely valuable, which is why they still remain behind glass. In addition to Sidna's pieces, one box carved by Wesley Edwards remains behind the glass. Another one resides in the Mt. Airy Museum of Regional History. These artifacts reclaim Sidna's identity. His reputation as a gangster and violent mountaineer is revoked; instead he is revered as an artist whose work signifies a rehabilitated member of 
the judicial system. He no longer stands as the hillbilly outlaw presented in the ballads, but is now an Appalachian folk artist. Using a particular set of Appalachian and romantic stereotypes to debunk the hillbilly stereotype, Sidna is re-humanized.

Another one of Sidna's tables is displayed after the glass cases. Above the table is a piece of paper ${ }^{13}$ describing that it was one of his early works. Interestingly, above the explanation there is a framed picture of Judge Massie, High Sheriff Lewis Webb, and District Attorney William Foster. Much like the plaques that stand in the courthouse just above the museum, this framed picture stands as a memorial to these men who died in service of the law. The small memorial falls in between Sidna's redemptive wood working and the wooden carving display of the shootout itself. Whether intentional or not, this placement of the framed picture represents an interruption in the redemption of Sidna Allen and a call back to the lives that were lost during the shootout. It's also worth noting these three men are the only ones who occupy the frames. Their civic duty makes them worth remembering, just as the plaques above in the courthouse are dedicated to those who were carrying out their civic duty in the courthouse on that day. This memory created here is masculine and evokes the consequences of the violence of the shootout.

To the right of the framed picture of the men is a brief explanation of the shootout including pictures and text. The first panel that visitors read states: "The Allens Prospered — they were a rugged, hardworking family that knew how to make money. Both Floyd and Sidna farmed and owned stores." There is a picture of Sidna's store to the left of the caption. This first depiction of the Allen men demonstrates that they did not fit

\footnotetext{
${ }^{13}$ All of the displays are explained on regular paper. These displays demonstrate how, despite low budgetary concerns, the history of the shootout still remains an important part of Hillsville history.
} 
the stereotypical depictions that occurred in the terministic screens of the media of the time. This exhibit argues that they were successful businessmen in the region and not violent mountaineers.

Next to this explanation of Floyd and Sidna there is another one of Sidna's Victorian home with a picture from the time to the right of the explanation. There are other common pictures of the Allen men during the search and capture of them immediately after the shootout. In the middle of the pictures and captions there is a brief explanation of the shootout, complete with a picture of Ronald W. Hall's book, The Carroll County Courthouse Tragedy. While this caption is a marketing ploy (and why shouldn't it be), it provides an excellent, quick overview of the shootout for visitors who are not familiar with the shootout. While this information is repeated on the opposite wall, patrons are informed here of the basics of the shootout. It provides a local depiction of the shootout that humanizes these individuals. To further push the tragic nature of the shootout, the temporary grave marker of Floyd and Claude Allen occurs in both places. The repetition of the marker and its inscription ${ }^{14}$ demonstrates that this museum values this memorial and the local folklore that surrounds it. Its appearance denotes that the museum wants to memorialize Floyd and Claude's deaths, but also wants to participate in the folklore around the stone. As mentioned in Chapter One, the memorial has since disappeared, but, according to an Allen family informant it "is still being used" and is "still in the family." Most of these pictures, including the gravestone, were printed in the local press.

${ }^{14}$ The inscription reads "Sacred to the Memory of Claude S. Allen and his father Who was judicially murdered in the Va. Penitentiary March 28, 1913 by order of the Governer of the State over the protest of 100000 Citizens of the State of Va. Placed here by a friend and citizen of Va." 
In addition to the pictures and captions, visitors look down to see a complete wooden carving recreating the moment of the shootout. See Figure 1 below:

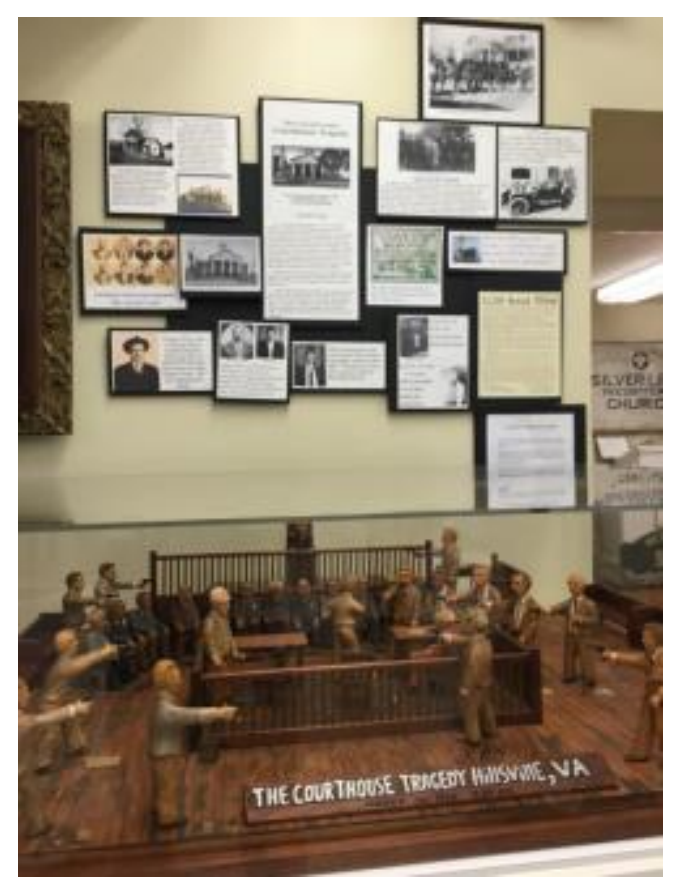

Figure 8 Photograph by author

Like the reenacted play that I addressed in Chapter Two, this re-creation of the shootout contains all of the main actors, except for the women. The carving was made by a Floyd County resident and housed in a lawyer's office before moving to the museum (Webb interview). Alongside the Sidna Allen word workings this piece of craftsmanship presents the shootout as something that is distinctly folksy. Each face displays emotion down to Floyd's scowl. We move from Sidna's rehabilitation in the previous display to the action of the shootout in this model. The model is significant because it presents the local shootout in a specifically Appalachian folk art tradition humanizing those involved. It does not present the men as outlaws, but merely as those who were there during the tragedy. 
While these depictions are masculine, the courthouse museum has the only depiction of the women in the shootout in a glass case that houses a medal that was caste for Jezebel Goad, Dexter's Goad's daughter, by Etta Donavan Mann, the governor's wife. As noted in Chapter One, there were news reports that Jezebel helped her father to reload his gun at the top of the stairs. Mrs. Mann immediately followed the news reports and had the medal caste. The museum includes the letter that Mrs. Mann sent to Jezebel on March 18,1912 . Figures 3 and 4 show a typed version of the letter as well as the medal from Richmond, Virginia. 


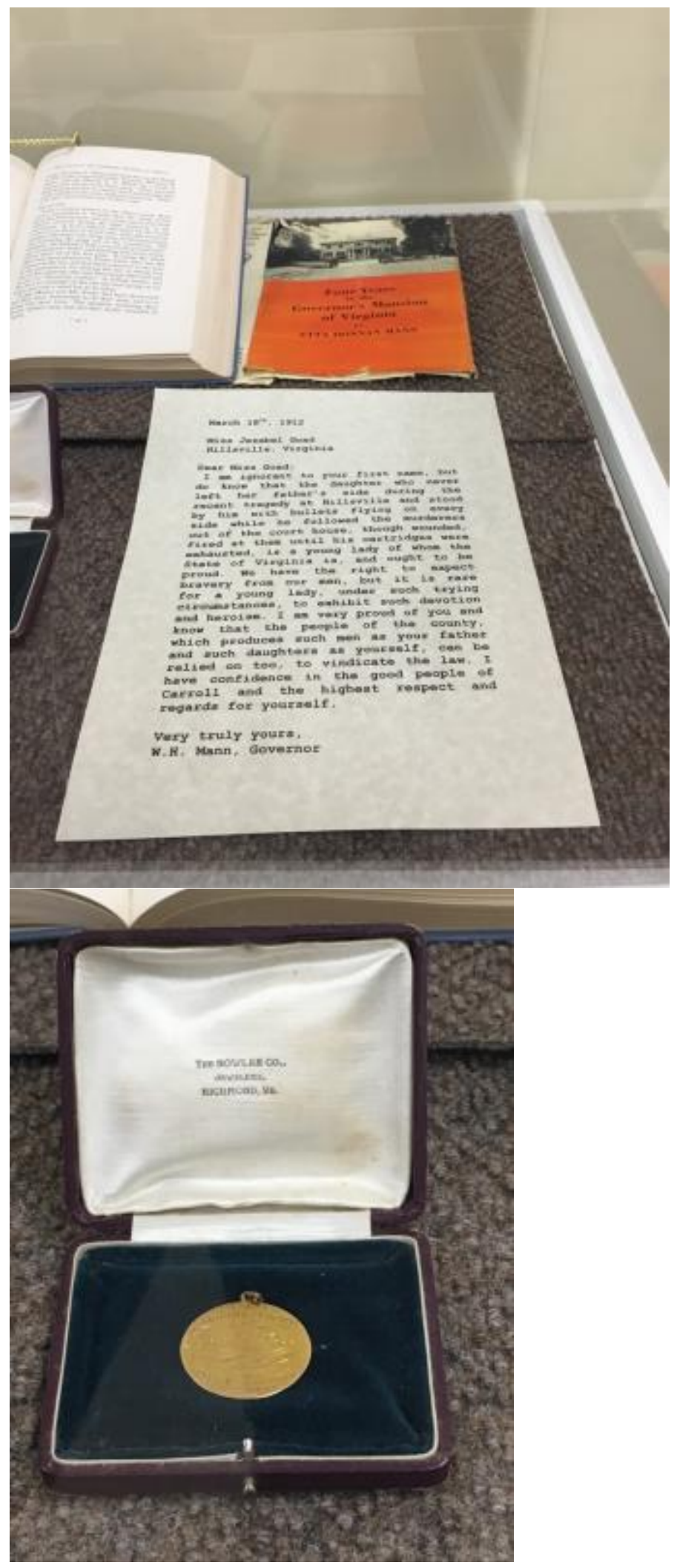

Figures 9 and 10 Photographs by the author 
The letter invokes the rhetoric that we see in the memorials on the courthouse wall. Jezebel's helping her father defend the courthouse are actions of "a young lady of whom the State of Virginia is, and ought to be proud." In the first invocation of Jezebel, Mrs. Mann has already gendered her as a "young lady" who the state should be "proud" of. The letter continues with a deeper glimpse of how gendered is constructed by Mrs. Mann (and her association with the entire state of Virginia). She writes,

We have the right to expect bravery from our men, but it is rare for a young lady, under such trying circumstances, to exhibit such devotion and heroism. I am very proud of you and know that the people of the county, which produces such men as your father and such daughters as yourself, can be relied on too, to vindicate the law. I have confidence in the good people of Carroll and the highest respect and regards for yourself. Jezebel's "vindication of the law" sounds awfully familiar as it harkens back to the declarative statements on the walls of the courthouse (even though these plaques were not posted till years later). Ironically, the last statement in Mrs. Mann's letter, tells Jezebel that she has the "highest respect and regards for yourself." This is ironic because 1) she is completely ignorant of Jezebel's first name and 2) this letter responds to a completely fabricated newspaper article that reporters created for dramatic effect for the shootout. Also, the attention paid to Jezebel in this case of lies is detracted as right above it there is a framed picture of her father with his law degree. In the next chapter, I will go deeper into the implications of gender and the shootout. The inclusion of this medal here and the exhibit on Jezebel does prove that, even though it's fictional, women do claim a space in the epideictic history making in the courthouse museum. The inclusion of Jezebel here 
asks patrons to remember that women were involved during and after the shootout. Even though her story is fictionalized her voice should still be heard. Even though it is historically wrong, the terministic screen here focuses on retelling Jezebel's story through a masculine and violent lens.

The final stage of the museum is the peg board that contains the story of the shootout. This peg board is vernacular because it expects patrons to be able to decipher the story of the shootout. In the middle of the peg board, there is a piece of poster board that contains the story of the shootout; however, this story tends to lean toward the Allen point of view. To the right of the peg board the words "Social Prejudice," "Political Enmity," "Economic Jealousy," and "Personal Animosity" appear in red. Because of the red font visitors' eyes are caught by those words first and then work their way around. Underneath the red words, "Threats Recorded" and "Inadequate Courtroom Security" appear. Then the right side of the poster states "December 1910 Nephews and Advisories fight outside Church," "Nephews Indicted; Arrested in N.C.," "Mr. Floyd Allen Intervenes; Charged With Assaulting an Officer," "Mr. Allen on Trial Before a Jury," "Warnings Ignored." These words attempt to retell the initial happenings of the shootout focusing on humanizing Floyd's story instead of stereotyping him as an outlaw. While the recount of the nephews tells the why, the fact that "Warnings Ignored" alludes to the fact that Judge Massie ignored the warnings that supposedly happened (and were told to him by other court officials). The inclusion of the warnings suggests that if Judge Massie had carried a gun or paid attention to the warnings, the shootout could have been averted. In addition, the middle panel demonstrates how this display leans heavier on the Allen side. It states, "It was a moment on March 14, 1912. Mr. Floyd Allen, then a free 
citizen, stood to hear the verdict of his peers, upon conviction of inferring with an officer of the law, the jury impose '[sic] a sentence of one-year imprisonment." The inclusion of "free citizen" here alludes to Floyd having no criminal record. The use of "Mr." here as well demonstrates respect for Floyd that he did not receive often in the news media. Floyd is referred to as a responsible community member on the poster and not a criminal. The "one-year imprisonment" also demonstrates that he was tried and convicted. It acts as a leading up to the moment of the actual shootout.

The next few paragraphs contain the set-up of the shootout in a lapse of time. The first phrase merely sets up the appeal while the second demonstrates Floyd as a prisoner: "The defense attorney moved for an appeal; Judge Massie agreed to hear the appeal the next morning." The prisoner statement reads, "A moment before, Mr. Allen had been a free man; a moment later, a prisoner awaiting appeal. The change was momentous; one which the Allen family was not prepared to accommodate"; i.e. they were ready for violence if the sentence was carried out. Next, the famous words are written: "Mr. Allen is reported to have said, “'Gentlemen, I ain't a goin,"” (display's emphasis). The final statement on the poster brings up the temporality of the shootout itself; how it was hectic and happened quickly: "Gunfire, chaos, and death ensued...All in a moment. (display's emphasis).

Surrounding the display there are pictures and other ephemera mostly from photographs that were included for the newspapers at the time. From left to right we get pictures of "Participants" from the "Allen Family" and then "The County Officials" below is labeled as "Baldwin Felts Take Charge" with, again, pictures that were taken from the newspapers of the time. To the very right of the poster are the mugshots of the 
Allen men. The arrangement of these materials is similar to the earlier one above the carving of the men. This arrangement, while sometimes hard to decipher, presents a vernacular remembering of the shootout. The story is made richer by having Bill Webb there to fill in the gaps. Webb goes into details about the Allen family and their arrests here paying close attention to scoff at the media depictions of the event and to focus on the interpersonal lives of the Allens.

The basis of the story is on the peg board, but the exhibit focuses almost entirely on Hillsville's role in the shootout and does not broaden out to the region. There is little mentioning of Appalachia rather three newspaper clippings are present. The first is from The Carroll News "John Farris Is Last Living Member of Famous Courthouse Tragedy," below that is the grave inscription for Floyd and Claude's original tombstone, and right above that is Sidna Allen's obituary from The Carroll News. The inclusion of these three articles demonstrates the local presence of these exhibitions and the focus on humanizing instead of exploiting the participants of the shootout. The tombstone and Sidna's obituary display sympathy toward the Allen side. Sidna's obituary is included because he, Floyd, and Claude were the top three men in the media; these articles are meant to displaces the earlier stereotypical depictions of them and replace them with realistic ones. The tombstone is included because of its cultural significance in the town's lore. These articles place the shootout in the past as they all depict death; however, they are used to display how this museum chooses to refuse the stereotypical depictions of these men.

The demonstration of Sidna Allen's woodwork, the courtroom carvings, Jezebel's medal, and the peg board's local display express that the Carroll County Historical Society and Museum attempts to include many of the local narratives to the courthouse 
shootout. The rehabilitation and the peg board demonstrates the Allen side as they both portray the Allen men not as criminals, but as sympathetic victims of the shootout. Much like the two memorials in the historic courthouse, the Goad medal displays an attempt to reach out and demonstrate the town's side of the shootout.

\section{"The Story of the Century": The Mount Airy Museum of Regional History}

Unlike the Courthouse Museum, the Mt. Airy Museum of Regional History, established in 1993, contains an attempt at official history through a small display on the second floor of the museum; however, these displays sensationalize the event through the use of masculine violence seen in the violent outlaw and uncolonized other terministic screens. While the museum does try to humanize the Allen men, the exhibit fails because it overreaches by depending on stereotypes rendered in the newspapers it uses. The website demonstrates how the museum's main focus is to tell stories about the region:

Ours is an all American story - typical of how communities grew up all across our great nation. While our story takes place in the back country of northwestern North Carolina at the foot of the Blue Ridge Mountains, it is likely to bear many similarities to the development of crossroads, towns, and cities throughout America

The description collides the Appalachian identity with a developing America. This is an epideictic moment that celebrates the ways in which mountain life is an "all American story." It wants to conflate both identities in ideas of the life of the pioneer, which is alluded to several times throughout the museum. Similar to the pioneer exhibits, other displays throughout the museum are clearly funded. Their glass cases and name plates are 
sponsored by donations. ${ }^{15}$ These displays are interactive containing buttons to push to hear an automated voice talk about what is encased in the class or in the exhibit. Despite the expensive displays, the telling of the Hillsville shootout occurs on a board covered in carpet. Opposite of the courthouse exhibit, this museum Whereas in the Courthouse carefully outlines the participants in the shootout as seen in Figure 5 below.

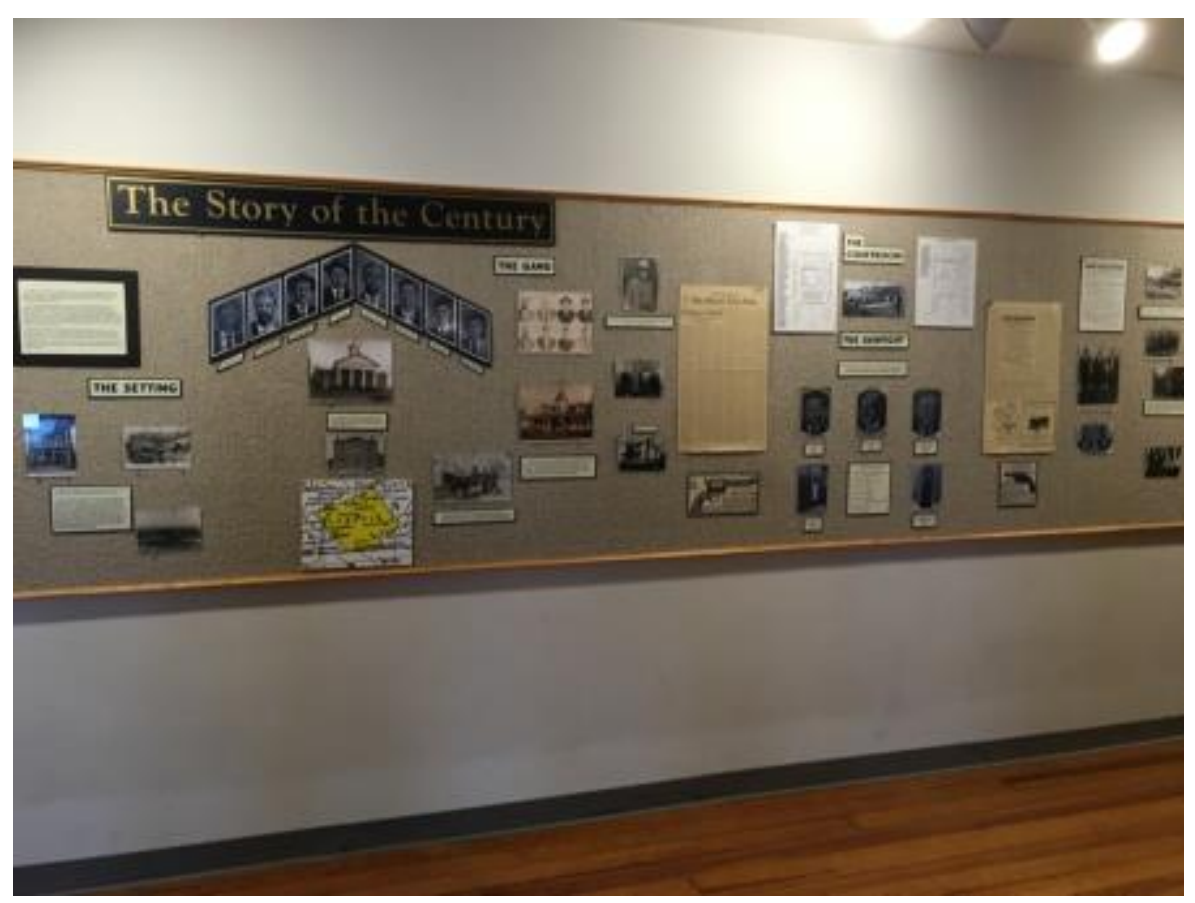

Figure 11 photograph by author

The story is very carefully and implicitly told by this display using subtitles and pictures.

The story is made official as it is placed in the museum; however, it still remains vernacular as it still contains artifacts such as newspaper clippings throughout. This analysis will examine how, unlike the previous museum, the Mt Airy Museum of Regional History wants to tell the complete story; however, this is a story that privileges the productive members of the Allen men and condemns the others.

\footnotetext{
${ }^{15}$ Donations can be made at their website as well which could explain the amount of money poured into this museum as opposed to the Hillsville Museum.
} 
Unlike the Courthouse museum, there is no guide here to present the story of the shootout to patrons. They must construct the story using the materials that the exhibit presents. Organized in a chronological manner, these materials tell a story that places Hillsville in the Appalachian region and Appalachia within the national identity of America. Because there is no one there to tell stories about each article, patrons construct their own narrative of the shootout.

The introduction slide sets the scene with the story: "No single event in the twentieth century received more news coverage in area newspapers, nor sparked more conversation and heated debate than did the courthouse tragedy that happened in nearby Carroll County, Virginia on March 14, 1912.” The mentioning of the media sets up patrons for all the newspapers clippings they are about to see. It demonstrates the stereotypical, violent mountaineer terministic screen mentioned in Chapter One.

Next the display gives an overview of the shootout, those involved, as well as the governor's call to send troops to "quell the insurrection." The introduction continues: "This story is filled with intrigue involving blockaders, money, politics, power, romance and social injustice. Nearly 94 years after its occurrence the story remains an open book, with the final chapter yet to be written." The inclusion of the describers above not only serve as buzzwords of interest for visitors, but also to represent the social and economic class of the Allen men and those in the courthouse.

The introduction ends with a call for action from the viewers: "This PhotoJournalism exhibit is presented with one purpose in mind - the viewer to ponder the times, the circumstances with the relativity to our society today." Like the courthouse museum, many of these pictures were printed in local and national papers of the time. By 
using these papers, this exhibit depends on the violent mountaineer and uncolonized other terministic screens. It concentrates on these identities of the mountaineer refusing to engage with the gangster images; instead, the exhibit gives us details of a mountain community.

In section titled "The Setting" viewers see depictions of Hillsville; however, the curators decide to start with the "normal" life in Hillsville and then how the Allens veered from that life to become moonshiners. There is not even a threat of violence here, but just a sign. The introduction sentence casts Hillsville as a "Sleepy, little" town with the "population" of "500." The narrative then turns: "In 1912, would hardly seem the likely setting for a massacre.” The use of massacre here mirrors the use of tragedy earlier; both of these reveal the local government side and the Allen side. ${ }^{16}$ The use of shootout would be much more objective; however, the exhibit demonstrates that it knows the vernacular of the people of Hillsville. The story continues as it states that People lived life doing the everyday things people do as reflected in the photograph on the left of the Hillsville General Store. Two other photographs tell a different, darker story of Hillsville, Virginia. Notice the warning message expressed in the top photograph, 'Don't Go This Path' leading to Floyd Allen's moonshine still. The lower photograph shows evidence gathered of making illegal liquor. Though the Allen Family always denied making moonshine, legal records show raids on their property indicated that they did.

\footnotetext{
${ }^{16}$ The residents for the Allen side denote the shootout with "tragedy" whereas the residents who side with the local government call it "massacre."
} 
This piece of text demonstrates the turning again of the story from the "normal" life of people in the mountains to the scandalous, dangerous, violent mountaineer terministic screen. It reveals the Allen family as something out of the norm. A family that will not be forced to fit the values of progressive America. Ironically, both Floyd and Sidna owned successful stores in and around Hillsville. ${ }^{17}$

Interestingly, the exhibit has numerous descriptions about Sidna Allen, his home, family, and rehabilitation, but offers very little about Floyd Allen. The descriptions that we get of Floyd are the stereotyped ones that occur in the newspaper clippings in and around the exhibit. These depictions show Floyd as an outlaw. The focus on Sidna leads viewers to believe that he was sorry for his crimes. The lack of information on both Floyd and Claude remains only on the tombstones that occur later although there is little pity there as shown in Levering's plays or the courthouse museum. The exhibit illustrates the lives they lead after the shootout and the penance that they had to pay for the crime.

The middle panel introduces the characters of the shootout. Pictures of Floyd Allen, Sidna Allen, Claude Allen, Friel Allen, Wesley Edwards, Sidna Edwards, Victor Allen, and Byrd Marion are above pictures of the new and old courthouse. Again, Sidna Allen is featured in this part of the display as a picture of his house is on it and he is described as "one of the wealthiest men in Hillsville." Floyd Allen's modest home is also pictured. "The Courtroom" and "The Gunfight," which presents pictures of those who died as well as a schemata of the courtroom. This demonstrates the scientific proof of how the shots were fired and how each person was maimed or killed. Finally, Betty Ayers is mentioned who was "shot one time, killed." Unlike the Courthouse museum, this

\footnotetext{
${ }^{17}$ Selling of goods was how Sidna Allen made most of his money to afford to build his beautiful Victorian home.
} 
mere mentioning of Betty Ayers demonstrates that this coverage of the shootout is mostly masculine and embedded in violence.

"The Hunt" focuses on the tracking of the Allen men by the Baldwin Felts Agency engaging with the outlaw-violent mountaineer terministic screen. It presents numerous pictures of the posse that left Hillsville, places where the Allen men could have hidden, as well as, a picture of the hounds who tracked the Allen men. There are also wanted posters and the pictures of Sidna and Friel. This panel also presents the injured Floyd being carried out of the hotel where he laid after he was shot on Main Street. This is supposedly where he also tried to take his life (as seen in the bandage on his neck in the picture). As with the contemporary media of the time, this panel wants to tell an exciting story of the chase and capture of the Allens. While these images depict the Allens as outlaws engaging with the violent mountaineer terministic screen, the next panels entitled "The Trials" and "The Sentences" present a sense of justice to the shootout. While this panel demonstrates the public reception of the trials with pictures of crowds gathered around Sidna Allen and Wesley Edwards as they went to court, it also includes pictures of the juries of each of the Allens' trials. The inclusion of these pictures provide closure to the outlaw images through the trials.

"The Aftermath" focuses on the final moments of Floyd, Claude, and Sidna in attempts to humanize them much like the museum. There is a picture of Floyd and Claude's funeral procession. Below it is the headstone that still remains on the grave today. Below that one is the gravestone that has since disappeared, but is rumored to still remain with the Allen family. These provide closure to the outlaw images we saw earlier; 
however, the depictions of Sidna are reminiscent of the courthouse museum in its attempt to humanize Sidna.

To the right of the Floyd and Claude pictures, Sidna again sits front and center to this part of the exhibit in a chair with his arm on one of his homemade tables. Much like the Courthouse museum, the rest of the exhibit presents the rehabilitated Sidna. Below his picture curators wrote

J. Sidna Allen was pardoned in 1926 by Virginia Governor Harry F. Byrd. On the advice of friends, he decided not to return to Carroll County. Rather, he went to stay with an older brother, Victor, who was living in Leaksville (Rockingham County), North Carolina. In the 1930s, he moved to Mount Airy where he lived until 1941. Later that same year, due to sickness, he went to live with a daughter in Carroll County where he died on September 26, 1941.

While we see Floyd and Claude's funeral and gravestones, these words give patrons a rehabilitated Sidna who can no longer live in Hillsville. We do not hear about how Betty Allen continued to live in Hillsville and provided for their two daughters by cleaning houses and doing laundry for those in town. We clearly see the continuation of the masculine depictions here of the shootout. The only mention of the women is Sidna's daughter who he moved in with at the end of his life. Their story is not important in this retelling of the shootout in the exhibit; instead, the importance lies in the definition of the rehabilitated Sidna Allen who decorated his home in Mt. Airy with a stone wall.

One of the last parts of this panel is two pieces of text that 1) demonstrate that this history is vernacular and also 2) there is a valuable commodity attached to the shootout. 
The first piece of text states "The Mountain Airy Museum of Regional History would like to thank Ron Hall, Steve Talley, Rossie George and Angela Schmoll for their assistance with the photo exhibit 'Story of the Century."” To the uninformed patron, these names could just be of people who helped put the exhibit together, but those who know a history of the shootout know that Hall is the writer of The Carroll County Courthouse Tragedy and is considered to be the informant about the shootout. He, more than likely, contributed to the exhibit through telling his version of the story. This explanation leads to the next section of text, which gives brief descriptions of Hall's book, Sidna's memoir, and dates the 1912 editions of the Mount Airy News that is included in the display. The text tells patrons that these are "for sale in the museum shop." These are important because through including them here, this exhibit, much like the Courthouse gift shop, asks readers to do their own research on the shootout.

The last text on the board and to the right of "The Aftermath" is a Quick Response $(\mathrm{QR})$ code that guides readers to an article that appeared in The Roanoke Times in November 1982. This QR code is an attempt to keep the exhibit updated; however, the link is doesn't add much to the retelling of the event. These QR codes do exist in other exhibits throughout the museum so the inclusion here does demonstrate that the curators find this exhibit valuable (but not valuable enough to keep updated). Again, this asks patrons to interact with the exhibit and create their own vernacular history of the event.

Besides the carpeted exhibit, there is a glass-covered exhibit that houses two keys from the Hillsville jailhouse as well as the jailhouse in Floyd County and a special issue from the Mount Airy Leader from March 1912. These articles and keys contribute to telling a "local" story of the shootout. Next to these artifacts are two boxes that Wesley 
Edwards made. While the courthouse museum placed Sidna's pieces first, this museum chooses to put these pieces by Wesley last. As seen in the "final chapter yet to be written" at the introductory statements, putting Wesley's artifacts there at the end represents a nod towards tradition and learning. Wesley learned how to wood work from Sidna while in the penitentiary. Interestingly, they both were Masons as the Mason moon and star is still found atop Sidna's home and is also found on one of the boxes that Wesley made. It distinctly says "From Wesley" on the box as well. Displaying his work here signifies Wesley's rehabilitation and penance for his crimes, a nod towards Appalachian craftsmanship, but also it demonstrates a glance towards the future of the Allen men. Unlike Sidna Allen, Wesley Edwards was only 21 during the shootout and was pardoned in 1923 at the age of 32 . He lived until 1939 (W. Hall 257).

Through these remembrances, we see that the Mount Airy Museum of Regional History presents an organized historical look at the shootout, but that it still relies on stereotypes to tell the story. The exhibit attempts to couch the history and identity of Appalachia within the shootout; however, only in ways that turn to masculine violence that were also depicted in the courthouse museum. Instead of depicting Appalachia as a developing region and the Allen men as business men in the area, the curators depend on the images of the Appalachian moonshiner and violent mountaineer to pull patrons into the story. The Allens are once again rendered as sensationalized outlaws who shoot up the courthouse and must pay for their outlaw behavior.

\section{Cowboy Boots, a Two-Headed Calf, and Artifacts From the Shootout: The Harmon Museum}




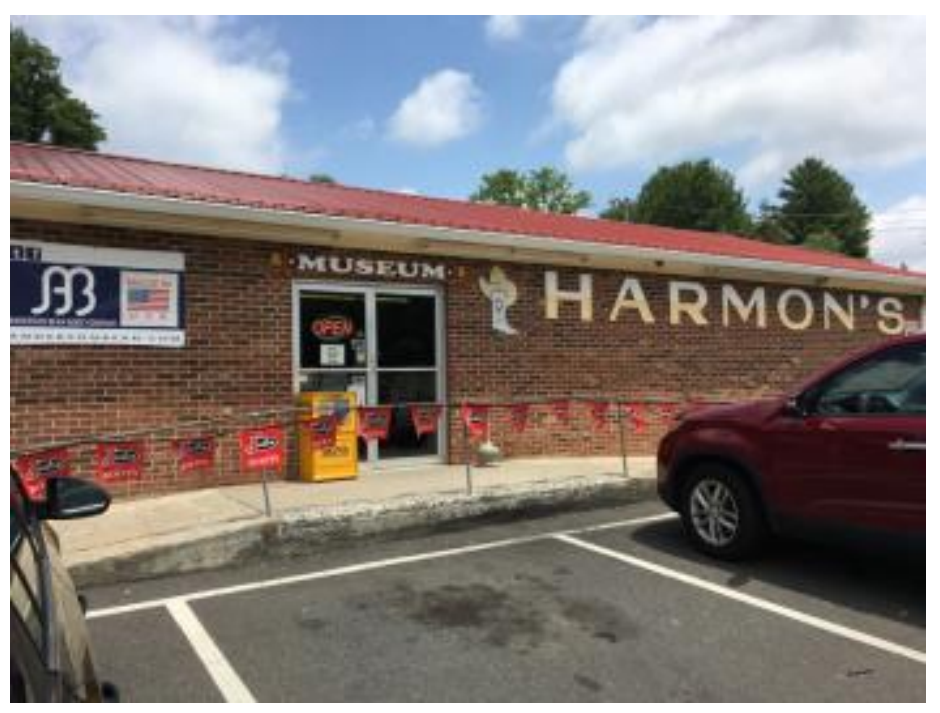

Figure 12 photograph by author

The third site I would like to examine is the Harmon Museum, which utilizes the violent mountaineer terministic screen. To consider this site a "museum" would be a stretch as it is Gooch Harmon's personal collection; however, it still operates as a site of public memory where a certain rhetorical memory of the shootout is created. To enter the museum, patrons have to walk through the lobby of Harmon's store, past shelves of cowboy boots, and racks of western shirts then down a short hallway. Much like the previous museums the hallway houses local historical books to buy about the shootout and other histories. Entering the museum, patrons see the shootout memorabilia, a Native American artifact collection, stone collection, an Appalachian fireplace surrounding by farming equipment, and even a stuffed two-headed calf. Despite the presentation of artifacts, Harmon's Museum contains probably one of the most expansive displays of the shootout. It spans for two isles and contains a wealth of articles about the shootout, framed family pictures, framed pictures of the surrounding areas, and other artifacts. While these things are under glass they most certainly invoke an informal telling of the shootout. It offers visitors the chance to peruse the articles at their leisure and to construct 
their own views on it; however it, again, conveys the Allens as violent mountaineers since it depends so heavily on the media for the portrayal of the shootout. While this collection is organized into certain areas as I mentioned above, each is cluttered with so much information it's often overwhelming. When approaching this archive, my analysis glosses over certain sections of what is presented instead of digging deep into each artifact.

The first thing that patrons will notice is the sheer number of artifacts here. Framed pictures of participants adorn the newspapers here. There are artifacts surrounding it ranging from Floyd Allen's saddle bags, Wesley Edwards's hat, to Vernon Dalhart album of Sydny Allen. Theses artifacts represent a materialistic view of the shootout; one that wants viewers to gawk at things that were actually there or associated with the history of the event. The speculative nature of the museum allows patrons to have a tangible thing to witness.

The biggest part of this collection is the newspapers. Harmon has literally collected almost every issue of local and national newspapers pertaining to the event. Each issue is under glass asking patron to slow down to read about the event. Through slowing down visitors are able to pick and choose what they want to read about the event. While it's good that the articles are under glass, they are by no means preserved in a manner that an archivist would preserve them. The florescent lights over the glass will further lead to the deterioration of the articles, but the fact that Harmon has them preserved under glass and not touchable is worth noting.

The showcase does not only focus on the Allens and the shootout, but gives another glimpse into the Baldwin Felts Agency as lawful heros. Located at the end of the 
shootout display, this exhibit directly clashes with the exhibits of the Allens earlier. The inclusion of these materials asks observers to believe in the justice and honor of the Baldwin Felts Agency completely opposite of the sympathy of the Allens acknowledging Bodnar's point that objects in public spaces "can even clash with one another" (14). At the end of the expansive newspaper trail on the shootout, patrons see in bright yellow "Baldwin Felts Detectives" on a punch board and "T.L. Felts Six Scrap Books" written on the case below. The case contains pieces from Felts' scrapbook, below is a hat, pistols, a wooden box, among other personal items. On the punch board, Harmon placed pictures of the Baldwins and Felts. What is missing from the display is the cruelty of the nature of the Baldwin Felts Agency. There is little demonstration of their terrible role in the Matewan disaster or their activity in any of the Coal Wars that were also happening in the Appalachians shortly after the shootout. We see here that the vernacular re-telling of the detective agency showcases their role as detective agency and not as coal mining gun thugs.

While the Harmon museum does carry more volume of materials than the other two museums, it is the retelling of the event that is overwhelming. Unlike the chronological, chosen pieces for both the Courthouse and Mount Airy museum, Harmon puts all of his artifacts out to display giving patrons the opportunity to choose for themselves what they want to learn about the shootout. While there is no official capacity located in his museum (except for the big sign that says museum outside his store), Harmon relies solely on the stereotypical remembrances of the shootout through newspapers and artifacts that invoke the violent mountaineer. While this way of retelling the event is interesting because of the personal touches like Floyd's saddle bags, it is also 
dangerous because it leads to his own version of the story as seen in the one-sided documentation of the Baldwin-Felts agency.

\section{Conclusion}

Returning back to the Historic J. Sidna Allen House, I sit at a large table in the dining room while it rains outside. It is myself, two actors from the recent Levering plays, and another couple who attended the media event earlier in the day. Stu Shenk, who played Sidna, retells the story of Sidna, how he came to wealth, the shootout, and a brief history of the house. Kay Cox, who played Betty in the play, interjects frequently with Betty's role in the shootout. Their retelling of the story in the historic home reminds me of the power of the history of the shootout. It not only resides in these places and artifacts of public memory, but is retold through generations of residents, and often ancestors of the shootout. There is indeed power in the retelling of the story; a power that privileges certain sides of the story depending on who is telling it. But perhaps the most important thing that I realized after visiting the house and hearing Kay's frequent interjections is what is not recorded in the museums nor in the history of the shootout. The voices of the women who were left behind and helped to continue to tell the story even though for many it was hard to talk about (and still continues to be hard to talk about today). While I'll explore the gendering of the shootout in the next chapter, the visiting of each of these museums demonstrates the privilege of the persons telling the story. Each display shows how the event is powered by the vernacular re-telling of it not only orally, but also through the stereotyped newspaper articles that were written about it. While the town is conflicted on the representations of its citizens, seen from all three sites of public memory, the articles are still used to depict the history of the shootout. In addition, the 
emphasis on Sidna Allen in the Mount Airy Museum demonstrates how each museum chooses who to focus on in their displays. With the gradual uptake of technology, such as the Friends of the J. Sidna Allen House Facebook group, these places of public memory will continue to evolve to become even more vernacularly-based instead of government sanctioned. Rita Edlein's photographs of the house and also the performance of Levering's plays in the old courthouse demonstrate how these spaces are now used differently than merely a place to memorialize the events that took place there. They now function as places where art is created. These new uses of these places will only add to the continuation of the re-telling of the story of the shootout; a story that, like these museums, is vernacularly official. 


\section{CHAPTER FOUR:}

\section{FEMININE SILENCE AND ACTION: THE GENDERING OF THE COURTHOUSE} SHOOTOUT IN PUBLIC MEMORY

As I sat in the Historic Sidna Allen House listening to Stu Shenk ${ }^{18}$ tell the story of the shootout, Kay Cox interrupted frequently. She was adamant about telling Betty Allen's side of the story. While I and the other couple sat around the table, she told us how Betty was there at the house the night before the shootout when Floyd stayed with Sidna. Betty had stayed at the house with their two daughters when the shootout happened. She fought the law against the attachment of the house to the trial, but ultimately lost the house after only living there for 11 months. She had to move "in town" to make a living doing laundry and cleaning house for the citizens of Hillsville, many of whom hated her husband for his role in the shootout, including Clerk of Court, Dexter Goad, who became a small town celebrity after the shootout.

Betty's example demonstrates that when all the men were either incarcerated or killed after the shootout, the women themselves had to pick up the pieces of their broken families and continue living. In contrast to Kay, they explicitly did not want to talk about the shootout after it happened, understandably as it was a traumatic event that ripped their families apart. Instead, they continued living, picking up the pieces and forging a life with their families. Despite the reality of their situations, these women's stories worked

\footnotetext{
${ }^{18}$ Stu Scenk played Sidna Allen and Kay Cox played Betty Allen in Thunder in the Hills.
} 
against the masculine violence that the terministic screens display. These women all had direct involvement during and after the shootout; in fact, they took rhetorical actions of their own to impact aspects of the shootout, such as Francis Allen writing a column in the newspaper to ask for money for representation for Floyd and Claude; Betty Allen providing an older picture of Sidna to slow the Baldwin Felts Agency search and writing to her husband in prison; and Jezebel Goad who later wrote to a television station that she could not speak out about her role in the shootout (because she didn't have any); and Maude Iroler who wrote to Wesley Edwards after he escaped to Iowa, which could have led the Baldwin/Felts Agency to capture Sidna and Wesley Edwards. ${ }^{19}$ In all of these women's stories, however, they invoke silence about the shootout. They create a new terministic screen of resilient mountain women who invoke silence.

Another screen is seen in more recent depictions of women playing powerful roles in the narrative of the shootout as well. As mentioned in Chapter Two, Frank Levering constructs the women in his play as pivotal characters. Both Betty and Francis Allen have powerful speaking roles that contribute to the sense of morality and sympathy of the shootout and its victims. Another construction of the shootout is by Betty W. Chandler, Sidna Allen's granddaughter, as she republishes her grandfather's memoirs with her own narrative of the shootout at the end. Both of these examples create a modern terministic screen that recovers these women's voices through memories of the shootout. Betty writes herself into the history of the shootout as opposed to Levering including the voices

\footnotetext{
${ }^{19}$ I will not be writing about Betty Ayers who died in the shootout. While her identity is often an afterthought to the all-male government officials who died, I want this chapter to focus on the rhetorical actions of the women who may not have been explicitly involved in the shootout.
} 
of the women as main characters in his play; they both are changing the narrative to include pivotal women's voices.

Unlike the medal and letter to Jezebel, the actions of these women rarely are documented in the museums or sites of public memory. Rather they are hidden within special collections or in bylines of newspapers. Historically speaking, Appalachian women's voices are silenced throughout the development of Appalachian Studies. In Sandra L. Ballard and Patricia L. Hudson's pivotal collection, Listen Here: Women Writing in Appalachia (2003), they note that

the absence of Appalachian women's voices in American literature though lamentable, is understandable when we realize that much of the work of these writers has remained uncollected or is no longer in print. The inaccessibility of much of the best Appalachian literature means that students from Appalachia who study American literature rarely find their "place" depicted in textbooks. Why they can see the relevance of literature set in other places, it is easy for them to come to the conclusion that writes come from other places. (2)

The silence that we see in the above quotation from Appalachian women writers can absolutely be compared to the silence that we see in the research of the Hillsville women. While the "uncollected" or out of print works are just now being archived and anthologized the voices of the Appalachian women are just now being recognized and spoken about. However, there seems to be power in their silences as they are powerful in the domestic sphere: 
Unlike Carl Sandburg and Ernest Hemingway whose wives brought them breakfast on a tray and set it outside the door so as not to disturb them, most of these writers have had no such emotional or physical 'elbow room' in which to create. Yet this anthology makes it impossible to deny their creativity $(3)^{20}$

The " "elbow room"” is indeed vacant from the lives of the Hillsville women as they did not have the time to rest, but had to continue onward with their lives. They found power and voice in the rhetorical acts that they enabled. Much like the women in Katrina Powell's work on the Shenandoah National Park these women's writings are "examples of the mountain families' knowledge of the kind of values privileged by those in power" (11). When the Allen women do speak, which is rarely, they do "construct identities that they believe will be persuasive to those in power so that they might obtain materials or gain access to certain privileges" (ibid). They realize their identities as mountaineers, women, and wives and mothers of convicted criminals.

These written artifacts they produced formed a new "lower-case- $a$ archive" that provides an alternative telling of the story (Glenn and Enoch17). As these voices are being recognized in popular recreations of the shootout a new archive is being created, a narrative that comes from gendering the telling of the shootout. These women's actions interrupt the masculine telling of the shootout. These stories create a new history of the shootout as Glenn and Enoch articulate in "Invigorating Historiographic Practices:

\footnotetext{
${ }^{20}$ For a historical account of women's roles during the late nineteenth to early twentieth century see Johnson, Nan. "Reigning in the Court of Silence: Women and Rhetorical Space in Postbellum America." Philosophy and Rhetoric 33.3 (2000): 241-242.
} 
As we engaged in this process, we soon realized that this relationship between archival reading and theoretical grounding creates a generative tension that opens up possibilities for what we see, value, and then leverage... feminist theory enabled us (and many others) to resist traditional histories and historiographic practices at the same time that we were creating new kinds of historical inquiry and archival reading practices. (22)

This "possibility" that they write about here indeed happens with the shootout. These new terministic screens of the resilient mountain women and the recovered women's voices provide ways for these voices to be heard. Their tensions and travails during the shootout become apparent. They are no longer in the background of the chaos, but are brought forward and given action.

Even though these women's rhetorical actions were supposed to be limited, these actions after the shootout still stand as terministic screens that should be acknowledged more in the vernacular and official history of the shootout. The women involved in the shootout write to attempt to save the lives of their husbands and sons (Francis and Betty Allen), correct errors (Jezebel Goad), or even possibly lead to the capture of their loved ones (Maude Irolar). The recovering of these women's voices in their writing allows for us a different re-telling and remembering of the shootout. One that involves men, but that also involves women and the integral imagined and real roles that they played during and after the shootout. ${ }^{21}$ Sadly, only Francis's note to the Galax Post Herald and Jezebel's

${ }^{21}$ It's also worth noting here that while researching these women, their names do not come up in searching on Pro Quest nor are they included in the New York Times index further demonstrating how their stories are ignored or simply not told. 
letter to the television are the two actual voices that we hear. Betty and Maude's rhetorical acts are reported indirectly by outsiders; however, these are still recorded and still stand as powerful contributions. ${ }^{22}$ Through Levering's plays, however, we do get fictional constructions of their voices. By acknowledging the women's voices and roles, these two new terministic screens demonstrate how the women's stories are made legitimate and important in the shootout. Their stories give us another view of the shootout; one that depicts the realism of the consequences of the shootout, sympathy for the family members, and how they were to be perceived in the re-telling of the shootout.

\section{"In Defense of My Husband and My Boy": Francis Allen}

Francis Allen was most directly affected by the shootout by losing both her husband and her son. She was an orphan when Floyd met her. They lost their first child from fever at age 5, then had Floyd, then Claude who she "doted over" (Puckett, Centennial Talk). As mentioned earlier, after Claude went to business school in Raleigh, NC, he returned home to help his parents with the farm. During the shootout, Francis was 54 years old, but she appears much older in newspaper photographs.

During the trial and afterward, the portrayals of Francis Allen contain words that depict her as weak and mournful. Francis is known to the be "woman of woe" and the "lady in black" after the deaths of her husband and son. Throughout the trials, Francis "sat without saying anything and that tears would roll down her face" (Centennial talk).

\footnotetext{
${ }^{22}$ I have made a genuine effort here to allow the women to speak for themselves as much as possible. In fact, for much of the research done on this chapter I rely on Shelby Puckett's presentation titled "Aftermath of the Courthouse Tragedy" that she presented at the Centennial Symposium in Hillsville, VA. There are places, however, where I have had to rely on male-written speculation, such as newspapers and non-fiction writing, such as J. Sidna Allen's memoirs to construct my argument that these women's rhetorical actions were integral after the shootout.
} 
She visited the men frequently in jail, always appearing sickly or weak. Floyd's own words demonstrate that his wife was indeed sick. Floyd writes in his final statement in prison that "This trouble, of course, is awfully hard on my wife. No man has ever had a better wife than I have. Her health has been bad and she has not been well for some time, and I know that her suffering is something awful" (Allen Statement 31). He is rumored to have gotten emotional in the jail when talking about how hard Francis' life was and how the trial has affected her. Francis was not allowed to attend the execution of the two men. At the funeral, Francis held Claude's body at the grave and wept. She is reported to not have even looked at Floyd's casket. After the shootout, she moved with Victor to New Jersey where they both lived until her death in 1944. She was known as a bitter woman who seldom spoke, but as Puckett notes in her talk, how could she be blamed for being bitter because of all the trauma that she had gone through during the trials and deaths of her children and husband.

Despite these depictions, Francis plays a large role in the advocacy of her husband and son in jail. Through writing a card to the Galax Post Herald on October 19, 1912 she articulates that her family wanted to pay for the trials of her son and husband. ${ }^{23}$ This type of self-reliance is typical of the mountain family as they do not seek help from outside sources; however, in the letter we do see her turning to the public after the family barn catches fire. The fire was more than likely caused by arson as tools were found stacked in a pile after the fire was put out. In addition, her thanking of the public echoes Floyd's own thanking of the folks who wrote in the papers: "I thank the Journal for the fight that

${ }^{23}$ Puckett states that in mid-December The Richmond Evening Journal had begun funds to help Claude. This fund could have been attributed from Francis's letter to the Galax Post Herald. 
they have made to save our lives. I also want to thank the papers in the State who have helped us and who have tried to give the true facts to the people of this and other States" (Allen Statement 31-32). Their acknowledgement of the papers demonstrates the critical impact that these publications had on the trials of these two men. Because Francis's voice is one of two that we actually hear it is important to include here in its totality to hear her powerful and sympatheitic voice:

To the public

The members of my family and our attorney have received many letters from persons offering to start public subscriptions to aid me in carry on the defense of my husband Floyd Allen and my son Claude Allen. We have refused these offers as we wanted to pay the expenses of these trials ourselves as long as we had anything to pay with. My husband and my two sons have gone through long and costly trials all summer that have taken all that we could raise on our home and during last summer our barn was burned without insurance while I was at Claude's trial in Wythville and with it almost all the feed and farm machinery on the place. So that I have nothing to pay any further now. My husband and my boy are under death sentence and the appeals which our lawyers are preparing are expensive and we need money now because we have only a little over a month. If the people who have made these kind offers still want to help us anything they can collect and will send to me at Mount Airy, North Carolina will be used in the defense of my husband and my boy. I thank 
the many people who have written to me and have told me of their sympathy and their offers of help.

Mrs. Francis Allen (as dictated by Puckett, Centennial speech)

The pardons that the public wrote for Claude more than likely inspired her to write this public outcry as this is published right when the petitions start to appear in the public to pardon Claude. Francis contributes to the resilient mountain women screen by refusing to accept help. She wants to remain silent, but for her family's own well-being she cannot. Now functioning as the matriarch of the family she must go to the public for help. She constructs a story of her husband and son not as murders, but as two men who should be pardoned. She comes to us as wife and mother pleading for our help; however, she is

also trying to provide sympathy for herself. She has lost everything she owns and is about to lose her husband and son to the judicial system. She positions herself as the victim of her circumstances here. While she played the role of devoted wife and loving mother at the trials of Claude and Floyd, someone took advantage of her and burned her livelihood. If her audience for this letter sympathizes with Claude and Floyd then that's ok as long as she is able to get money to survive for herself.

“This noble, courageous woman": Betty Allen

Betty Allen, the wife of J. Sidna Allen, continues the terministic screen of the resilient mountain woman. The media fabricates her involvement in the shootout as masculine violence when, in fact, it was her role as a woman to steer the detectives away from her husband and to provide care for him while he served time.

Betty economically lost the most because she and Sidna's house was attached to the trial and lost after the shootout. She moved into town and did laundry and cleaning 
for the townspeople to provide for their daughters. The first winter in Hillsville was particularly cold and there are reports that they suffered greatly during this time (Cox interview). However, one of the first times we see Betty Allen active in the shootout is her fictional death in the newspapers. On March 16, 1912, an article titled "Two More Dead in Allen Feud" in the New York Times notes, "in a battle in which she was assisting her husband to resist arrest, the wife of Sidna Allen was instantly killed" and that Sidna Allen was "believed to be dying as the result of the wound received in yesterday's fray" (1). The reporter completely fabricates a gunfight that happened at Sidna Allen's Victorian home, where his wife is killed trying to help him. ${ }^{24}$ It's worth noting that this is one of the few times that witness Betty Ayers is mentioned as well as the emphasis of the memorization in the articles circulates mostly around the men serving their civic duty in the courthouse that day. However, in this depiction of Betty Allen, we are shown that she participates in the masculine violence of the shootout as she is "assisting her husband." She is constructed as violent and, like the other victims of the shootout, falls victim to that violence. While these descriptions are clearly not true, Betty did, in fact, intentionally help her husband as he fled to Iowa.

When the Baldwin Felts Agency came to her to get a picture of her husband, she gave them an old picture presented below (Sidna is top right):

\footnotetext{
${ }^{24}$ Sidna also describes this same fictional shootout in his memoir, but instead of referring to the newspaper articles he remarks that the standoff at his house is written in a book.
} 


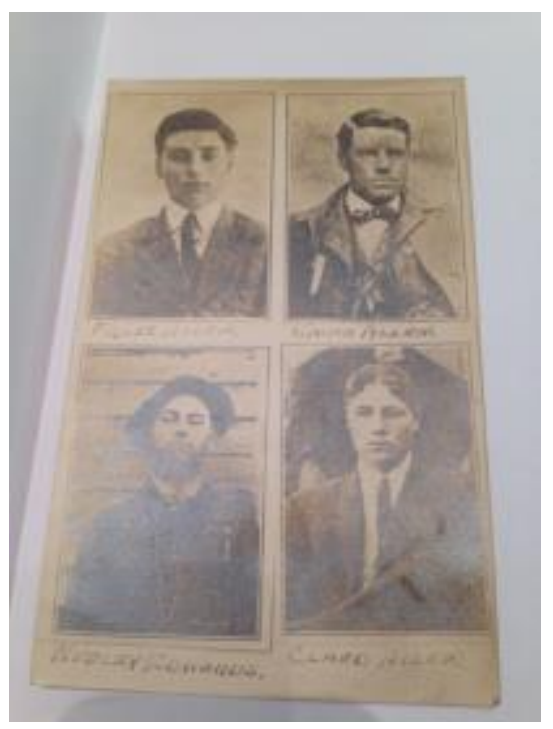

Figure 13 Photograph from Floyd Landreth Papers, Library of Virginia, folder 8 This photograph depicts Sidna as substantially younger than he was in 1913. During the time of the shootout, he wore circular glasses and parted his hair down the middle of his head. By misrepresenting Sidna, she bided time for her husband and her nephew as they escaped to Iowa. This simple act allowed them for more time to get settled. The picture is run in all the newspapers that depict Sidna as the ringleader of the Allen men. Betty's manipulation of the detectives is clearly not as active as her role in the fictional shootout; however, I would argue that it is just as important as she did slow the men down in finding her husband.

While we don't see Betty writing to the newspapers for money or representation, she does maintain writing to her husband in jail. This may seem like a simple task; however, it helped Sidna to keep hope. He writes,

during the first year I was in prison my wife wrote me fifty-one letters and one post card, an average of one missive a week. The week she sent a card she was too ill to write a letter. During all of the time I was in prison she wrote me regularly. Her letters, always cheery and optimistic, heartened 
me wonderfully. She also had my daughters to write me occasionally. All letters that came from my wife or others were opened and read by prison officials. (141)

While these letters may not exist today, at the time they served as Sidna's lifeline to the outside world. While in jail, Sidna is bound to have thought his fate similar to his brother, Floyd and his nephew, Claude. These letters brought him hope and more than likely mentioned the numerous petitions that were coming in for the pardons of him and Wesley Edwards.

Betty's rhetorical actions are further illustrated in Sidna's memoirs as the only picture he includes of her is sitting in a chair reading a paper. Located next to a picture of him that states "J. Sidna Allen and some of his art work," Betty's “work" could be literacy as she is concentrating on the paper in front of her. She looks stately in a white dress, legs crossed, reading the paper. While she isn't a gun slinger rendering masculinity, ${ }^{25}$ Betty is portrayed as a letter-writer and reader. Like Francis, she takes rhetorical agency in giving the detectives the wrong picture of Sidna; however, she is still able to retain her composure as a domestic, literate woman. She does not evoke the level of pity or desperation that Francis provokes, but, historically, she suffered just as much.

\footnotetext{
${ }^{25}$ Neither is Sidna depicted as violent as he sits stately at his table as the rehabilitated wood worker that appears in the sites of public memory.
} 

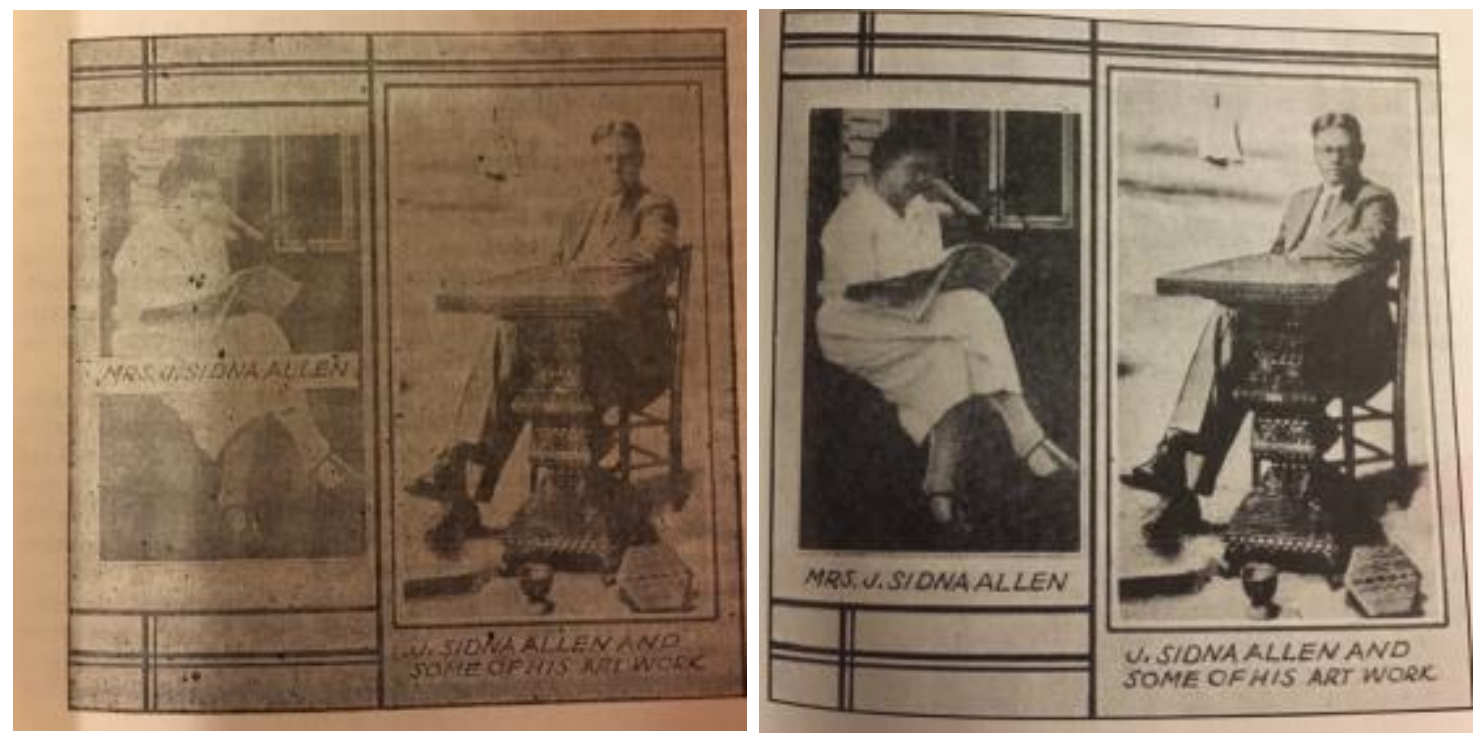

Figures 14 and 15

Picture on left is included in the original monograph of Sidna's memoirs, the second is included in the reprint by his granddaughter, Betsy W. Chandler

\section{“I Do Not Wish to Comply": Jezebel Goad}

Similar to Betty's fictional shootout, Jezebel Goad's role in the shootout develops from a fictional story about her. It is her response to this story and also to a future interview about the shootout where she refuses to speak about the shootout, engaging with the resilient mountain women terministic screen.

Ronald W. Hall reports that Jezebel was 17 at the time of the shootout and was in her father's office. She only "ran to her father and beseeched him to stay inside" during the shootout (W. Hall 95). Her father, however, ran back out and fired at the Allens. Despite her brief interaction in the shootout, Jezebel becomes infamous in the papers for helping her father load his guns, a claim that is totally fabricated and written for dramatic 
emphasis in at least two newspaper articles. This need to make her a female hero relies in the early depictions of the Allen men as villains in the initial media constructions of the shootout. Unlike Betty who becomes a victim of the violence, Jezebel becomes a hero for defending her father and falling on the side of justice. She, like Betty Allen, is given more agency to act in non-feminine ways as she helps defend against the Allen men. The question as to why this fictional experience exists is one worth exploring. Why should we herald Jezebel as a folk hero who helps her father? Could it be that her role asserts that women were indeed a part of the shootout? Does this story render us one that sides with the local government side? Do we read Jezebel as the antithesis of Claude as mentioned earlier? Despite whether Jezebel was truly at the courthouse or not really isn't important. What is important is the fictional character of Jezebel. Like the fictional Betty at the Victorian Home, the media (and rumors) conflate her with the masculine violence that happens with the shootout. While she is still helping her father, she is taken out of the home and given an action in the retelling of the story of the shootout. Her appearance in the news gives us a new story that builds upon the feminine contributions towards the shootout; a feminine contribution that is often lost to more popular male-oriented depictions of the shootout. To take apart this constructed memory, we need to first look at the assembly of this fictional event and then notice how Jezebel, much like Francis and Betty, reacts with intentional silence about the shootout.

In response to this coverage by the paper, the governor sends Jezebel a letter as well as a medal inscribed with "Tribute of Honor... for Heroic Courage in Defense of Justice, Hillsville, VA March 14, 1912” and “A Brave and Devoted Daughter." This medal is created by his wife, Etta Donnan Mann. In her memoir, Four Years in the 
Governor's Mansion, she writes "His daughter, the Deputy-Clerk, evinced the greatest bravery, assisting her father and handing him more ammunition when all of his was gone" (99). In her official role as Deputy-Clerk, Jezebel was helping to defend the state with her father. This family affair could also be easily compared to Floyd and Claude whereas both children were attempted to defend their fathers' lives during the chaos of the shootout. Both children are given medals; however, Jezebel is written up and praised by the governor's wife and Claude is given the electric chair.

Mrs. Mann's letter describes Jezebel's actions as masculine:

We have the right to expect bravery from our men, but it is rare for a young lady, under such trying circumstances, to exhibit such devotion and heroism. I am very proud of you and know that the people of the county, which produces such men as your father and such daughters as yourself, can be relied on too, to vindicate the law. I have confidence in the good people of Carroll and the highest respect and regards for yourself.

Through these statements, the Governor's wife notes that the men are "brave," but that that type of behavior is not expected from the women of Hillsville (however, we do see this "behavior" enacted by the fictional Betty at her home). While her story is a fascinating aspect to the story of the shootout, the only presentation of her is through paper and oral storytelling. She remains nebulous in the visitors of the museum as well as in the telling of the tale. Her embodiment as a female is left to the imaginary and is not represented in the physical unlike her father who looms above with his law degree to his right. 
Despite Mann's letters and medal, Jezebel did not help her father reload his pistol. In the trial of Floyd on Friday, May 3, 1912 that started at 9:30 AM Dexter Goad is questioned by Judge N.H. Hairston for the defense:

Q: You say your daughter came in there. Did she bring you a pistol?

A: No sir, she did not.

Q: So the publication was a mistake?

A: Yes sir, the publication was a mistake

However, as Bill Lord notes "In later years, however, he often remarked, yes, Jezebel did give him a gun, 'and it worked like a charm' (Personal communication, Glenn Jackson of Jackson's Family Shoe Store, Hillsville 1995 qtd in Lord 107). There are still rumors that Jezebel contributed to the shootout as seen on the Library of Virginia's website: http://www.virginiamemory.com/blogs/fit-to-print/tag/jezebel-goad/. Again, her actual appearance at the shootout is insignificant, but the real interest is the desire for the media and public memory to create her as a folk hero who helped her father.

In contrast to the fictional Jezebel's feminine action, we actually see the "real" Jezebel Goad asserting real action in her defiance to participate in the retelling of the shootout. In 1965, Don Murray, the news director at WDBJ Television out of Roanoke, VA, wanted to do a segment that showcased the shootout. Murray asked Senator Floyd Landreth, who was the special prosecutor in the trials, to ask Jezebel if she would like to be included in the program. Jezebel's response to Landreth is terse, short, and shows exactly how she did not want to talk about the shootout:

Hillsville, Virginia May $3^{\text {rd }}, 1965$ 
Dear Floyd: I have your letter of April $30^{\text {th }}$ in regard to the WDBJ Television Program relating to the Allen Tragedy. I am sorry but I do not wish to comply with your request as it would be very distasteful to me. It is a subject that I have tried to forget and which I never discuss with anyone. Anyway, I have forgotten so many of the details that it would not be of any interest to the public except those of morbid curiosity. Therefore, I do not wish to discuss, reminisce, nor rehearse the affair for public consumption. I am sorry. With my best wishes to you, Sincerely yours, Jezebel Goad. (“Jezebel Goad Letter”)

This letter shows that she does not want to talk about the shootout here and is explicit in detailing those who do as having a "morbid curiosity." Although this letter is terse, Jezebel insistence on silence is important in her retelling of the story. The idea of silence is explored by Cheryl Glenn in Unspoken: A Rhetoric of Silence that the most important use of silence is for users to "fulfill their rhetorical purpose, whether it is to maintain their position of power or resist the domination of others" (23). We can see that in Jezebel's case, her rhetorical purpose assumes a female role—polite and tasteful—and rejects the gun-loading heroine role that the press gave her. Unlike Betty or Francis, who do not articulate their silence surrounding the event, Jezebel finds it "distasteful" to talk about. Glenn presents the reasoning behind why Jezebel would remain silent when she writes: The power of language itself, however, can yield silence in cases where words and actions are used to impose silence on someone else or to suggest silence as the best tact for someone else. Thus, those who embrace silence in these situations do so for psychological and intentional 
purposes. That person must remain silent or be hurt in some way, some emotional, intellectual, physical, or professional way. The silencer dominates the silenced, once again gendering the conditions of speaking and silence. (Glenn 41)

The act of speculation by the media on Jezebel, the "gendering" by the Governor and his wife, and the traumatic event itself are more than likely the reasons that Jezebel remains intentionally silent. Her refusal to "discuss, reminisce, nor rehearse the affair for public consumption" demonstrates how she does not want to revisit the shootout. By refusing to participate in the "public consumption" of the shootout, Jezebel retains control over her narrative of the shootout. Her silence demonstrates that she is the one who knows the "true" story of what happened. Her notions that she has "tried to forget" the shootout, but also has "forgotten many of the details" demonstrates that she still remembers the trauma suffered there, but retains the right to talk about it; her deliberate silence acts as a powerful rhetorical action.

\section{"The Innocent Cause of the Arrest": Maude Iroler}

The last woman who adds to the resilent mountain woman terministic screen is Wesley Edward's girlfriend, Maude Iroler. While Francis, Betty, and Jezebel serve as minor characters in the retelling of the shootout, Maude is a major player. She led the Baldwin/Felts agency to Iowa leading to the capture of Sidna and Wesley and the ending of the coverage of the event. Through looking at her story and role in the shootout, we notice that the ending of the shootout hinges on the creation of Maude as an innocent informant. This contributes to the terministic screen by giving voice to these silenced women voices and starting to encourage talk about the shootout. 
Maude's boyfriend, Wesley, was one of the two boys who fought in Garland Allen's church that started the trial with Floyd Allen. Immediately after the shootout, Wesley fled to Des Moines, Iowa with J. Sidna Allen to start a new life. During this time, Wesley did keep in touch with Maude through letters and even a secret visit to Hillsville. During the visit he exchanged money with Maude to ensure her passage and their marriage out west. Maude's father found out about the money and supposedly made a deal with the Baldwin/Felts detective agency to follow her out there. The retelling of Maude's story and the capture of Wesley and Sidna signify how the retelling of the story of the shootout must include Maude.

Seen in his memoirs Sidna's accounts demonstrate that he was none too pleased with Maude. He writes, "For a few hundred dollars she had betrayed both me and the man she promised to marry" (81). He continues with

He would talk very little to me about her. He knew what I thought about the whole matter. I felt sure she had betrayed us to the detectives. They say love is blind, so I suppose that accounted for his faith in her. I was informed by the detectives that she sold Wesley for five hundred dollars. Soon after her return to Virginia, she married another man. (83) He does say that he was excited to end his life of lies and be back with his wife and children, but we do see his bitterness over his capture. Maude's intervention in their capturing meant that he finally had to face justice for his role in the shootout.

While Sidna is clearly adamant that Maude led to their capture, the media portrays Maude as mostly innocent. The New York Times on September 15, 1912 reports that "Wesley Edwards's sweetheart, Maude Iroler of Mount Airy, N.C., was the innocent 
cause of the arrest of the last of the clan for whom a country-wide search has been conducted." The article continues with "Little thinking that dogging her trail were four detectives" and how she was the "innocent cause of the betrayal of the whereabouts of Allen and Edwards, took their capture nonchalantly" ("Catch Sidna Allen by Trailing Girl”). “Allen Explains Shootout" on September 16 ${ }^{\text {th }}$, continues to show that Maude "unconsciously gave the police the clue to their hiding place" but that she and Wesley "stoutly denied that the girl had deliberately betrayed Edwards. Detective Baldwin corroborated their statements. He said that when Edwards left Mount Airy, N.C., the girl's home, he had left $\$ 50$ with her to be used to join him when he was safely secreted. The money was stolen and then replaced, and in this manner Miss Iroler's father learned of it" (ibid).

The earlier article gives an impression of Maude as a headstrong young woman. As she is "the daughter of Frank Iroler. She lived with her parents and has known the Allens, she says, since she was old enough to remember anything." Maude's voice is included in the article as well as she states "'I just kind of got tired of staying at home. When Wesley was back there a short while ago he told me that I must come some time during this month.'” When asked if he visited his home she replied “'Why, yes, he was,' she replied firmly. 'I have known him longer than you, and it was then that we arranged that I was to come to Des Moines." (ibid). Maude's expedition out west, then, was to get out of Hillsville and to start a life of her own with Wesley. Her bravery and determination are to be noted as she traveled out west by herself to meet up with Wesley.

After the shootout, Maude had a successful life as she married Ken Marsh shortly after the trials of Sidna and Wesley. Much like the other women, she didn't talk much 
about the event; however, according to Ron W. Hall, she did agree to an interview (which wasn't recorded) with Ruth Minick where Maude “admitted going to Des Moines with the detectives at her father's direction, putting to rest the years of rumors and theories about her part in the capture of the fugitives. She died September 19 ${ }^{\text {th }}, 1972$ ” (258).

After Sidna, the media, and Maude's supposed interview with Minick, her innocence in leading to the capture of the Allen men is questionable. Whether she was in cahoots with the Baldwin/Felts Agency is really irrelevant; rather, the issue is that she is included in every telling of the capture of the men. By constructing her as an innocent participant, Maude signifies the ending of the male-dominated, violence-rendering event. Much like Francis's refusal to talk, Betty's carrying on with her livelihood, and Jezebel's silence, Maude's intervention in the event leads to not only the capturing of the men, but also normalcy back to the mountain community. However, if the media constructs Maude as innocent, the possibility that Maude really could have schemed to arrest the two men is lost. This action would turn the depiction of her as lovelorn on its head and depict her as a smart woman who was out to gain money to support herself. If her joining with the detectives is true, then it would depict Maude as rejecting the traditional role of early twentieth century women and taking an active role in the shootout.

\section{Contemporary Uptakes of Feminist Voices:}

\section{"What Could Francis Allen Do?": Constructions of Survival in the women characters in Thunder in the Hills}

While these archival examples serve as instances of how women's voices impact the retelling of the shootout immediately during and after the shootout, the fictional representations in Levering's plays of the women and also Betty W. Chandler's re- 
printing of J. Sidna Allen's memoir stand as two more recent rhetorical acts that demonstrate how women are still being inserted into the shootout's narrative. These representations are more contemporary than the archival materials. Glenn and Enoch's ideas that we need to "resist traditional histories and historiographic practices at the same time that we were creating new kinds of historical inquiry and archival reading practices" plays well with the earlier archival material (22). The artifacts need to be discovered in closed collections or in microfiche whereas the more contemporary depictions are found in artistic forms. These narratives of the women bring them out of the silence in which they historically have placed themselves and gives them voice creating a modern terministic screen that involves these recovered women's voices. Making Francis Allen and Betty Allen main characters in Thunder in the Hills, Levering asserts that their stories are not only valuable, but important in the retelling of the shootout. In addition, Sidna's granddaughter Bettie W. Chandler demands that her own side of the story be told. Like the vernacular stories told in the museum, she claims her own retelling of the shootout to reveal her grandfather in her own way. All of these recent depictions push women to the forefront of the retelling of the shootout; their voices give a new perspective on the tragedy.

While Jezebel and Maude are not included in Levering's plays, he does include many of the Hillsville women: Betty Ayers, Lewis Webb's wife, Claude's girlfriend, Nellie, and Alverta Edwards. ${ }^{26}$ The two most dominant voices though are those of Francis and Betty Allen. Both of these women change the all-male narrative as Levering

\footnotetext{
${ }^{26}$ The omission of Jezebel and Maude leads some citizens to claim that the plays are more Allen-sided than the local government.
} 
depicts them as strong influences on the men. Much like their namesakes, the women in the play are feisty, articulate, and empowered.

The spirited character of Betty, played by Kay Cox, is first introduced on the night before the shootout. Playing the foil of Francis Allen, Betty is full of zest and is willing to give her opinion. Her character is sexual with lines like: "Sidna hasn't thawed out yet...when I kiss him, his lips are still cold from being out west" and "Your brother loves his house more than the bedroom and me in the bed" (Levering). However, it's her calling out of the men that makes Betty's character important to the retelling of the tale. She tells Floyd on the night before the shootout "You drag Sidna into this and I'll pull a gun on you myself' (ibid). This initial conversation with Betty is important because it sets her character as prominent. While Francis is depicted as often weak and unhealthy, Betty is portray as headstrong and not afraid to tell her truth; a truth that was mostly unheard before these plays were written and performed.

Furthermore, Levering writes in Betty's actual rhetorical actions as described earlier. Betty states that she gave the detectives a fake picture that "looked more like Billy the Kid than Sidna Allen" (ibid). As mentioned before, this act is powerful because it demonstrates that Betty misguided the detectives. Her reference to "Billy the Kid" also demonstrates the comparison to the outlaws of the wild west mentioned in the media portrayals of the event in Chapter One. In the same scene she also mentions the newspaper article that said she was killed: "They said that Sidna's wife was killed in that battle. Well, I reckon they got me" (ibid). The mentioning of this article by Betty is particularly important because 1) it shows that she uses sarcasm to depict the complete and utter misguidance of the newspapers and 2) by talking about her own death she 
evokes laugther from the audience. Knowing she did not die in the shootout (and most of them knowing about the shootout), the audience roared with laugther at Kay's portrayal of this line; it was one of the biggest laughs in the play (and Kay will tell you that herself). The scene suddenly goes from funny to sad as Betty states that Sidna "did the right thing" by fleeing out west as she notes that "that would be the last chair you ever sat in" (ibid). In a moment of clarity, and somewhat surprising to audience members, Betty mentions to Dexter Goad that it was "all our fault there's no one else to blame" (ibid). This statement denotes blame to the Allen side of the shootout. Through her dialogue, Levering gives Betty voice. She is not the solemn, mournful Francis, but rather a woman who isn't afraid to speak to men. She's not afraid to be sarcastic or to make jokes about the coverage of the shootout. Her deadpan honesty reveals that Levering wants audiences to remember her as a strong willed woman who had a hard life, but was still able to survive despite her troubles.

What's missing here with Betty is the tie between her and Francis. While we do see Betty out in the street defending her husband and her family we do not have a scene of her with Francis at all. She mentions to Nancy Webb (Sheriff Webb's wife) that she told Francis that "there weren't no pain" to the electric chair, but we do not get a scene of the two women together. Instead, the last scene we get with Betty is her and Sidna stating that they will "make a life together. No, not in Hillsville" (ibid). This missing visit between the two women could signify that Levering did not want these two scene presences together. In reality, the two women were dealing with the shootout in different ways, Betty stayed in Hillsville and took in housework for folks, while Victor, Francis's son, took care of her. 
As noted in the previous chapter, the appearance of Francis's voice in the play serves as a rhetorical act. Besides her article cited earlier, Francis was mostly quiet for most of the shootout. Depictions of her weeping in the courthouse at Floyd and Claude's trial and her dressing as the "woman in woe" dominate most media coverage. Through this character, Levering brings her to life. While she is not as plucky as Betty, Francis's character presents us with a rationale of how the story is told from her sympathetic point of view. Her retelling indeed conveys the sadness, despair, and sense of tragedy that was felt by numerous family members after the shootout. She gives us a perspective of the shootout that incorporates our morose speculation. She evokes pity and sympathy for the families that were left behind. Unlike Betty, Francis was unable to put back together her family and leaned heavily on her son, Victor for support. Reading the beginning of Francis's speech, her comments right before the shootout, and then her final statements demonstrate feelings of morality and sympathy for those involved. She demonstrates a compassion for the victims of the shootout.

As mentioned in the previous chapter, Francis starts with an invocation to the audience by stating: "what do you want from me now...once aint enough for you..greedy for guns and blood...you want to see folks shot, dead. That's what you're here for trouble" (Levering). Levering's choice at starting the play with Francis's voice is important because she automatically hits us with guilt for wanting to see the traumatic incident (re)played out in the courthouse where it took place. She is given the starting point for the shootout. She acts as storyteller and also moralizes and sympathsizes the shootout from the very first moments of the play. Her anger and sadness is palpable in Terri Ingalls's portrayal of Francis. She reminds us that, as eyewitnesses to the play, we 
can judge for ourselves "Cause YOU are the jury" (ibid). This act is particularly powerful because 1) as seen in earlier archival material Francis is silent through the trials and 2) this is a woman presenting the tale to us, which has not occurred yet in all the retellings of the story of the shootout.

In the scene right before the shootout, we have a narrative jump in the play that is mostly told by Francis Allen. Even though this scene takes place the night before the shootout, Francis has visions of those killed in the shootout as they come to visit her as she is by herself at her home when Floyd stayed that rainy night with Sidna. These visions are fascinating because they foretell the shootout before it happens, but also because they happen to Francis and not her husband or son who were in the courthouse during the shootout. ${ }^{27}$ Levering gives Francis this dialogue and these visions to demonstrate how emotionally distraught the shootout made her. Her silence no longer happens and she is able to articulate the trauma that she suffered. She feels responsible for the violence that her son and father caused. She is rendered useless though.

In her visions, Francis refers to herself in the third person: "wind and rain like Noah's flood arising. What could Francis Allen do? Old before her time because it's gone back so fast. Death coming quick" (ibid). We see here that she already feels disconnected from the reality of the shootout. Her abrupt neurosis demonstrates the extreme trauma that she will endure in the next few days. Audience members watch as Betty Ayers comes to visit Francis from the grave attempting to comfort her in a moment of compassion stating: "What was you going to do with the rest of your life" to which Francis replies: "I

${ }^{27}$ Levering does include a brief emotional breakdown of Floyd right before his electrocution, but it is most certainly not as emotional as Francis's before the performed shootout. 
have lost myself and there's no place for me deep down" (ibid). This exchange demonstrates that Francis has already sunk into a deep depression that she can't even imagine herself dead or to a more Christian read, in hell, perhaps because she's already living it.

In this exchange, however, we do see Francis strike back. When Augustus Fowler visits he, like Betty Ayers, points to where he died. Then he states: "I got nothing against Floyd that we can't settle our accounts down yonder" gesturing that Floyd is in hell (ibid). Francis in her grief and sorrow reacts strongly stating, "I ain’t got no family...you leave this earth. You go farm in hell" (ibid). While this statement would obviously not be received well from the Fowler family, it shows Francis's frustrations and anger over the shootout. She in fact yells back: "Where are the rest of you?! Why won't you speak to me?!" attempting to conjure up the rest of the victims. Through these latter frustrations and visits with the killed, Francis works through her guilt over the killings. Although the redemption is lost on her (where it should have been laid upon those who were actually at the shootout), we can see how these interactions had a profound influence on the way that Levering presents her reactions to the shootout.

After the acting out of the shootout, Francis actually comes back on stage even though she was not there when the event happened. Levering gives her voice again here as she states each person's name that died during the shootout and they leave. Her narration here reveals how Levering is trying to convey a compassionate reenactment of the shootout. Through her voice, the dead are memorialized and remembered solemnly. We cannot hear from the men because they had already fled the shootout. It is only the women that are left to mourn the dead. Francis replies after stating all the names, "And I 
wish you had not thought to come here. And acted like it was something it was you needed to watch" revealing that this is indeed solemn space where trauma took place and that these women were the ones left to decide to tell the tale or not.

As described in the last chapter, Levering gives Francis the last lines of the play (besides the “Gentlemen I Ain’t A-Goin' line by Floyd). Her meaningful lines hinge on her experience throughout the place. She states "this place here where I never come and never will again" resonates strongly as she did not come to the courthouse during the shootout and did not even visit Hillsville after the shootout. It was too traumatic for her. Claude and Floyd's funeral contribute to her trauma as she describes "The awfullest crowd you ever laid eyes on" as being there and how Claude's "coffin was open" (ibid). She "walked past Floyd and I never did, would not look at my husband. When I came to Claude, I cradled my boy. I cradled him in my arms. I cradled my cold baby. He was so cold for the longest time" (ibid). Through these statements we see her grief tied up in her motherhood. She does not look at Floyd because she is concerned with Claude whom she doted over throughout his entire life. Giving her these lines gives us a compassionate look at the shootout and the impact of the loss on her personally. She ends the play with Hear that March wind a-blowin'. Well you all had to come see this again. A-lookin' at us this way. All the things we've done tried to do and tried not to do. So now you all go home tonight, crawl into your beds and have yourself a sweet dream. I hope you all are well satisfied. (ibid)

As mentioned in the earlier chapter, this is another place that invokes the audience; however, it's made even more meaningful that it comes from Francis who has been our moral storyteller throughout the play. Her voice presents us as audience members as 
spectators and gawkers at this traumatic event. She hopes that we're satisfied in investing in the bloody story that left her with no husband or son. We indeed should not leave the play "satisfied," but curious as to what draws us, as spectators, to want to learn more about the shootout and its aftermath.

\section{"A Granddaughter's Legacy Redeemed": Betty W. Chandler's memoirs}

One of the final ways that women's voices are recovered is through Sidna Allen's granddaughter, Betty Chandler, reprinting of his memoirs with her own attached in 1999. Her reclamation of the story of the shootout is to retell it in her terms. Her praising of her grandfather and absolute condemnation of the media renders a new telling. She notes "Through the eyes and heard of this granddaughter, he is best known as 'A Man Among Men' who, with the Lord's help, overcame a heartbreaking tragedy" (155). Betty's retelling of the tragedy depends on religious dogma throughout. We see the traumatic draw as Levering wrote with Francis as Betty writes "The tragedy, five people killed and two electrocuted, is heartbreaking any way one looks at it. This is a terrible happening to everyone involved-shocking and appalling to all" (158). However, she is entirely invested in Sidna's account of the shootout and clearly lays claim to the Allen side noting that she can "promise it is not saturated with 'conjectures' and 'speculations.' He was there." (173). Betty is clearly dependent on Sidna's view point and does not see past her familial bond to her grandfather (nor is she in the wrong for doing so). She was thirteen when he passed away and Sidna and his wife, Betty, lived the winters with their granddaughter and their family up until their deaths. Betty's depictions of Sidna are without fault; he is a rehabilitated, humble man who got caught up in the shootout. It was not his doing. 
What's truly fascinating about Betty's retelling of the story is her total bashing of media portrayals of the shootout. She pays particular attention to the speculation and exploitation of her ancestors writing

All to splash GIGANTIC HEADLINES across a page, hopefully titillating the public's contagious, insatiable appetite for the sensational and supposition. IT'S THE GOSPEL TRUTH! It happened THIS way!! THAT way! ANOTHER way! The truth is that The Truth is too often ignored. (her capitalization, 173-174)

Betty dismantles the media coverage from the event using biblical references. In fact, she particularly degrades The New York Times editorial that contains the educate or exterminate quotation. She calls the writer "poor dear Mr. Educated Editor" and attacks him again using biblical references to diffuse his point; she, in fact, calls them "Scriptural shot[s]" (175). Through critiquing the media, Betty is rewriting her own history of the shootout, a history that may be steeped in religion, but a history that she can claim for her own family. Her recovered memory here is very personal and, as an Allen, she deems herself the person to tell it.

At the ending of Betty's retelling of the shootout, she depends on the deathbed confessional of the Deputy Clerk of the Court, Woodson Quesinberry. She writes that he said he was the one who caused the shootout. She adds her own take to it: "Think of the years poor Mr. Quesinberry shouldered such an awful burden of sin on his conscience: 'He was the culprit who fired the first shot that boomeranged to cause the death of seven people. 'Added to that, by his own words, he went ot the courthouse with deliberate intention of killing Floyd Allen" (189). She immediately revokes the media's claim that 
he could have been paid off or that this deathbed confessional could be faulty. The affidavit rings true and she even includes it in her memoir.

Betty's retelling of this story demonstrates how not only were the men retelling the tale as one-sided, but also the women. Her investment in protecting her grandfather is clear and demonstrates that she will not change her mind nor budge on a different telling of the story. Her allegiance to "Grandpa Allen" creates him as a folk hero and a victim of circumstance. The "COURT FIRED FIRST and the 'mystery' is gone" (192). She continues to state "This happily forever concludes the matter, as far as I'm concerned and don't think I haven't had a ball concluding it. Thanks to the Lord" (192). This resolution and the conception of her grandfather as a rehabilitated, humbled man makes life easier. Her view of the shootout is not like the women mentioned above. She refuses to see the complications and wants to move forward, marking the past and creating her own story.

\section{The Story is Still Yet Told}

These women's experiences with the shootout continue to provide yet another glimpse into how the story is retold through two new terministic screens that speak back to the masculine violence screens the media uses. By studying the archives and the local fictional portrayals of these women, we no longer pay attention to the hillbilly stereotypes that are presented in the media. And, in fact, they become objects of ridicule as the audience during Levering's play laugh at Betty Allen describes her fictional death. Rather these archival and recent depictions, not only give another telling, but open up another way to talk about the shootout. The shootout was hard to talk about directly after the event. The silences that Betty, Francis, and Jezebel articulate provides proof. The trauma that they live through, they simply did not want to bring back up again. These silences; 
however, demonstrate that as the storytellers they chose not to repeat the story. It was too hard.

However, we see now that the silence is broken in the fictional portrayals of these women and in the Betty's memoir. The tremendous loss of these women is recovered and given voice. These recent retellings of the shootout demonstrate that there is a desire to hear from the women now. After listening and participating in the masculine retelling of the story for so long, it is overdue that we now incorporate these voices into a narrative that they had to live with their entire lives. 


\section{CONCLUSION:}

\section{Appalachian Hillsville Remembered}

105 years after the shootout, these rhetorical depictions demonstrate the importance not only in Hillsville, but also in the event's representation of Appalachia. In the newspapers, reporters from outside the region depict Floyd Allen as the quintessential violent mountaineer figure, a precursor to the modern day hillbilly. The media casts him either as a violent mountaineer or a gangster who shoots up the courtroom. However, by Floyd and Claude's trial the media changes its depiction. These men are then "othered" and pitied because they existed culturally outside of the progressive era. Because of these stereotypes, Burkes' terministic screens serve as an appropriate means to set up for future rememberings of the shootout. The performances of the ballads and plays, the museums, and the feminist voices use a combination of these screens or totally break free of them to present their rendering of the shootout. While the media accounts give us stereotypical images from outside the region, artistic performances of the shootout give us insider depictions of the shootout. These performances in the ballads and plays demonstrate the change from the stereotypical to the sympathetic terministic screens. Participating in a historically Appalachian genre, the "Sidna Allen" ballad bifurcates town to the local government side and the Allen family side. The vicious, violent mountaineer presented in this ballad still resonates today in the minds of many citizens. In a recent trip to Hillsville, I found out that some of the tax money from the county was going to the construction of the Historic Sidna Allen House. There was upheaval in the town still because many citizens did not want their hard earned money to go to "that" house. However, “Claude Allen” presents a more sympathetic view of a young man who was 
merely defending his father. After his death his mother and girlfriend weep at his grave signifying Claude as a tragic hero.

105 years after these ballads circulated, Frank Levering's plays add to the realistic trauma felt by those who suffered during the shootout. The plays, performed on the historic site, gathered the community members and ancestors of the event to memorialize the shootout. This epideictic rhetorical history making not only participates in the praising of the past, but also unites the community in a space and place that was once taboo to embody. Levering intentionally writes moments in the play that acknowledge its presence in the historic courthouse. These moments are most certainly epideictic because many of them they ask the audience to stand as the jury on the trial of Floyd Allen. They invite participation and make the audience remember that they are "greedy for guns and blood. You want to see folks shot, dead" (Levering). Through these plays the past is blurred with the present; the players depict the history quite literally as they lay on the floor possibly in the same spot where the characters they play (and possibly their own ancestors) died. Audience members are indeed not, as Francis Allen says at the end of the play, "well satisfied," but perhaps horrified by the depictions of the tragic event rendering the use of the tragic terministic screen. This reemergence of the trauma that was silenced for so long helps for the conversation to be reopened and the community to talk with each other about the tragedy.

These plays would not be as powerful if they did not take place in the historic courthouse. The creation of these spaces of public memory demonstrate the vernacular and official retellings of the shootout. Like the media and artistic portrayals, these places and spaces convey different constructions of the shootout through different terministic screens. The Historic Courthouse Museum conveys a vernacular retelling that creates epideictic history making as the curator Bill Webb talks through the shootout and exhibits. Besides his 
retelling of the story, the exhibits themselves demonstrate a tale that focuses on Sidna Allen's rehabilitation and the buildup to the shootout. It still depends on the outlaw image of the men, but the local exhibits give patrons a more humanistic portrayal of the family. In opposition, the Mount Airy Regional Museum conveys a broader construction of the shootout. It places Hillsville in the context of the Appalachian region, operating as an example of what can happen in a small mountain town during the progressive era. This depiction is official because it is housed inside a government funded museum. Despite the exhibit being less detailed than the other exhibits in the museum, it is still carefully organized to retelling the story of the shootout; however, it, too, depends on stereotypical constructions of the Allens because of its dependence on the newspapers.

While the "story of the century" is logically organized, it is still sensationalized in this exhibit. Outside of both of these constructions is the Harmon Museum. Solely based in vernacular story-making, this museum relies on a smattering of artifacts that Harmon collected. Patrons must spend time walking down the aisles to decipher the construction of the shootout through newspaper articles, framed pictures, and other material artifacts. It depends totally on the images of the violent mountaineer through the use of the newspapers. Clearly, the sheer number of museums about the event in this small town demonstrates that the local citizens believe that this is an event worth remembering in several different ways.

Until the recent Levering plays, silence played a large role in the women's roles in the shootout. Francis Allen, Betty Allen, Jezebel Goad, and Maude Iroler all participated in rhetorical actions that impacted the shootout and its aftermath. They continued their lives after the shootout and had to put their families back together. Intentionally engaging in silence, they proved themselves resilient mountain women who survived this tragic event. 
The fictional characters of Levering's plays and Betty W Chandler demonstrate that there is a desire to hear these voices recovered.

These constructions of Hillsville, however, do not stay within the confines of the town. In each construction we see how Hillsville represents Appalachia. Seen in the contemporary depictions of Levering's plays and also in the continual performances of the event by independent scholars, such as Howard Sadler who presented on finding the affidavit served to Floyd Allen, the event is still very much in the minds of the citizens in the town. Implicit in these performances or not, these retellings depict Hillsville as a mountain community in Appalachia. The local retellings of the event fight against modern depictions of the region. One such moment is when Kay Cox as Betty Allen refers to her own death in the papers. This spectacular moment creates laughter in the audience because they all realized how the media coverage of the shootout serves as farce. The production of these cultural commodities fights against the popular stereotypical and, quite frankly, harmful rhetorics that are produced today by television shows and in popular non-fiction written about the region.

Similar to the media accounts about the shootout and histories, popular depictions of the hillbilly figure still bring up Appalachia as a forgotten or lost region whose people are backward. Since J.W. Williamson published Hillbillyland What the Movies Did to the Mountains and What the Mountains Did to the Movies (1995) and Emily Satterwhite's Dear Appalachia: Readers, Identity, and Popular Fiction Since 1878 (2015) we continue to see a consistent depiction of Appalachia as a stereotyped, exploited region in popular culture. These depictions directly echoe those rendered in the violent mountaineer and uncolonized other terministic screens seen in the media coverage of Hillsville. For example, Appalachian Outlaws, a popular show on The History Channel, participates in this pioneer imagery of 
Appalachia on its website:

As the rest of the United States has evolved through time, the Appalachians have stood the test of it. For centuries, its mountainous landscape has acted as a cultural barrier to the influences of the outside world, and its inhabitants act more like their ancestors from the 1700s than their modern day peers. ("About Appalachian Outlaws") Similar to the ethnic grounding in the early media portrayals of the shootout, these depictions present Appalachia as a cultural oasis. A land whose people "act more like their ancestors from the 1700s than their modern day peers." These images compare directly to the ethnic images of the Allen men who only knew the mountains and their own "clan." Clan imagery in Appalachia also operates in the show Outsiders where, like Appalachian Outlaws, the members of the mountain town restrict themselves to their Kentucky hollers to attempt to live off the grid. They "defend" their rights to live in the mountains just as their ancestors did and those who come to threaten them and their way of life face consequences. Grounded in masculinity and violence, the show again resembles the stereotypes that the media created about the shootout in the early twentieth century.

While Appalachian Outlaws and Outsiders depict a rejection of modern society and Appalachia, the television show Justified presents an attempt to modernize the region. Based in Harlan and Lexington, Kentucky protagonist Raylan Givens has to negotiate being a U.S. Marshall in a town where he is kin to or friends with local law breakers. The show addresses 
contemporary issues like religion, drugs, and mountain top removal. Much like the depictions of the Allens in the plays and some of the museums, Raylan is a realistic character who has his own flaws, but attempts to stand for justice and his own morals. He, like the Allens, sometimes shoots first and asks questions later. Like the mass media frenzy right after the shootout, these shows present constructions of Appalachia for the American public.

However, the most popular presentation of the region still engaging with these terministic screens is found in J.D. Vance's New York Times bestselling book, Hillbilly Elegy, A Memoir of A Family and Culture in Crisis. In this text, Vance presents an Appalachia that is wasted with drug abuse, violence, and poverty. Similar to the early fictional novels of the shootout, Vance depends on violence to weave his personal narrative. His story begins sympathetic as he recounts his childhood and the violent nature of his family members; however, these characteristics rely on hyperbole and exaggeration. Similar to The Dancing Outlaw, The Wild, Wonderful Whites of West Virginia, and Deliverance, his narrative depends on speculation and specter instead of reality. His descriptions of Appalachia and the media descriptions of the town are both created to make money and not tell a story of an actual Appalachia. Through his own experience he argues that Appalachia can help itself just as he did as he ascended into a new socioeconomic class and became a lawyer. He rejects any of the systematic oppression that happens in the Appalachian region and instead uses his voice and experience to speak for all of Appalachia. He engages with the same stereotypes of Appalachia as an uncolonized other that the media presented right after the shootout. His Appalachia is filled with a culture that remains in the past refusing to look towards the future. 
Seen through these examples, the courthouse shootout in Hillsville stands as an important part of our culture today because it symbolizes how Appalachia continues to be rhetorically constructed by those inside and outside the region. Perhaps research about the event will never be able to "see through the smoke" to reveal a true Appalachia nor a true Hillsville, but depictions like Levering's plays work against still recent stereotypes that are derogatory, exploitative, and harmful to the region. The true tragedy of the shootout lies not on the depictions that outsiders made of those involved nor in its bloody history, but in our lack of understanding how this historic event can have a remarkable presence in our past, present, and future. 


\section{REFERENCES}

\section{Primary Source Material periodicals (In Chronological Order) then other archival materials:}

“Three Killed in Virginia Court: Allen's Gang Illustrates the Recall by Murdering the Judge, Sheriff and Prosecutor.” The Wall Street Journal, Mar. 15, 1912, ProQuest Historical Newspapers: The Wall Street Journal.

"The Recall at Hillsville." The New York Times 15 Mar. 1912: 9. Print.

"Dead Judge Was Fine Shot: Thorton Massie a Man of Iron Nerve and Great Strength." The New York Times. 16 Mar. 1912. Proquest, Historical Newspapers: The New York Times.

“Mob Wipe Out Court.” Kansas Baptist Herald 16 Mar. 1912, n.p. Print.

“Two More Dead In Allen Feud.” The New York Times 16 Mar. 1912: 1. Print.

“Outlaw Once an Officer.” The New York Times 17 Mar. 1912: 6. Print. “Outlaws Slay

Judge in Court." The New York Times 18 Mar. 1912: 1. Print.

"Shoot the Judge." Wall Street Journal 18 Mar. 1912: 6. Print.

"Should Be a Hunt, Not a War." Voices of the Times. The New York Times. 19 Mar. 1912; ProQuest Historical Newspapers. The New York Times: 10

“Of Course They Are Not Monsters.” The New York Times 22 Mar. 1912: 8 Print.

“Trap Is Laid for Virginia Outlaws.” The New York Times 22 March 1912: 3. Print.

“Mountain Court Is Wiped Out.” Savannah Tribune 23 March 1912: 1. Print. 
“One Caught, Allen Gang Will Give Up.” The New York Times 23 Mar. 23, 1912: 1. Print.

"Posses Close in on Allen Outlaws." The New York Times 24 Mar. 24, 1912: 13. Print.

“Obsessions Should Be Shunned.” The New York Times 24 April 1912: 6. Print.

"Impressions of the Passing Show." The New York Times (March 24, 1912): ProQuest

Historical Newspapers: The New York Times: SM16.

“Explanations That Are Excuses.” The New York Times 25 Mar. 1912: 6.

“Allens Executed: Respite Plan Failed” The New York Times 29 Mar. 1912: 11. Print.

"Highways and Byways: 'The People's Rule in Government."' The Chautauquan, A Weekly Newsmagazine. Jun 1912; 67,1 American Periodicals.

“Catch Sidna Allen by Trailing Girl.” The New York Times 15 Sept. 1912: 1. Print.

“Allen Explains Shootout.” The New York Times 16 Sept. 1912: 13:4. Print.

Allen, Floyd. Statement. 29 March 1913. MS. Accession 28355. Personal Papers Collection, The Library of Virginia. Richmond, VA.

Chandler Betty, J. Ed. Memoirs of J. Sidna Allen, A True Narrative of What Really Happened at Hillsville 1912. Eden, NC: Alwith Publishing, 1929. Print.

Goad, Jezebel. Letter. 3 May 1965. TS. Floyd Landreth Papers Collection, The Library of Virginia. Richmond, VA.

\section{Secondary Source Material:}

Allen, Victor. Personal Interview. 9 July 2016.

“About Appalachian Outlaws.” A\&E Television Networks. 2017. Web. 4 Feb 2017. 
Aceves, Peter. "The Hillsville Tragedy in Court Record, Mass Media and Folk Balladry: A Problem in Historical Documentation." Keystone Folklore Quarterly. (Spring Issue, 1971): 1-38. Print.

Ballard, Sandra and Haeja Chung, eds. The Collected Short Stories of Harriette Simpson Arnow. East Lansing: Michigan State University Press, 2005. Print.

Bowers, Tom. "The Ethics of Memory: Commemorating Disasters in an Age of Risk." Southern Communication Journal 80.2 (2015): 119-136. Print.

Bowman, Rex. "Carroll Ponders 1912 Shootout as Tourist Bait." The Richmond Times Dispatch. 29 Oct. 2006. Web. 2 Nov 2006. Print.

Casey, Edward S. "Public Memory in Place and Time.” Framing Public Memory. Ed. Kendall R. Phillips. Tuscaloosa: The University of Alabama Press, 2004. 17-44. Print.

Dickinson, Greg, Carole Blair, and Brian Ott. Places of Public Memory, The Rhetoric of Museums and Memorials. Tuscaloosa: The University of Alabama Press, 2010. Print.

Glenn, Cheryl. Unspoken, A Rhetoric of Silence. Carbondale: Southern Illinois University Press, 2004. Print.

Glenn, Cheryl and Jessica Enoch. "Invigorating Historiographic Practices in Rhetoric and Composition Studies." Working in the Archives, Practical Research Methods For Rhetoric and Composition. Eds. Alexis E. Ramsey, Wendy B. Sharer, Barbara L'Eplattenier, and Lisa S. Mastrangelo. Carbondale: Southern Illinois University Press, 2010: 11-27. Print. 
Hall, Randal L. “Constructing Violence: Historical Memory and a 1912 Courtroom Massacre in Virginia's Blue Ridge Mountains.” (Re)Constructing Cultures of Violence and Peace ed. Richard Jackson New York: Rodopi, 2004. Print.

Hall, Ronald W. The Carroll County Courthouse Tragedy, A True Account of the 1912 Gun Battle that Shocked the Nation; Its Causes and the Aftermath. 2003 Second Reprinting. Hillsville, Va: The Carroll County Historical Society, 1997. Print. Harkins, Anthony. Hillbilly, A Cultural History of An American Icon. New York: Oxford, 2004. Print.

Hesford, Wendy S. Spectacular Rhetorics, Human Rights Visions, Recognitions, Feminisms. Durham: Duke University Press, 2011. Print.

Levering, Frank. Thunder in the Hills. Dir. Angell Caudill. March 24 and 25, 2012. Personal copy.

Lord, William "Bill.” The Red Ear of Corn. Pittsburg, PA: Tri-Ad Litho, Inc., 1999. Print.

Miller, Carolyn R. “Genre as Social Action.” Quarterly Journal of Speech 70.2 (1984): 151-176. Print.

Obermiller, Phillip J. and Shaunna L. Scott. "Making Appalachia: Interdisciplinary Fields and Appalachian Studies." Studying Appalachian Studies, Making the Path By Walking. Urbana: University of Illinois Press, 2015. Print.

Powell, Katrina M. The Anguish of Displacement, The Politics of Literacy in the Letters of Mountain Families in Shenandoah National Park. Charlottesville: University of Virginia Press, 2007. Print. 
Ridolfo, Jim and Danielle Nicole DeVoss. "Composing for Recomposition: Rhetorical Velocity and Delivery.” Kairos 13.215 Jan. 2009. Online.

Sheard, Cynthia Miecznkowski. “The Public Value of Epideictic Rhetoric.” College English 58.7 (Nov. 1996): 765-794. Print.

Schneider, Rebecca. Performing Remains, Art and War in Times of Theatrical Reenactment. New York: Routledge, 2011. Print.

Renwick, Roger deV. "Ballad.” American Folklore (3rd Edition). Ed. Jan Harold Brunvand New York: Garland, 1996. 57-61. Print.

Taylor, Diana. The Archive and the Repertoire, Performing Cultural Memory in the Americas. Durham: Duke University Press, 2003. Print.

Toelken, Barre. "Ballads and Folksongs." Folk Groups and Folklore Genres: An Introduction. Ed. Elliott Oring. Logan: Utah State University Press, 1986. 147174. Print.

Puckett, Anita. "Aftermath of the Courthouse Tragedy.”Courthouse Tragedy Centennial Symposium. 13 March 2012. Presentation.

Webb, Bill. Personal Interview. 8 July 2016. 


\section{CURRICULUM VITAE \\ Travis A. Rountree}

e-mail: tar2382@yahoo.com

Phone: (804) 356-2210

\section{EDUCATION}

Ph.D. Rhetoric and Composition. University of Louisville. May 2017.

Dissertation: "'Hard to See Through the Smoke': Remembering the 1912 Hillsville, Virginia Courthouse Shootout."

Committee: Dr. Stephen Schneider (Chair), Dr. Sara Webb-Sunderhaus, Dr. Amy

Clukey, and Dr. Tim Johnson.

M.A. English with an Appalachian Studies Certificate and Candidacy in Composition and Rhetoric. Appalachian State University. August 2007, 2012.

Master's Thesis: "Modern and Contemporary Appalachian Literature: Beyond the Southern Grotesque."

Committee: Dr. Sandra L. Ballard (Chair), Dr. Edwin T. Arnold, and Dr. Leon Lewis.

B.A. English with an American Studies Minor. James Madison University. May 2004. Undergraduate Thesis: "Modern and Contemporary Appalachian Literature: Beyond the Southern Grotesque."

Committee: Dr. Jean W. Cash (Chair), Dr. David K. Jeffrey, and Dr. Clive Hallman.

\section{EMPLOYMENT}

University of Indiana, East 2017-Present

University of Louisville 2013-2017

Appalachian State University 2004-2013

Caldwell Community College 2004-2013

\section{PUBLICATIONS}

"Returning to the Far Past: Isaac Garfield Greer's Ballad Collection Revisited." North Carolina Folklore Journal 56.1 (Spring-Summer 2009): 10-20.

Under Review

Co-Authored Book Chapter for Queer Appalachia: Reading, Writing, Teaching, and Imagining the 'Unspeakable' Other titled: “Are Y'all Homos?”: Mêtis as Method for and in Queer Appalachia

\section{Works in Progress}


"Performing Hillsville: Rhetorical Discourse on Frank Levering's Plays 1912 Courthouse Shootout"

\section{Book Reviews}

Upcoming: Review of Rough South, Rural South: Region and Class in Recent Southern Literature. Edited by Jean W. Cash and Keith Perry. South: An Interdisciplinary Journal. Issue 3 (Fall 2016): np.

Review of Crooked Letter i: Coming Out In The South. Edited by Connie Griffin. Appalachian Journal 43: 3-4 (2016): 270.

Review of Cub, by Jeff Mann. Appalachian Journal. 42: 1-2 (Fall 2014/Winter 2015): 114.

Review of Writing About Writing, A College Reader, Second Edition, by Elizabeth Wardle and Doug Downs. Boston: Bedford/St. Martin's, 2014.

Co-editor of Cardinal Compositions, A Journal of Student Writing at University of Louisville. Boston: Bedford/St. Martin's, 2015.

ADMINISTRATION

University of Indiana, East $\bullet$ Richmond, Indiana

Director of Composition Fall 2017-Present

University of Louisville $\bullet$ Louisville, Kentucky

Assistant Director, Composition Program Fall 2014 to Spring 2016

- Served as chair of the Student Symposium on Writing in Spring 2015, 2016

- Contributed to rewriting course goals and outcomes for Expository and Researchbased Writing Courses

- Contributed to General Education Assessment within the program

- Aided with other Composition personnel matters

Appalachian State University $\bullet$ Boone, North Carolina

Assistant Director, Composition Program Fall 2012 to Spring 2013

- Served as Webmaster for the Composition Program website

- Helped develop course goals and outcomes for Developmental, Expository, and Introduction to Writing Across the Curriculum Composition courses

- Contributed to assessment within the program

- Aided with Composition Program personnel matters

- Served as Chair of Celebration of Student Writing event

Writing Across the Curriculum Consultant Fall 2008 to Spring 2013 
- Served as Webmaster for the WAC website

- Met with various writing in the discipline faculty members about writing in their programs

- Initiated and organized annual Writing Across Institutions Community College Conference

\section{AWARDS AND HONORS}

Barker Endowment for Southern Letters, University of Louisville 2016.

Barbara Plattus Teaching Award, University of Louisville 2016.

Gesa Kirsch Travel Award for Conference on College Composition and Communication University of Louisville 2015.

The Digital Media and Composition Institute (DMAC) funded by Ideas to Action Grant, University of Louisville 2016.

Appalachian Studies Association Scholarship Fund recipient 2013.

University College Award for Excellence in Community Engagement, Appalachian State University 2012.

North Carolina Housing Officers Faculty Partnership Award for work with the Black and Gold Residential Learning Community, Appalachian State University 2008.

English Department Teaching Assistant of the Year Award, Appalachian State University 2005-2006.

David A. Hallman Award in Southern Literature, James Madison University 2003.

\section{PRESENTATIONS}

\section{Invited Talks}

Keynote Speaker with Erin Zimmerman "History in the Making: Meaningful Public Rhetoric Pedagogy” Writing Across Institutions Conference. Boone, NC. Spring 2016.

Keynote Speaker with Erin Zimmerman, "WAC Programs" Professional Development Day at Craven Community College. New Bern, NC."WAC Programs" Coastal Community College. Jacksonville, NC. Fall 2010.

Invited Speaker. "WAC in your Classroom" Coastal Carolina Community College. Jacksonville, NC. Fall 2010.

\section{Conference Workshops}


Forthcoming: "Writing for the Mountains." College Composition and Communication Conference. Portland, OR. Spring 2017.

"Full Service WAC." Pre-conference Workshop, IWAC Conference. Savannah, GA. Summer 2012.

"Writing Across the Community: A WAC Program Redefines Its Mission." College Composition and Communication Conference. Louisville, KY. Spring 2010.

\section{Conference Presentations}

"My Ol', Queer, Kentucky Home: Teaching, Theorizing, and Cultivating Queer Archives." College Composition and Communication Conference. Portland, OR. Spring 2017.

Roundtable Discussion on Walk Till the Dogs Get Mean, Meditations on the Forbidden from Contemporary Appalachia. Appalachian Studies Association Conference. Blacksburg, VA. Spring 2017.

"Hillbilly Gangsters of the Wild West: Changing Depictions of the 1912 Hillsville, Virginia Courthouse Shootout" Rhetoric Society of America. Atlanta, GA. Spring 2016.

“'Educate or Exterminate' the 'Brave Mountaineer': Remembering the Allen Ballads from the 1912 Hillsville Courthouse Shootout" Society for the Study of Southern Literature Boston, MA. Spring 2016.

"Action, Advocacy and Appalachia: Cultural-Rhetorical Strategies for Public Writing and Rhetorics." College Composition and Communication Conference. Houston, TX. Spring 2016.

"Art as Memory: Documenting Disabled Lives." Society for Disability Conference. Atlanta, GA. Spring 2015

"The Risky Red Bird: Creating University of Louisville's Cardinal Compositions, a Print and Digital Journal of Undergraduate Student Work." College Composition and Communication Conference. Tampa, FL. Spring 2015.

"From the Mountains to the Downs: Responding to Appalachian Students at University of Louisville." Watson Conference. Louisville, KY. Fall 2012.

"From the Mountains to the Downs: Place-Based Pedagogy Redefined." Research Network Forum, College Composition and Communication Conference. Indianapolis, IN. Spring 2012.

"A Story About A Brave Mountaineer": Ballad Interpretations of the Hillsville, Virginia Courthouse Shootout of 1912.” Appalachian Studies Association Conference. Huntington, WV. Spring 2012. 
"Mountains of Opportunity: An Appalachian-Themed, Introduction to Writing Across the Curriculum Course." College Composition and Communication Conference. St. Louis, MO. Spring 2013.

"Write from the Hills: Using Appalachian Studies in Place-Based Composition Classroom Pedagogy.” Appalachian Studies Association Conference. Boone, NC. Spring 2013.

"Writing For Appalachia(n): Community Based Group Writing Project." North Carolina Teaching Symposium. Raleigh, NC. Spring 2013

"Supporting Critical Thinking in a Vertical Writing Model," Quinnipiac University. Hamden, CT. Fall 2010.

“"A Story About A Brave Mountaineer' and 'His Awful Debt to Pay': Ballad Interpretations of the 1912 Hillsville, Virginia Courthouse Shootout." American Folklore Society. Nashville, TN. Fall 2010.

"Highlighting Shared Interests Among Writing Programs: Centralizing WAC, Writing Centers, and Composition Programs." College Composition and Communication Conference. Louisville, KY. Spring 2010.

“"Of Moonshine and Manhood': Historical and Fictional Depictions of the Allen Family involved in the Hillsville Courthouse Shootout of 1912.” Appalachian Studies Association Conference. Dahlonega, GA. Spring 2010.

“Exploring English 2001: Appalachian State University’s Sophomore level WAC Odyssey." Two-Year College English Association. Chattanooga, TN. Spring 2010 .

"Deadliest Catch: Reeling Faculty into the Residence Halls" North Carolina Housing Officers Conference. Winston, NC. Fall 2008.

“"Down Out of the Far Past': Issac Garfield Greer's revisions of 'Black Jack Davy' and 'Beaulampkins."' Appalachian Studies Association Conference. Huntington, WV. Spring 2008.

"More Than The Need for Speed: A Foucaultian Analysis of Nascar." Popular Culture Association in the South Conference, Savannah. GA. Fall 2006.

“"If Ever a Man Was One of Them, I Am He': The Use of Land in the Fiction of Erskine Caldwell and Larry Brown." Popular Culture Association in the South Conference. Jacksonville, FL. Fall 2005. 
“"Bill' and 'Brother H': The Correspondence Between William Faulkner and Ernest Hemingway.” Philological Association of the Carolinas. Myrtle Beach, SC. Spring 2005.

“'Honky Tonk Blues': Country Western Music in the Works of Larry Brown.” Popular Culture Association in the South Conference. New Orleans, LA. Fall 2004.

"The Portrait of Loss: A Historical Examination of Serpent-Handlers in the Upper South.” Sigma Tau Delta Undergraduate Paper Conference. Harrisonburg, VA. Spring 2004.

\section{Performances and Readings}

Forthcoming Summer 2017- Louisville, KY, Poetry Reading

Fall 2012- Jefferson, NC, Reading of Short Story "Bonafide," Wordkeepers of Jefferson, $\mathrm{NC}$

Summer 2010- Derry, Ireland, "Witchwork," Black Sheep Theatre Troupe Spring 2008- Boone, NC, "Day All Day, Dark All Night" Black Sheep Theatre Troupe

\section{ACADEMIC EMPLOYMENT AND TEACHING EXPERIENCE}

\section{Four-Year College Teaching}

University of Louisville $\bullet$ Louisville, Kentucky

Women in Literature, focused on Southern and Appalachian Literature Summer 2016

Scientific and Technical Writing Spring 2015

Introduction to College Writing Fall 2016, Fall 2013, 2015

Intermediate College Writing Fall 2015, Spring 2014, 2016

Appalachian State University $\bullet$ Boone, North Carolina

Introduction to Writing Across the Curriculum Fall 2010 to Spring 2013

Freshmen Composition Fall 2005 to Spring 2013

English 1100 Writing Across the Curriculum Pilot Course Spring 2007-Spring 2009

Introduction to Literature Spring 2006

Developmental Writing Fall 2005, 2006

Spring 2008 Writing Center Consultant Fall 2004-Spring 2005

\section{Two-Year College and Community College Teaching}

Caldwell Community College and Technical Institute,

Watauga Campus • Boone, North Carolina

Appalachian Culture Spring 2009 to Spring 2013

Literature-Based Research Spring 2009 to Spring 2012

American Literature I Fall 2009

Southern Cultures Spring 2009

Writing Center Consultant Spring 2009, 2010

\section{Other relevant experience}




\section{Primary and Secondary School}

2009

Duke Talent Identification Program, Appalachian Tales, Instructor Summer 2008,

- Taught gifted $7-10^{\text {th }}$ graders from all over the Southeast about Appalachian customs and traditions

- Planned speakers to visit classroom to talk about bluegrass, Appalachian folklore, and literature

- Supervised teaching assistant for the course

Mountaineer Enrichment Program, Creative Writing in Nature, Instructor Fall 2009, 2011

- Taught gifted 7th-11th graders from North Carolina about using creative writing to write about nature

- Edited publication at the end of weekend to publish student writing

\section{PROFESSIONAL SERVICE}

Present Member of Steering Committee for Appalachian Studies Association 2016Present.

Member of Bedford/St. Martin's New Scholars Advisory Board 2015-2016.

Member of Weatherford Award Committee for Appalachian Studies Association 20142015.

Teaching Mentor for Graduate Teaching Assistants for English 101: Introduction to College Writing, University of Louisville 2015.

Teaching Mentor for Graduate Teaching Assistants for English 101: Introduction to College Writing, University of Louisville 2014.

Teaching Mentor for Graduate Teaching Assistants for English 2001: Introduction to Writing Across the Curriculum Course, Appalachian State University 2012.

Teaching Mentor for English 2001 Instructors, Appalachian State University 2008-2013.

Mentor for Graduate Level Teaching Developmental Writing Course, Appalachian State University 2006.

President English Graduate Student Organization (EGSO), Appalachian State University 2005-2006.

Faculty Liaison for EGSO, Appalachian State University 2005-2006.

Active Member Social Order of Graduate Students, Appalachian State University 20052006. 
Member of Finance Committee for EGSO, Appalachian State University 2004-2005.

Vice-President Sigma Tau Delta, James Madison University, Editor-in-Chief of Annual Literary Journal, Sympoison 2004.

\section{GRADUATE COURSEWORK}

\section{University of Louisville}

English 602 Teaching Composition (U of L)

English 674 Community Literacy (U of L)

English 688 Genres (U of L)

English 654 Post-Colonial Novels (U of L)

English 670 Composition Theory and Practice (U of L)

English 681 Digital/New Media (U of L)

English 681 Cultures of Authorship (U of L)

English 620 Research Methods (U of L)

\section{Appalachian State University}

English 5100 Comp Theory Practice and Pedagogy (ASU)

English 5720 Appalachian Literature (ASU)

English 5585 Studies in Ethnic American Literature: Magical Realism (ASU)

English 5530 Tutoring in the Writing Center (ASU)

English 5000 Bibliography and Research-Appalachian State University (ASU)

English $579020^{\text {th }}$ Century American Literature (ASU)

English 5840 Shakespeare (ASU)

English 5500 Modern and Post Modern British Literature (ASU)

English 5531 Teaching ENG 0900 Developmental Writing (ASU)

English 5532 Teaching ENG 1000 Expository Writing (ASU)

English 5600 Literary Criticism Theory (ASU)

English $586518^{\text {th }}$ Century British Literature (ASU)

English 5531 Teaching 1100 Writing about Literature (ASU)

English 5870 British Romantic Period (ASU)

History 5208 Seminar in Appalachian History (ASU)

Religion 5400 Appalachian Religion (ASU)

English 5710 Advanced Folklore (ASU)

Appalachian Studies 5030 Bluegrass Traditions (ASU) 


\section{REFERENCES}

Dr. Stephen Schneider

Director of Graduate Studies

University of Louisville

English Department

315 Bingham Humanities Hall

2211 South Brook St.

Louisville, KY 40292

Phone: 5028522188

E-mail: stephen.schneider@louisville.edu

Dr. Brenda Brueggemann

Professor and Aetna Chair of Writing Studies

Austin Hall 119

University of Connecticut

English Department

215 Glenbrook Road, U-4025

Storrs, CT 06269-4025

Phone: 8604862141

E-mail: brenda.brueggemann@uconn.edu

Dr. Amy Clukey

Director of Honors Studies

University of Louisville

English Department

315 Bingham Humanities Hall

2211 South Brook St.

Louisville, KY 40292

Phone: 5028522187

E-mail: amy.clukey@louisville.edu

Dr. Georgia Rhoades

Writing Across the Curriculum Director

Appalachian State University

Writing Across the Curriculum Program

253 Anne Belk Hall

Boone, NC 28608

ASU box 32033

Phone: 8282622075

E-mail: rhoadesgd@appstate.edu 